\title{
Software Verification and Validation for Commercial Statistical Packages Utilized by the Statistical Consulting Section of SRTC
}

by

T. B. Edwards

Westinghouse Savannah River Company

Savannah River Site

Aiken, South Carolina 29808

R. A. Baker

S. P. Harris

C. D. Harvel

E. P. Shine

This paper was prepared in connection with work done under the above contract number with the U.S. Department of Energy. By acceptance of this paper, the publisher and/or recipient acknowledges the U. S. Government's right to retain a nonexclusive, royalty-free license in and to any copyright covering this paper, along with the right to reproduce and to authorize others to reproduce all or part of the copyrighted paper. 
This document was prepared in conjunction with work accomplished under Contract No.

DE-AC09-96SR18500 with the U.S. Department of Energy.

\section{DISCLAIMER}

This report was prepared as an account of work sponsored by an agency of the United States Government. Neither the United States Government nor any agency thereof, nor any of their employees, makes any warranty, express or implied, or assumes any legal liability or responsibility for the accuracy, completeness, or usefulness of any information, apparatus, product or process disclosed, or represents that its use would not infringe privately owned rights. Reference herein to any specific commercial product, process or service by trade name, trademark, manufacturer, or otherwise does not necessarily constitute or imply its endorsement, recommendation, or favoring by the United States Government or any agency

thereof. The views and opinions of authors expressed herein do not necessarily state or reflect those of the United States Government or any agency thereof.

This report has been reproduced directly from the best available copy.

Available for sale to the public, in paper, from: U.S. Department of Commerce, National Technical Information Service, 5285 Port Royal Road, Springfield, VA 22161, phone: (800)

553-6847, fax: (703) 605-6900, email: orders@ntis.fedworld.gov online ordering: http://www.ntis.gov/ordering.htm

Available electronically at http://www.doe.gov/bridge

Available for a processing fee to U.S. Department of Energy and its contractors, in paper, from: U.S. Department of Energy, Office of Scientific and Technical Information, P.O. Box 62, Oak Ridge, TN 37831-0062, phone: (865 ) 576-8401, fax: (865) 576-5728, email: reports@ adonis.osti.gov 
WSRC-RP-99-00422

Revision 1

Keywords: Regression, ANOVA, Descriptive Statistics, Experimental Design, Fractional Factorial, Mixture, Control Chart

\section{Software Verification \& Validation for Commercial Statistical Packages Utilized by the Statistical Consulting Section of SRTC (U)}

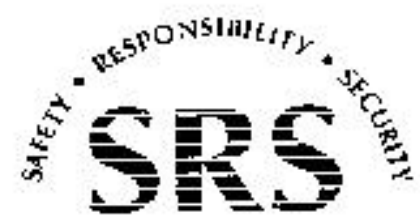




\section{Software Verification \& Validation for Commercial Statistical Packages Utilized by the Statistical Consulting Section of SRTC (U)}

October 31,2000

Prepared by

the

Statistical Consulting Section

\begin{tabular}{|c|c|c|}
\hline \multicolumn{2}{|c|}{ Contributors } & Date \\
\hline R. A. Baker & & $11 / 1 / 00$ \\
\hline T. B. Edwards & antr & $11 / 1700$ \\
\hline S. P. Harris & & 1111100 \\
\hline C. D. Harvel & & $11 / 1 / 00$ \\
\hline E.P. Shine & & $11 / 1 / 10$ \\
\hline
\end{tabular}

\section{Approvals}

aype t.


WSRC-RP-99-00422

Revision 1 
WSRC-RP-99-00422

Revision 1

Revisions Page

\begin{tabular}{|c|c|c|}
\hline Revision No. & Date & Revision \\
\hline 1 & $10 / 31 / 2000$ & JMP Version 4 was added to the baseline software list. \\
\hline
\end{tabular}


WSRC-RP-99-00422

Revision 1 


\section{ABSTRACT}

The purpose of this report is to provide software verification and validation (v\&v) for the statistical packages utilized by the Statistical Consulting Section (SCS) of the Savannah River Technology Center (SRTC). The need for this v\&v stems from the requirements of the Quality Assurance (QA) programs that are frequently applicable to the work conducted by SCS. This document is designed to comply with software QA requirements specified in the 1Q Manual Quality Assurance Procedure 20-1, Revision 6. The SCS baseline software history covering this revision of our software QA plan is provided in the following tables

\begin{tabular}{|c|c|c|c|c|}
\hline \multicolumn{5}{|c|}{ Revision 0 - SCS Baseline Software List } \\
\hline \multirow{3}{*}{$\begin{array}{c}\text { Computing Platform } \\
\text { IBM Personal Computer 300PL } \\
\text { or }\end{array}$} & Operating System & Software & Version & Software User's Manuals \\
\hline & Windows NT Version 4.0 & $\mathrm{JMP}^{\circledR}$ & 3.2 .2 & JMP® User’s Guide, Version 3 (1995) \\
\hline & & Microsoft Excel ${ }^{\circledR}$ & 97 SR-1 & Site-licensed software; no manual distributed \\
\hline \multirow{2}{*}{$\begin{array}{l}\text { IBM Personal Computer 300XL } \\
\text { (i.e., any Pentium II processor) }\end{array}$} & & MIXSOFT TM & 2.3 & MIXSOFT $^{\mathrm{TM}}$ User's Guide Version 2.3 (1998) \\
\hline & & Statgraphics Plus ${ }^{\circledR}$ & 4.0 & Statgraphics Plus ${ }^{\circledR}$ Standard Edition (1998) \\
\hline $\begin{array}{l}\text { Digital AlphaServer Model } 4100 \\
5 / 533\end{array}$ & $\begin{array}{c}\text { VMS-AXP } \\
\text { Open VMS V7 }\end{array}$ & SAS $^{\circledR}$ & 6.12 & $\begin{array}{l}\text { SAS Procedures Guide, Ver 6, } 3^{\text {rd }} \text { Edition (1990) } \\
\text { SAS/STAT User's Guide Volumes } 1 \text { \&2 (1990) } \\
\text { SAS/QC Software: Reference, Ver 6, } 1^{\text {st }} \text { Ed (1989) } \\
\text { SAS/IML Software: Usage \& Ref, Ver 6,3 } 3^{\text {rd }} \text { Ed (1990) }\end{array}$ \\
\hline
\end{tabular}

\begin{tabular}{|c|c|c|c|c|}
\hline \multicolumn{5}{|c|}{ Revision - 1: SCS Baseline Software List } \\
\hline \multirow{3}{*}{$\begin{array}{c}\text { Computing Platform } \\
\text { IBM Personal Computer 300PL } \\
\text { or }\end{array}$} & Operating System & Software & Version & Software User's Manuals \\
\hline & Windows NT Version 4.0 & $\mathrm{JMP}{ }^{\circledR}$ & 3.2 .2 & JMP® User’s Guide, Version 3 (1995) \\
\hline & & $\mathrm{JMP}^{\circledR}$ & 4.0 & JMP® User’s Guide, Version 4 (2000) \\
\hline \multirow{3}{*}{$\begin{array}{l}\text { IBM Personal Computer 300XL } \\
\text { (i.e., any Pentium II processor) }\end{array}$} & & Microsoft Excel ${ }^{\circledR}$ & 97 SR-1 & Site-licensed software; no manual distributed \\
\hline & & MIXSOFT ${ }^{\mathrm{TM}}$ & 2.3 & MIXSOFT $^{\mathrm{TM}}$ User's Guide Version 2.3 (1998) \\
\hline & & Statgraphics Plus ${ }^{\circledR}$ & 4.0 & Statgraphics Plus ${ }^{\circledR}$ Standard Edition (1998) \\
\hline $\begin{array}{l}\text { Digital AlphaServer Model } 4100 \\
5 / 533\end{array}$ & $\begin{array}{c}\text { VMS-AXP } \\
\text { Open VMS V7 }\end{array}$ & SAS $^{\circledR}$ & 6.12 & $\begin{array}{l}\text { SAS Procedures Guide, Ver 6, } 3^{\text {rd }} \text { Edition (1990) } \\
\text { SAS/QC Software: Reference, Ver 6, } 1^{\text {st }} \text { Ed (1989) } \\
\text { SAS/STAT User's Guide Volumes } 1 \& 2(1990) \\
\text { SAS/IML Software: Usage \& Ref, Ver 6,3 } 3^{\text {rd }} \text { Ed (1990) }\end{array}$ \\
\hline
\end{tabular}


WSRC-RP-99-00422

Revision 1

Revision 1 of this QA plan adds JMP Version 4 to the family of (commercially-available) statistical tools utilized by SCS. JMP Version 3.2.2 is maintained as a support option due to features unique to this version of JMP that have not as yet been incorporated into Version 4 . SCS documents that include JMP output should provide a clear indication of the version or versions of JMP that were used. The IBM Personal Computer 300PL and 300XL are both Pentium II based desktops. Therefore, the software verification and validation in this report is valid interchangeably between both platforms. As new computing platforms, statistical packages, or revisions to existing packages are introduced into the Statistical Consulting Section, the appropriate problems from this report are to be reevaluated, and this report is to be revised to address their verification and validation. 
WSRC-RP-99-00422

Revision 1 
$\begin{array}{lr}\text { Software Classification } & 1\end{array}$

Software Configuration Management and Control 1

SCS BASELINE SOFTWARE LIST 2

$\begin{array}{ll}\text { DISCUSSION } & 3\end{array}$

$\begin{array}{lr}\text { Descriptive Statistics } & 3\end{array}$

Regression $\quad 5$

$\begin{array}{lr}\text { ANOVA } & 6\end{array}$

$\begin{array}{ll}\text { One-Way ANOVA } & 7\end{array}$

One-Way ANOVA with Random Factor $\quad 8$

Two-Way ANOVA 9

Two-Factor Nested ANOVA 11

$\begin{array}{lr}\text { Experimental Designs } & 13\end{array}$

Fractional Factorial $\quad 13$

Mixture $\quad 14$

$\begin{array}{ll}\text { Optimal Designs } & 15\end{array}$

$\begin{array}{lr}\text { Control Charts } & 17\end{array}$

CONCLUSIONS and RECOMMENDATIONS 19

$\begin{array}{lr}\text { REFERENCES } & \mathbf{2 0}\end{array}$

$\begin{array}{ll}\text { APPENDICES } & 21\end{array}$ 


\section{LIST OF TABLES}

1 SCS Computing Platforms and Associated Statistical Software Programs

2 Data on Lot Size and Number of Man-Hours

3 Summary of Descriptive Statistics for Lot-Size Values by Software Package

4 Summary of Regression Statistics for Each Software Package

5 Number of Cases Sold by Stores for Each of Four Package Designs--- Kenton Food Company Example

6 ANOVA for Kenton Food Company Example

7 One-Way ANOVA Summary Statistics for Each Software Package

8 Ratings by Personnel Officers of Apex Enterprises

9 One-Way ANOVA (Random Factor) Summary Statistics for Each Software Package

10 Insurance Premiums

11 ANOVA for Insurance Example

12 Two-Way ANOVA Summary Statistics for Each Software Package

13 Sample Data for Nested Two-Factor Study (Training School Example from [1])

14 ANOVA for Training School Example

15 Two-Way Nested ANOVA Summary Statistics for Each Software Package

16 Two-Way Nested and Random ANOVA Summary Statistics for Each Software Package

17 Selected Fractional Factorial Experiments of the Complete Factorial Experiment for a 6-Factor Study

18 Extreme Vertices for Region Defined by Equation (2)

19 Face-Centered Cube Design

20 Data in Subgroups Obtained at Regular Intervals (Example 5.1, Table 5.1 of [11])

21 Control Chart Summary Statistics for Each Software Package 
WSRC-RP-99-00422

Revision 1

\section{INTRODUCTION}

The mission of the Statistical Consulting Section (SCS) of the Savannah River Technology Center (SRTC) is to apply statistical thinking, methods, and computing in collaborative decision support, technology development, and continuous improvement at the Savannah River Site and to disseminate our knowledge and experience into the Federal Government complex via Department of Energy (DOE) sponsored work. Computers and computer software are essential tools utilized by the SCS statisticians in pursuit of this mission. Many of these software programs are site-licensed and general purpose while some are special-purpose statistical packages.

As a general rule, memoranda, research reports, and technical reports prepared by members of SCS in response to customer requests for assistance are technically reviewed as part of the quality assurance (QA) for the section. ${ }^{1}$ In SRTC, calculations are frequently checked by alternate means (e.g., hand calculations) performed by an independent reviewer, but this is not always completely possible on modeling or other complicated calculations performed by some software programs. However, the technical review would certainly include an assessment of the appropriateness of the statistical approach and routines utilized in the document. In addition, validation and verification $(\mathrm{v} \& \mathrm{v})$ of the software utilized for the analysis are frequently requirements of the applicable QA program directing the investigation. These requirements are typically addressed uniquely in the document or in the supporting task plan, etc. The purpose of this report is to provide a central repository for the software verification and validation (v\&v) for the statistical packages utilized by SCS. This document also demonstrates the $v \& v$ of some simple statistical software such as Excel. As new computing platforms, statistical packages, or revisions to existing packages are introduced into the Statistical Consulting Section, the appropriate problems from this report or new problems are to be evaluated using these new tools, and this report is to be revised to address their v\&v.

\section{Software Classification}

The software considered in this report is commercial software (some of which is site-licensed), and these packages are considered to have a Level D software classification (as defined in the WSRC 1Q Quality Assurance Manual, QAP 20-1, Revision 6) in that they are important to day to day operation of the business and analyses conducted by SCS, but their failure to perform as intended at any point in time will not affect the safety or reliability of SRS facilities.

\section{Software Configuration Management and Control}

This report specifies the SCS plan for software configuration management and control, which covers the use of off-the-shelf, commercially available software by SCS members to perform work associated with RW-0333P (or similar) tasks. The SCS section manager controls, via the purchase approval process, the introduction into the section of new software or new versions of existing software for general use. The purchase approval process, under the section manager's direction, also controls the software available to each SCS member for his or her statistical support activities. This report is to be revised to include a new software product before the software is used by an SCS member in support of a task requiring software v\&v at the RW-0333P QA level. The SCS section manager controls the revision of the report (via the document approval process).

When the QA requirements for the work being conducted by a member of SCS include software v\&v (e.g., RW-0333P tasks), the SCS member must clearly identify (as part of his/her task deliverable) the commercial software package(s) used to support the analyses. This identification should include the name of the software, the version number, and the vendor. A reference to the appropriate revision of this document may also be included in the deliverable, if this is seen as beneficial.

\footnotetext{
${ }^{1}$ Such reviews may be a requirement of the applicable QA program directing a particular technical task.
} 


\section{SCS BASELINE SOFTWARE LIST}

The initial SCS baseline software list identified in Revision 0 of this report is provided in Table 1.0.

Table 1.0: SCS Baseline Software List - Revision 0

\begin{tabular}{|c|c|c|c|c|}
\hline \multirow{5}{*}{$\begin{array}{c}\text { Computing Platform } \\
\text { IBM Personal Computer 300PL } \\
\text { or } \\
\text { IBM Personal Computer 300XL } \\
\text { (i.e., any Pentium II processor) }\end{array}$} & Operating System & Software & Version & Software User's Manuals \\
\hline & Windows NT Version 4.0 & $\mathrm{JMP}^{\circledR}$ & 3.2 .2 & JMP® User’s Guide, Version 3 (1995) \\
\hline & & Microsoft ${ }^{\circledR}$ Excel & 97 SR-1 & Site-licensed software; no manual distributed \\
\hline & & MIXSOFT $^{\mathrm{TM}}$ & 2.3 & MIXSOFT $^{\mathrm{TM}}$ User's Guide Version 2.3 (1998) \\
\hline & & Statgraphics Plus ${ }^{\circledR}$ & 4.0 & Statgraphics Plus ${ }^{\circledR}$ Standard Edition (1998) \\
\hline $\begin{array}{l}\text { Digital AlphaServer Model } 4100 \\
5 / 533\end{array}$ & $\begin{array}{c}\text { VMS-AXP } \\
\text { Open VMS V7 }\end{array}$ & $\mathrm{SAS}^{\circledR}$ & 6.12 & $\begin{array}{l}\text { SAS Procedures Guide, Ver 6, } 3^{\text {rd }} \text { Edition }(1990) \\
\text { SAS/QC Software: Reference, Ver 6, } 1^{\text {st }} \text { Ed (1989) } \\
\text { SAS/STAT User's Guide Volumes } 1 \text { \&2 (1990) } \\
\text { SAS/IML Software: Usage \& Ref, Ver 6,3 } 3^{\text {rd }} \text { Ed (1990) }\end{array}$ \\
\hline
\end{tabular}

The current revision (Revision 1) of this report covers the software and computing platforms as identified in Table 1.1. The information in this table establishes the baseline software to be used by members of SCS, where warranted by the applicable QA requirements.

Table 1.1: SCS Baseline Software List - Revision 1

\begin{tabular}{|c|c|c|c|c|}
\hline \multirow{3}{*}{$\begin{array}{c}\text { Computing Platform } \\
\text { IBM Personal Computer 300PL } \\
\text { or }\end{array}$} & Operating System & Software & Version & Software User's Manuals \\
\hline & \multirow[t]{2}{*}{ Windows NT Version 4.0} & $\mathrm{JMP} \mathrm{P}^{\circledR}$ & 3.2 .2 & JMP® User's Guide, Version 3 (1995) \\
\hline & & $\mathrm{JMP}^{\circledR}$ & 4.0 & JMP® User’s Guide, Version 4 (2000) \\
\hline \multirow{3}{*}{$\begin{array}{l}\text { IBM Personal Computer 300XL } \\
\text { (i.e., any Pentium II processor) }\end{array}$} & & Microsoft ${ }^{\circledR}$ Excel & $97 \mathrm{SR}-1$ & Site-licensed software; no manual distributed \\
\hline & & MIXSOFT'M & 2.3 & MIXSOFT $^{\mathrm{TM}}$ User's Guide Version 2.3 (1998) \\
\hline & & Statgraphics Plus ${ }^{\circledR}$ & 4.0 & Statgraphics Plus ${ }^{\circledR}$ Standard Edition (1998) \\
\hline $\begin{array}{c}\text { Digital AlphaServer Model } 4100 \\
5 / 533\end{array}$ & $\begin{array}{c}\text { VMS-AXP } \\
\text { Open VMS V7 }\end{array}$ & $\mathrm{SAS}^{\circledR}$ & 6.12 & $\begin{array}{l}\text { SAS Procedures Guide, Ver 6, } 3^{\text {rd }} \text { Edition }(1990) \\
\text { SAS/QC Software: Reference, Ver 6, } 1^{\text {st }} \text { Ed (1989) } \\
\text { SAS/STAT User's Guide Volumes } 1 \text { \&2 (1990) } \\
\text { SAS/IML Software: Usage \& Ref, Ver 6,3 } 3^{\text {rd }} \text { Ed (1990) }\end{array}$ \\
\hline
\end{tabular}


The IBM Personal Computer 300PL and 300XL are both Pentium II based desktops. Therefore, the software $\mathrm{v} \& \mathrm{v}$ in this report is valid interchangeably between both platforms. JMP is a product of SAS Institute, Inc. [1 and 14]. In Revision 1 of this report, Versions 3.2.2 and 4.0 are included in the software baseline list. There are no known problems in Version 3.2.2 that are corrected by Version 4.0. JMP Version 4.0 offers a different "look and feel" that is better than Version 3.2.2 in many ways. Thus, using Version 4.0 has its advantages. However, for certain problems, Version 3.2.2 provides solution capabilities that are not featured in Version 4.0. Thus, to maintain functionality, there is a need to include both versions of the JMP software in the SCS baseline list.

The SAS ${ }^{\circledR}$ system is a set of products. Those considered in this report include Base SAS [2], SAS/QC [3], SAS/STAT [4 and 5], and SAS/IML [6]. Microsoft ${ }^{\circledR}$ Excel is a site-licensed product at the Savannah River Site. ${ }^{2}$ Mixsoft [7] is a specialized software program for mixtures and other constrained-region problems. Statgraphics [8] contains numerous statistical routines and is a product of Manugistics, Inc. Other products (such as terminal emulation and virus protection packages) are also involved in the utilization of these platforms and software. These are not deemed important to the performance of the statistical programs and are not reviewed in this report. The results from using each of the above packages to analyze the problems discussed below are organized by package as an appendix to this report.

The discussion that follows will demonstrate that the commercial software utilized by SCS will perform correctly, as designed. The SRTC approach is to take problems with known solutions from peer reviewed publications and run them on the commercial software to demonstrate that the vendor's program does indeed perform as designed. The solutions of these problems are generated using software routines that are frequently utilized at SRTC. Running these routines using SRTC platforms and systems software and generating the appropriate answers to the "textbook" problems demonstrates the $\mathrm{v} \& \mathrm{v}$ of the software under consideration.

\section{DISCUSSION}

In this section, problem types frequently encountered by members of SCS are identified. An example of each problem is selected from a well-established statistical textbook. The example is analyzed using a feature or features of the appropriate software described in the previous section. The results generated by the various software packages are compared to the information from the textbook and/or to each other for validation and verification. Little discussion is provided regarding the details of the problems, the underlying statistical theory, the statistical routines, or the statistical results. Information about the statistical packages, their capabilities, and details regarding their outputs can be found in their respective published documentation. These references, along with those cited as the sources of the problems, may be used to provide these details. The purpose of this report is show that the statistical packages, when used appropriately, provide reliable results.

\section{Descriptive Statistics}

The first area to be explored in this report is that of descriptive statistics, summary information about a set of data. Consider the set of data presented in Table 2, which is taken from Table 2.1 on page 40 of reference [9]. 
Table 2: Data on Lot Size and Number of Man-Hours

\begin{tabular}{|ccc|}
\hline Production Run & Lot Size & Man-Hours \\
$\mathrm{i}$ & $\mathrm{X}_{\mathrm{i}}$ & $\mathrm{Y}_{\mathrm{i}}$ \\
1 & 30 & 73 \\
2 & 20 & 50 \\
3 & 60 & 128 \\
4 & 80 & 170 \\
5 & 40 & 87 \\
6 & 50 & 108 \\
7 & 60 & 135 \\
8 & 30 & 69 \\
9 & 70 & 148 \\
10 & 60 & 132 \\
\hline
\end{tabular}

From [9], the average of the lot size values, $\bar{X}$, is equal to 50 (see page 46), and several graphical depictions (including a Box Plot, Time Plot, and Stem-and-leaf Plot) of these lot size values are provided on page 114 of [9].

\section{Using Excel Version 97 SR-1 on a Pentium II Processor Running Windows NT Version 4}

The data from Table 2 were entered into Excel and the Excel Tools/Data Analysis/Descriptive Statistics pull-down menus were used to obtain descriptive statistics on the lot-size values that were cut and pasted into this report as Table A.1a in Appendix A. There are Excel functions that provide descriptive statistics as well. Table A.1b provides the results of applying some of these functions to the lot-size values.

Using JMP Version 3.2.2 on a Pentium II Processor Running Windows NT Version 4

The data from Table 2 were entered into JMP Version 3.2.2, and the descriptive statistics capability of JMP (the Distribution-of-Y platform) was used to generate Exhibit B.1 in Appendix B for the lot size values. These results were determined by JMP Version 3.2.2, saved using JMP's journal feature, and imported (electronically) directly into this report. The average of the lot size values, 50, is included in the information presented by JMP. A Box Plot, a Stem-and-leaf plot, and a time plot (a plot by production run number) are also provided; these compare very favorably to the information on page 114 of [9].

\section{Using SAS Version 6.12 on the AlphaServer Running Open VMS V7}

The data from Table 2 were included in a SAS program that used PROC MEANS, PROC

SUMMARY, and PROC UNIVARIATE to generate some descriptive statistics for the lot size values. The SAS program and results were downloaded to the PC and incorporated in this report. This information is provided in Exhibit C.1 of Appendix C.

\section{Using Statgraphics, Version 4.0 on a Pentium II Processor Running Windows NT Version 4}

The data from Table 2 were entered into Statgraphics and the numeric data one variable analysis routine of Statgraphics was used to generate Exhibit E.1 in Appendix E for the lot size values. These results were saved using Statgraphics StatReporter feature, and imported (electronically) directly into this report. The average of the lot size values, 50, is included in the information presented by Statgraphics. A Scatter Plot, a Box-and-Whisker Plot, a Histogram, a Stem-and-leaf plot, and a Normal Probability Plot are also provided. The results compare very favorably to the information on page 114 of [9] and to the JMP output in Exhibit B.1.

\section{Using JMP Version 4.0 on a Pentium II Processor Running Windows NT Version 4}

The data from Table 2 were entered into JMP Version 4.0, and the descriptive statistics capability of JMP Version 4.0 (the Distribution-of-Y platform) was used to generate Exhibit F.1 in Appendix F for the lot size values. These results were determined by JMP Version 4.0, saved using JMP's journal feature, and imported (electronically) directly into this report. The average of the lot size values, 50, 
is included in the information presented by JMP Version 4.0. A Box Plot, a Stem-and-leaf plot, and a time plot (a plot by production run number) are also provided; these compare very favorably to the information on page 114 of [9].

\section{Descriptive Statistics Summary Table}

The critical descriptive information generated by the software packages reviewed above is summarized in Table 3.

Table 3: Summary of Descriptive Statistics for Lot-Size Values by Software Package

\begin{tabular}{|lccc|}
\multicolumn{1}{|c}{$\begin{array}{c}\text { Source of Information/ } \\
\text { Software Package }\end{array}$} & $\begin{array}{c}\text { Mean } \\
\text { Deviation }\end{array}$ & $\begin{array}{c}\text { Standard } \\
\text { Error }\end{array}$ \\
As described in [9] on page 46 & 50 & & 6.1464 \\
Excel Version 97 SR-1 on PC running Windows NT Version 4 & 50 & 19.4365 & 6.1464 \\
JMP Version 3.2.2 on PC running Windows NT Version 4 & 50 & 19.4365 & \\
SAS/STAT Version 6.12 on AlphaServer Running OpenVMS V7 & & & 6.1464 \\
$\quad$ PROCs MEAN, SUMMARY, and UNIVARIATE & 50 & 19.4365 & 6.1464 \\
Statgraphics Version 4.0 on PC running Windows NT Version 4.0 & 50 & 19.4365 & 6.1464 \\
JMP Version 4.0 on PC running Windows NT Version 4 & 50 & 19.4365 & \\
\hline
\end{tabular}

Table 3 summarizes what is revealed in the details of the related exhibits: a consistent set of values for the descriptive statistics from these software packages across the computer platforms for the Table 2 data. Please note, however, that the output from the different packages often includes different statistics.

\section{Regression}

The information presented in Table 2 also provides an opportunity for a look at various regression routines in fitting the simple linear model

$$
\mathrm{Y}=\beta_{0}+\beta_{1} \mathrm{X}+\varepsilon
$$

where $Y$ represents man-hours, $X$ represents lot-size, the $\beta$ 's represent the unknown coefficients that are to be estimated, and $\varepsilon$ represents the error term (assumed to be independently, normally distributed with zero mean and constant variance over the Y's.)

From page 44 of [9], the estimate of the y-intercept, $\beta_{0}$, is represented by $b_{0}$ and is determined to be 10.0, and the estimate of the slope, $\beta_{1}$, is represented by $b_{1}$ and is determined to be 2.0 .

\section{Using Excel Version 97 SR-1 on a Pentium II Processor Running Windows NT Version 4}

The data from Table 2 were entered into Excel and used to fit the model given in equation (1). Two methods were used to analyze these data with Excel. Tools/Data Analysis/Regression pull-down menus were used to fit the data to the model given by equation (1). The results were cut and pasted into this report as Table A.2 in Appendix A.

The matrix handling capability of Excel was also used to perform the least-squares estimation of the regression parameters. The discussion of this approach to the data of Table 2 is provided in [9] on pages 207 and 208. The results from using Excel's matrix handling capability to analyze this problem were cut and pasted into this report as Table A.3 in Appendix A.

\section{Using JMP Version 3.2.2 on a Pentium II Processor Running Windows NT Version 4}

The data from Table 2 were entered into JMP Version 3.2.2 and used to fit the model given in equation (1). Two methods were used to analyze these data with JMP Version 3.2.2. Exhibit B.2 in Appendix B provides the results from using the Fit Y By X platform to perform this analysis. 
Exhibit B.3 in Appendix B provides the results from using the Fit Model platform to perform the analysis. In both cases, the JMP Version 3.2.2 results were journaled and imported into this report, and in both cases, the estimates for the slope and y-intercept are 2 and 10, respectively.

\section{Using SAS Version 6.12 on AlphaSever Running Open VMS V7}

The SAS set of procedures provides several ways of analyzing the data from Table 2. Exhibit C.2 in Appendix C provides the SAS/STAT program that utilizes PROC REG to perform the regression. Exhibit C.3 in Appendix C provides a SAS/IML program that estimates the $\beta^{\prime}$ s .

\section{Using Statgraphics, Version 4.0 on a Pentium II Processor Running Windows NT Version 4}

The data from Table 2 were entered into Statgraphics and used to fit the model given in equation (1). The Simple Regression method was used. The results are included in Exhibit E.2 in Appendix E. The StatReporter routine in Statgraphics was used to import the results into this report. The estimates for the slope and y-intercept are 2 and 10, respectively.

\section{Using JMP Version 4.0 on a Pentium II Processor Running Windows NT Version 4}

The data from Table 2 were entered into JMP Version 4.0 and used to fit the model given in equation (1). Two methods were used to analyze these data with JMP Version 4.0. Exhibit F.2 in Appendix $\mathrm{F}$ provides the results from using the Fit $\mathrm{Y}$ By X platform to perform this analysis. Exhibit F.3 in Appendix F provides the results from using the Fit Model platform to perform the analysis. In both cases, the JMP Version 4.0 results were journaled and imported into this report, and in both cases, the estimates for the slope and y-intercept are 2 and 10, respectively.

\section{Regression Summary Table}

The critical regression information generated by the software packages reviewed above is summarized in Table 4 along with the results from [9].

Table 4: Summary of Regression Statistics for Each Software Package

\begin{tabular}{|c|c|c|c|c|}
\hline $\begin{array}{l}\text { Source of Information/ } \\
\text { Software Package }\end{array}$ & $\begin{array}{l}\text { Estimate } \\
\text { of } \\
\text { Intercept }\end{array}$ & $\begin{array}{l}\text { Estimate } \\
\text { of } \\
\text { Slope }\end{array}$ & $\mathbf{R}^{2}$ & $\begin{array}{l}\text { Root Mean } \\
\text { Square Error }\end{array}$ \\
\hline As discussed in [9] on page 44 & 10 & 2 & & \\
\hline $\begin{array}{l}\text { Excel Version } 97 \text { SR-1 on a PC running Windows NT Version 4--- } \\
\text { Regression } \\
\text { Excel Version } 97 \text { SR-1 on a PC running Windows NT Version 4--- }\end{array}$ & 10 & 2 & 0.9956 & 2.7386 \\
\hline Matrix handling capability & 10 & 2 & & \\
\hline JMP Version 3.2.2 on a PC running Windows NT Version 4 --- Fit $\mathrm{Y}$ by $\mathrm{X}$ & 10 & 2 & 0.9956 & 2.7386 \\
\hline $\begin{array}{l}\text { JMP Version } 3.2 .2 \text { on a PC running Windows NT Version } 4 \text {--- Fit Model } \\
\text { SAS/STAT Version } 6.12 \text { on AlphaServer Running OpenVMS V7 }\end{array}$ & 10 & 2 & 0.9956 & 2.7386 \\
\hline PROC REG & 10 & 2 & 0.9956 & 2.7386 \\
\hline SAS/IML Version 6.12 on Alphaserver Running OpenVMS V7 & 10 & 2 & & \\
\hline Statgraphics Version 4.0 on a PC running Windows NT Version 4.0 & 10 & 2 & 0.9956 & 2.7386 \\
\hline JMP Version 4.0 on a PC running Windows NT Version 4 --- Fit $\mathrm{Y}$ by $\mathrm{X}$ & 10 & 2 & 0.9956 & 2.7386 \\
\hline JMP Version 4.0 on a PC running Windows NT Version 4 --- Fit Y by X & 10 & 2 & 0.9956 & 2.7386 \\
\hline
\end{tabular}

Table 4 summarizes what is revealed in the related exhibits: a consistent set of regression results from these software packages across these computer platforms for the Table 2 data.

\section{ANOVA}

Analysis of variance (ANOVA) models are versatile statistical tools for studying the relation between a dependent variable and one or more independent variables [9]. Several of these models are investigated in this section. 


\section{One-Way ANOVA}

The example provided in Table 5 is from Table 14.1 on page 533 of [9]. In this table are recorded the number of cases sold by store for each of four package designs. An ANOVA is used to investigate for differences in sales across the four package designs.

Table 5: Number of Cases Sold by Stores for Each of Four Package Designs--Kenton Food Company Example

\begin{tabular}{|cccc|}
\hline & \multicolumn{3}{c|}{ Cases Sold by Store } \\
Package & \multicolumn{3}{c|}{ Store } \\
Design & 1 & 2 & 3 \\
1 & 12 & 18 & \\
2 & 14 & 12 & 13 \\
3 & 19 & 17 & 21 \\
4 & 24 & 30 & \\
\hline
\end{tabular}

The discussion in [9] leads to the ANOVA results presented in Table 6 (this information appears as Table 14.4 on page 543 in [9]).

Table 6: ANOVA for Kenton Food Company Example

\begin{tabular}{|cccc|}
\hline Source of Variation & SS & df & MS \\
\hline Between designs & 258 & 3 & 86 \\
Error & 46 & 6 & 7.67 \\
\hline Total & 304 & 9 & \\
\hline
\end{tabular}

\section{Using Excel Version 97 SR-1 on a Pentium II Processor Running Windows NT Version 4}

The data from Table 5 were entered into Excel, and Tools/Data Analysis/ANOVA: Single Factor pull-down menus were used conduct the analysis of variance. The results were cut and pasted into this report as Table A.4 in Appendix A.

\section{Using JMP Version 3.2.2 on a Pentium II Processor Running Windows NT Version 4}

The data from Table 5 were entered into JMP Version 3.2.2, and the Fit Model platform was used to analyze these data. Exhibit B.4 in Appendix B provides the JMP Version 3.2.2 results that were journaled and imported into this report.

\section{Using SAS Version 6.12 on AlphaServer Running Open VMS V7}

Two different tools available in the SAS system were used to analyze the data from Table 5. Exhibit C.4 in Appendix C provides the input and results of PROC ANOVA, and Exhibit C.5 in Appendix C provides this information for PROC GLM.

\section{Using Statgraphics, Version 4.0 on a Pentium II Processor Running Windows NT Version 4}

The data from Table 5 were entered into Statgraphics, and the One-Way ANOVA routine was used to analyze these data. Exhibit E.3 in Appendix E provides the Statgraphics results that were imported into this report using StatReporter.

\section{Using JMP Version 4.0 on a Pentium II Processor Running Windows NT Version 4}

The data from Table 5 were entered into JMP Version 4.0, and the Fit Model platform was used to analyze these data. Exhibit F.4 in Appendix F provides the JMP Version 4.0 results that were journaled and imported into this report.

\section{One-Way ANOVA Summary Table}

Some of the critical information from the ANOVA tables generated by the software packages reviewed above is summarized in Table 7 along with the results from [9]. 
Table 7: One-Way ANOVA Summary Statistics for Each Software Package

\begin{tabular}{|c|c|c|c|c|}
\hline $\begin{array}{l}\text { Source of Information/ } \\
\text { Software Package }\end{array}$ & $\begin{array}{l}\text { Sum of } \\
\text { Squares } \\
\text { Between }\end{array}$ & $\begin{array}{c}\text { Sum of } \\
\text { Squares } \\
\text { For Error }\end{array}$ & $\begin{array}{c}\text { Mean } \\
\text { Squares for } \\
\text { Designs }\end{array}$ & $\begin{array}{l}\text { F Statistic } \\
\text { for } \\
\text { Differences }\end{array}$ \\
\hline As discussed in [9] pages 543 and 548 & 258 & 46 & 86 & 11.2 \\
\hline $\begin{array}{l}\text { Excel Version } 97 \text { SR-1 on Windows NT Version 4--- } \\
\text { ANOVA: Single Factor }\end{array}$ & 258 & 46 & 86 & 11.217 \\
\hline JMP Version 3.2.2 on a PC running Windows NT Version 4 --- Fit Model & 258 & 46 & 86 & 11.217 \\
\hline $\begin{array}{l}\text { AS/STAT Version } 6.12 \text { on Alphaserver Running OpenVMS V7 } \\
\text { PROC ANOVA }\end{array}$ & 258 & 46 & 86 & 11.217 \\
\hline $\begin{array}{l}\text { SAS/STAT Version } 6.12 \text { on Alphaserver Running OpenVMS V7 } \\
\text { PROC GLM }\end{array}$ & 258 & 46 & 86 & 11.217 \\
\hline Statgraphics Version 4.0 on a PC running Windows NT Version 4 & 258 & 46 & 86 & 11.22 \\
\hline JMP Version 4.0 on a PC running Windows NT Version 4 --- Fit Model & 258 & 46 & 86 & 11.217 \\
\hline
\end{tabular}

Table 7 summarizes what is revealed in the related exhibits: a consistent set of ANOVA results from these software packages across these computer platforms for the Table 3 data.

\section{One-Way ANOVA with Random Factor}

The example provided in Table 8 is from Table 17.3 on page 654 of [9]. In this table are recorded the ratings by five (randomly selected) personnel officers of Apex Enterprises for four randomly assigned (to each officer) candidates. An ANOVA is used to estimate the variation in ratings among all personnel officers of this company.

Table 8: Ratings by Personnel Officers of Apex Enterprises [9]

\begin{tabular}{|c|c|c|c|c|}
\hline Officer & \multicolumn{4}{|c|}{ Candidate (j) } \\
\hline (i) & 1 & 2 & 3 & 4 \\
\hline A & 76 & 64 & 85 & 75 \\
\hline B & 58 & 75 & 81 & 66 \\
\hline C & 49 & 63 & 62 & 46 \\
\hline D & 74 & 71 & 85 & 90 \\
\hline E & 66 & 74 & 81 & 79 \\
\hline
\end{tabular}

The ANOVA for this problem is generated as in the previous section, but the interpretation of the information in the ANOVA under the conditions of a random factor lead to some additional calculations used to estimate the variance in ratings among the personnel officers. A discussion of the details of this estimation process is provided on page 660 of [9], leading to an estimate of 73.6 for this variance. Currently, Excel does not automatically generate this estimate as part of its ANOVA: Single Factor routine.

\section{Using JMP Version 3.2.2 on a Pentium II Processor Running Windows NT Version 4}

The data from Table 8 were entered into JMP Version 3.2.2, and the Fit Model platform was used (with a random factor designated in the fit) to analyze these data. Exhibit B.5 in Appendix B provides the JMP Version 3.2.2 results that were journaled and imported into this report.

\section{Using SAS Version 6.12 on AlphaServer Running Open VMS V7}

PROC GLM and PROC VARCOMP demonstrate the capability of SAS to handle this type of problem for the data in Table 8. The inputs and results from each of these two procedures for solving this problem are provided in Exhibits C.6 and C.7 in Appendix C.

\section{Using Statgraphics, Version 4.0 on a Pentium II Processor Running Windows NT Version 4}

The data from Table 8 were entered into Statgraphics, and the ANOVA-Variance Components routine was used to analyze these data. Exhibit E.4 in Appendix E provides the Statgraphics results that were imported into this report using StatReporter 


\section{Using JMP Version 4.0 on a Pentium II Processor Running Windows NT Version 4}

The data from Table 8 were entered into JMP Version 4.0, and the Fit Model platform was used (with a random factor designated in the fit) to analyze these data. Exhibit F.5 in Appendix F provides the JMP Version 4.0 results that were journaled and imported into this report.

\section{One-Way ANOVA (with a Random Factor) Summary Table}

Some of the critical information from the ANOVA tables generated by the software packages reviewed above is summarized in Table 9 along with the results from [9]. Note that PROC GLM provides the equation for solving for the desired estimate. Using this equation along with the ANOVA information leads to an estimate of 73.6 for the rating variance.

\section{Table 9: One-Way ANOVA (Random Factor) Summary Statistics} for Each Software Package

\begin{tabular}{|c|c|c|c|c|}
\hline $\begin{array}{c}\text { Source of Information/ } \\
\text { Software Package }\end{array}$ & $\begin{array}{l}\text { Sum of } \\
\text { Squares } \\
\text { Between }\end{array}$ & $\begin{array}{c}\text { Sum of } \\
\text { Squares } \\
\text { For Error }\end{array}$ & $\begin{array}{c}\text { Mean } \\
\text { Squares for } \\
\text { Offices }\end{array}$ & $\begin{array}{c}\text { Estimate of } \\
\text { Rating } \\
\text { Variance }\end{array}$ \\
\hline As discussed in [9] pages 655 and 660 & 1480 & 1134 & 370 & 73.6 \\
\hline $\begin{array}{l}\text { JMP Version } 3.2 .2 \text { on a PC running Windows NT Version } 4 \text {--- } \\
\text { Fit Model (random) }\end{array}$ & 1480 & 1134 & 370 & 73.6 \\
\hline SAS Version 6.12 on Alphaserver Running OpenVMS V7 & & & & \\
\hline PROC GLM & 1480 & 1134 & 370 & 73.6 \\
\hline SAS Version 6.12 on Alphaserver Running OpenVMS V7 & & & & \\
\hline PROC VARCOMP & 1480 & 1134 & 370 & 73.6 \\
\hline Statgraphics Version 4.0 on a PC running Windows NT Version 4.0 & 1480 & 1134 & 370 & 73.6 \\
\hline $\begin{array}{l}\text { JMP Version Version } 4.0 \text { on a PC running Windows NT Version } 4 \text {--- } \\
\text { Fit Model (random; traditional approach) }\end{array}$ & 1480 & 1134 & 370 & 73.6 \\
\hline
\end{tabular}

Table 9 summarizes what is revealed in the details of the exhibits covering this example: a consistent set of ANOVA results for these software packages across these computer platforms for the data of Table 8.

\section{Two-Way ANOVA}

The example provided in Table 10 is from Table 21.2 on page 787 of [9]. In this table automobile insurance premiums (in dollars) are provided for a city of small, medium, and large size in each of two regions (East and West) of the US. An ANOVA is used to investigate differences between the regions and among the cities. An assumption is made that there is no interaction between these two factors.

Table 10: Insurance Premiums [9]

\begin{tabular}{|c|l|c|c|}
\hline \multicolumn{3}{|c|}{ Insurance Premiums in Dollars } \\
\hline & \multicolumn{3}{|c|}{ Region } \\
\hline \multirow{3}{*}{$\begin{array}{c}\text { Size } \\
\text { of } \\
\text { City }\end{array}$} & & East & West \\
\cline { 2 - 4 } & Small & 140 & 100 \\
\cline { 2 - 4 } & Medium & 210 & 180 \\
\cline { 2 - 4 } & Large & 220 & 200 \\
\hline
\end{tabular}

The discussion in [9] leads to the ANOVA results presented in Table 11 (this information also appears in Table 21.2 on page 787 in [9]). 
Table 11: ANOVA for Insurance Example

\begin{tabular}{|cccr|}
\hline Source of Variation & SS & df & MS \\
\hline Size of City & 9,300 & 2 & 4,650 \\
Region & 1,350 & 1 & 1,350 \\
Error & 100 & 2 & 50 \\
\hline Total & 10,750 & 5 & \\
\hline
\end{tabular}

\section{Using Excel Version 97 SR-1 on a Pentium II Processor Running Windows NT Version 4}

The data from Table 10 were entered into Excel, and Tools/Data Analysis/ANOVA: Two Factors Without Replication pull-down menus were used conduct the analysis of variance. The results were cut and pasted into this report as Table A.5 in Appendix A.

\section{Using JMP Version 3.2.2 on a Pentium II Processor Running Windows NT Version 4}

The data from Table 10 were entered into JMP Version 3.2.2, and the Fit Model platform was used to analyze these data. Exhibit B.6 in Appendix B provides the JMP Version 3.2.2 results that were journaled and imported into this report.

\section{Using SAS Version 6.12 on AlphaServer Running Open VMS V7}

The data from Table 10 were analyzed using PROC ANOVA and PROC GLM of the SAS system. Exhibits C. 8 and C.9 in Appendix C provide the inputs and results from using these two procedures to perform this analysis.

\section{Using Statgraphics, Version 4.0 on a Pentium II Processor Running Windows NT Version 4}

The data from Table 10 were entered into Statgraphics, and the Multi Factor ANOVA routine was used to analyze these data. Exhibit E.5 in Appendix E provides the Statgraphics results that were imported into this report using StatReporter

\section{Using JMP Version 4.0 on a Pentium II Processor Running Windows NT Version 4}

The data from Table 10 were entered into JMP Version 4.0, and the Fit Model platform was used to analyze these data. Exhibit F.6 in Appendix F provides the JMP Version 4.0 results that were journaled and imported into this report.

\section{Two-Way ANOVA Summary Table}

Some of the critical information from the ANOVA tables generated by the software packages reviewed above is summarized in Table 12 along with the results from [9].

Table 12: Two-Way ANOVA Summary Statistics for Each Software Package

\begin{tabular}{|c|c|c|c|c|}
\hline $\begin{array}{l}\text { Source of Information/ } \\
\text { Software Package }\end{array}$ & $\begin{array}{c}\text { Sum of } \\
\text { Squares for } \\
\text { City Size }\end{array}$ & $\begin{array}{c}\text { Sum of } \\
\text { Squares } \\
\text { For Region }\end{array}$ & $\begin{array}{c}\text { Sum of } \\
\text { Squares for } \\
\text { Error }\end{array}$ & $\begin{array}{l}\text { F Statistic } \\
\text { for Region }\end{array}$ \\
\hline As discussed in [9] pages 787 and 788 & 9300 & 1350 & 100 & 27 \\
\hline \multicolumn{5}{|l|}{ Excel Version 97 SR-1 on a PC running Windows NT Version 4--- } \\
\hline ANOVA: Two-Factors without replication & 9300 & 1350 & 100 & 27 \\
\hline $\begin{array}{l}\text { JMP Version } 3.2 .2 \text { on a PC running Windows NT Version } 4 \text {--- Fit Model } \\
\text { SAS Version } 6.12 \text { on Alphaserver Running OpenVMS V7 }\end{array}$ & 9300 & 1350 & 100 & 27 \\
\hline PROC ANOVA & 9300 & 1350 & 100 & 27 \\
\hline \multicolumn{5}{|l|}{ SAS Version 6.12 on Alphaserver Running OpenVMS V7 } \\
\hline PROC GLM & 9300 & 1350 & 100 & 27 \\
\hline Statgraphics Version 4.0 on a PC running Windows NT Version 4 & 9300 & 1350 & 100 & 27 \\
\hline JMP Version 4.0 on a PC running Windows NT Version 4 --- Fit Model & 9300 & 1350 & 100 & 27 \\
\hline
\end{tabular}


Table 12 summarizes what is revealed in the exhibits covering this example: a consistent set of ANOVA results from these software packages across these computer platforms for the data of Table 10.

\section{Two-Factor Nested ANOVA}

A nested two-factor model differs from the previous two-factor (crossed) model in that the levels of the second factor are unique to each level of the first factor. An example of this situation is provided in Table 13 (this example is provided as Table 26.1 on page 971 of [9]).

Table 13: Sample Data for Nested Two-Factor Study (Training School Example from [9])

\begin{tabular}{|c|cc|}
\hline & \multicolumn{2}{|c|}{ Factor B (Instructor) } \\
Factor A (School) & 1 & 2 \\
\hline Atlanta & 25 & 14 \\
& 29 & 11 \\
Chicago & 11 & 22 \\
& 6 & 18 \\
San Francisco & 17 & 5 \\
& 20 & 2 \\
\hline
\end{tabular}

The discussion in [9] leads to the ANOVA results presented in Table 14 (this information appears in Table 26.5 on page 981 in [9]).

Table 14: ANOVA for Training School Example Example

\begin{tabular}{|cccr|}
\hline Soure of Variation & SS & df & \multicolumn{1}{c|}{ MS } \\
\hline Schools & 156.5 & 2 & 78.25 \\
Instructors within Schools & 567.5 & 3 & 189.17 \\
Error & 42.0 & 6 & 7.00 \\
\hline Total & 766.0 & 11 & \\
\hline
\end{tabular}

\section{Using JMP Version 3.2.2 on a Pentium II Processor Running Windows NT Version 4}

The data from Table 13 were entered into JMP Version 3.2.2, and the Fit Model platform was used to analyze these data. Exhibit B.7 in Appendix B provides the JMP Version 3.2.2 results that were journaled and imported into this report.

If both of these factors were random instead of fixed for the data in Table 13, the questions of interest would be different (what variation in scores is due to school? and what variation in scores is due to instructor?) and the test statistics to answer these questions would be different (this is discussed on page 984 of [9]). JMP Version 3.2.2 handles this type of problem in its Fit Model platform. Using this approach leads to the results presented in Exhibit B.8 in Appendix B.

From the discussion of page 985 of [9], the test statistics for this random-effects problem are given by

and

$$
\text { Test for schools }: \mathbf{F}=\mathbf{M S A} / \mathbf{M S B}(\mathbf{A})=78.25 / 189.17=0.414
$$

$$
\text { Test for instructor } \mathbf{s} \mathbf{F}=\operatorname{MSB}(\mathbf{A}) / \mathrm{MSE}=189.17 / 7=27.0
$$

From Exhibit B.8, the test statistic for schools is 0.414 and for instructors is 27.0.

\section{Using SAS Version 6.12 on AlphaServer Running Open VMS V7}

The SAS system's PROC ANOVA was used to analyze the data in Table 13 and the results are presented in Exhibit C.10. Exhibit C.11 provides the results from the use of PROC GLM to analyze these same data. 
If both factors are assumed to be random, there are still at least two-ways to analyze these data with SAS: PROC GLM and PROC VARCOMP. Exhibits C.12 and C.13 provide the inputs and results for these two procedures. Note that PROC VARCOMP does not compute the F statistic for schools, but the procedure does estimate this variance (-27.7) as does the JMP (both versions) procedure, by following the equation on page 985 of [9]. (A negative estimate indicates that this variance is not statistically significant for these data.)

\section{Using Statgraphics, Version 4.0 on a Pentium II Processor Running Windows NT Version 4}

The data from Table 13 were entered into Statgraphics, and the Special, Advanced Regression, General Linear Model platform was used to analyze these data. Exhibit E.6 in Appendix E provides the Statgraphics results that were imported into this report using StatReporter. No option is provided for allowing both factors to be random. However, the Statgraphics results using Variance Components are presented in Exhibit E.7.

\section{Using JMP Version 4.0 on a Pentium II Processor Running Windows NT Version 4}

The data from Table 13 were entered into JMP Version 4.0, and the Fit Model platform was used to analyze these data. Exhibit F.7 in Appendix F provides the JMP Version 4.0 results that were journaled and imported into this report.

If both of these factors were random instead of fixed for the data in Table 13, JMP Version 4.0 would handle this type of problem in its Fit Model platform. Using this approach leads to the results presented in Exhibit F.8 in Appendix F, with a test statistic for schools of 0.414 and for instructors of 27.0 .

\section{Two-Factor Nested ANOVA Summary Table}

Some of the critical information from the ANOVA tables generated by the software packages reviewed above is summarized in Table 15 along with the results from [9].

Table 15: Two-Way Nested ANOVA Summary Statistics for Each Software Package

\begin{tabular}{|c|c|c|c|c|}
\hline $\begin{array}{l}\text { Source of Information/ } \\
\text { Software Package }\end{array}$ & $\begin{array}{l}\text { Sum of } \\
\text { Squares for } \\
\text { School }\end{array}$ & $\begin{array}{l}\text { Sum of } \\
\text { Squares } \\
\quad \text { For } \\
\text { Instructor }\end{array}$ & $\begin{array}{l}\text { Sum of } \\
\text { Squares for } \\
\text { Error }\end{array}$ & $\begin{array}{l}\text { F Statistic } \\
\text { for Schools }\end{array}$ \\
\hline As discussed in [9] pages $981-984$ & 156.5 & 567.5 & 42 & 11.2 \\
\hline JMP Version 3.2.2 on Windows NT Version 4 --- Fit Model & 156.5 & 567.5 & 42 & 11.2 \\
\hline JMP Version 4.0 on Windows NT Version 4 --- Fit Model & 156.5 & 567.5 & 42 & 11.2 \\
\hline $\begin{array}{c}\text { SAS/STAT Version } 6.12 \text { on Alphaserver Running OpenVMS V7 } \\
\text { PROC ANOVA }\end{array}$ & 156.5 & 567.5 & 42 & 11.2 \\
\hline $\begin{array}{c}\text { SAS/STAT Version } 6.12 \text { on Alphaserver Running OpenVMS V7 } \\
\text { PROC GLM } \\
\text { Statgraphics for Windows Version } 4.0\end{array}$ & $\begin{array}{l}156.5 \\
156.5\end{array}$ & $\begin{array}{l}567.5 \\
567.5\end{array}$ & $\begin{array}{l}42 \\
42\end{array}$ & $\begin{array}{c}11.2 \\
11.18\end{array}$ \\
\hline
\end{tabular}

Table 15 summarizes what is revealed in the exhibits covering this example: a consistent set of ANOVA results from these software packages across these computer platforms for the data of Table 13.

Some of the critical information from the ANOVA tables generated by the software packages reviewed above for the situation in which the two factors of Table 13 are random is summarized in Table 16 along with the results from [9]. 
Table 16: Two-Way Nested and Random ANOVA Summary Statistics for Each Software Package

\begin{tabular}{|c|c|c|c|c|}
\hline $\begin{array}{l}\text { Source of Information/ } \\
\text { Software Package }\end{array}$ & $\begin{array}{c}\text { Sum of } \\
\text { Squares for } \\
\text { School }\end{array}$ & $\begin{array}{c}\text { Sum of } \\
\text { Squares } \\
\text { For } \\
\text { Instructor }\end{array}$ & $\begin{array}{c}\text { Sum of } \\
\text { Squares for } \\
\text { Error }\end{array}$ & $\begin{array}{l}\text { F Statistic } \\
\text { for Schools }\end{array}$ \\
\hline As discussed in [9] pages 981 - 984 & 156.5 & 567.5 & 42 & 0.414 \\
\hline JMP Version 3.2.2 on Windows NT Version 4 --- Fit Model & 156.5 & 567.5 & 42 & 0.414 \\
\hline $\begin{array}{l}\text { SAS/STAT Version } 6.12 \text { on Alphaserver Running OpenVMS V7 } \\
\text { PROC GLM }\end{array}$ & 156.5 & 567.5 & 42 & 0.414 \\
\hline $\begin{array}{l}\text { SAS/STAT Version } 6.12 \text { on Alphaserver Running OpenVMS V7 } \\
\text { PROC VARCOMP }\end{array}$ & 156.5 & 567.5 & 42 & \\
\hline Statgraphics for Windows Version 4.0 & 156.5 & 567.5 & 42 & - \\
\hline JMP Version 4.0 on Windows NT Version 4 --- Fit Model & 156.5 & 567.5 & 42 & 0.414 \\
\hline
\end{tabular}

Table 16 summarizes what is revealed in the exhibits covering this example: a consistent set of ANOVA results from these software packages across these computer platforms for the data of Table 13 with both factors random.

\section{Experimental Designs}

Another major area of interest is that of experimental design. Two important types of problems in this area, which are addressed in this section, are fractional factorial experiments and mixture experiments. Several packages are utilized by SCS in planning these types of experiments.

\section{Fractional Factorial}

An excellent aid in the planning of these types of experiments is provided in Table 9A.1 on pages 182 and 183 of [10]. A portion of this table covering 6-factor experiments is provided in Table 17.

Table 17: Selected Fractional Factorial Experiments of the Complete Factorial Experiment for a 6-Factor Study

\begin{tabular}{|cccccc|}
\hline $\begin{array}{c}\text { Number of } \\
\text { Factors }\end{array}$ & $\begin{array}{c}\text { Number of Test } \\
\text { Runs }\end{array}$ & Fraction & Resolution & Defining & Added \\
6 & 8 & $1 / 8$ & Equations & Factors \\
& & & I = ABD & $4=12$ \\
& & & I=ACE & $6=23$ \\
& 16 & $1 / 4$ & IV & I=ACF & $5=123$ \\
\hline
\end{tabular}

The features of this quarter fraction design for this 6-factor study of interest

\section{Using JMP Version 3.2.2 on a Pentium II Processor Running Windows NT Version 4}

Using the Design Experiment feature of JMP Version 3.2.2, candidate designs involving 6 factors can be explored. One option presented is a 16-run experiment (a quarter fraction of the complete factorial experiment). Exhibit B.9 in Appendix B provides the results of selecting this option from the list of JMP Version 3.2.2 candidates.

\section{Using SAS Version 6.12 on AlphaServer Running Open VMS V7}

PROC FACTEX in SAS/QC can be used to generate such designs. The input and results for this SAS procedure are provided in Exhibit C.14 of Appendix C.

\section{Using Mixsoft Version 2.3 on a Pentium II Processor Running Windows NT Version 4}

This is a specialized software program that aids in experimental designs. Exhibit D.1 in Appendix D provides the results of using this program to select a fractional factorial experiment consisting of 16 trials for a 6 -factor problem. 


\section{Using Statgraphics Version 4.0 on a Pentium II Processor Running Windows NT Version 4}

Using the Experimental Design platform of Statgraphics, a quarter fraction of the complete factorial experiment for a 6-factor problem was selected. The results appear in Exhibit E.8 in the Appendix.

\section{Using JMP Version 4.0 on a Pentium II Processor Running Windows NT Version 4}

Using the DOE (Design of Experiment) platform of JMP Version 4.0, candidate designs involving 6 factors can be explored. One option presented is a 16-run experiment (a quarter fraction of the complete factorial experiment). Exhibit F.9 in Appendix F provides the results of selecting this option from the list of JMP Version 4.0 candidates.

\section{Fractional Factorial Summary}

Four different packages were used to generate this fractional factorial experiment, and the results are identical except that the columns for the Mixsoft results are in a different order (these can be rearranged to match results from the other packages exactly).

\section{Mixture}

Mixture experiments have been of critical importance in the support of DWPF and in other studies of the vitrification of legacy materials. In mixture experiments, the factors are ingredients of a mixture, and their levels are not independent. Extreme vertices designs are used to support these types of problems. For a full discussion, see Chapter 9 of reference [11]. An example from this reference will be used to illustrate the capabilities of the software utilized by SCS in support of mixture experiments. This example is discussed in Section 9.3.2 and involves a mixture of three components with each component being bounded as given in the equation (2)

$$
0.20 \leq \mathrm{x}_{1} \leq 0.60 \quad 0.10 \leq \mathrm{x}_{2} \leq 0.60 \quad 0.10 \leq \mathrm{x}_{3} \leq 0.50
$$

where the three components are represented by the x's. The discussion in [4] on pages 353 through 358 identifies 6 extreme vertices for the region defined by equation (2). These extremes are given in Table 18 [10].

Table 18: Extreme Vertices for Region Defined by Equation (2)

\begin{tabular}{|c|c|c|c|c|}
\hline Count & $\mathbf{x}_{\mathbf{1}}$ & $\mathbf{x}_{\mathbf{2}}$ & $\mathbf{x}_{\mathbf{3}}$ & Sum \\
\hline 1 & 0.6 & 0.3 & 0.1 & 1 \\
\hline 2 & 0.3 & 0.6 & 0.1 & 1 \\
\hline 3 & 0.2 & 0.6 & 0.2 & 1 \\
\hline 4 & 0.2 & 0.3 & 0.5 & 1 \\
\hline 5 & 0.4 & 0.1 & 0.5 & 1 \\
\hline 6 & 0.6 & 0.1 & 0.3 & 1 \\
\hline
\end{tabular}

\section{Using JMP Version 3.2.2 on a Pentium II Processor Running Windows NT Version 4}

Using the Design platform of JMP Version 3.2.2, the region defined by equation (2) was entered and the Extreme Vertices design option invoked. Exhibit B.10 in Appendix B provides the results of selecting this option under the JMP Version 3.2.2 software.

\section{Using SAS Version 6.12 on AlphaServer Running Open VMS V7}

Exhibit C.15 in Appendix C provides the input and results from using the mixture design capabilities provided in SAS/QC to generate the extreme vertices for the region defined by equation (2). 


\section{Using Mixsoft Version 2.3 on a Pentium II Processor Running Windows NT Version 4}

Once again, Mixsoft is specialized software; one of its capabilities is mixture experimental design. Exhibit D.2 in Appendix D provides the inputs and outputs generated by this program to select generate the extreme vertices for the problem defined by equation (2).

\section{Using Statgraphics, Version 4.0 on a Pentium II Processor Running Windows NT Version 4}

Using the Experimental Design platform of Statgraphics, the region defined by equation (2) was entered and the Extreme Vertices design option selected. Exhibit E.9 in the Appendix provides the Statgraphics results.

\section{Using JMP Version 4.0 on a Pentium II Processor Running Windows NT Version 4}

Using the DOE (Design of Experiment) platform of JMP Version 4.0, the region defined by equation (2) was entered and the Mixture Design/Extreme Vertices design options invoked. Exhibit F.10 in Appendix F provides the results of selecting this option under the JMP Version 4.0 software.

\section{Mixture Summary}

Five different packages were used to generate the set of extreme vertices for the mixture experiment described by equation (2), and the results are identical to those of Table 18 across all five packages.

\section{Optimal Designs}

Selecting an optimal design from a set of candidate points is frequently a necessity during the planning of an experiment. Computer-aided design of experiments routines utilize one or more of design optimality criteria to choose such a set of points (the design) from a candidate list of points. Almost all of these computer-aided design routines are model dependent. Once a model is chosen and a list of candidate design points is specified, a particular design (of a designated size) that minimizes or maximizes a particular criterion is selected from the candidate points. One of the more frequently selected criteria for choosing a design is

D-optimality, which seeks to minimize the determinant of $\left(\mathbf{X}^{\prime} \mathbf{X}\right)^{-\mathbf{1}}$ where each row of the matrix $\mathbf{X}$ is a design point, i.e., a set of explanatory variables: $\mathrm{x}_{1}, \mathrm{x}_{2}, \ldots, \mathrm{x}_{\mathrm{p}}$.

This is a model-dependent criterion, and a design that is optimal for one model form, for example a first-degree model, will not necessarily be optimal for another model such as a second-degree model. The example to be considered, as part of this report, is the use of this criterion to select 8 design points from those listed in Table 19. 
Table 19: Face-Centered Cube Design

\begin{tabular}{|ccccc|}
\hline Pattern & $\mathbf{x}_{\mathbf{1}}$ & $\mathbf{x}_{\mathbf{2}}$ & $\mathbf{x}_{\mathbf{3}}$ & Comment \\
+00 & 1 & 0 & 0 & Axial \\
++- & 1 & 1 & -1 & FF \\
--- & -1 & -1 & -1 & FF \\
000 & 0 & 0 & 0 & Center-FF \\
$00-$ & 0 & 0 & -1 & Axial \\
000 & 0 & 0 & 0 & Center-FF \\
-00 & -1 & 0 & 0 & Axial \\
$00+$ & 0 & 0 & 1 & Axial \\
+++ & 1 & 1 & 1 & FF \\
+-+ & 1 & -1 & 1 & FF \\
000 & 0 & 0 & 0 & Center-FF \\
--+ & -1 & -1 & 1 & FF \\
-+- & -1 & 1 & -1 & FF \\
$0-0$ & 0 & -1 & 0 & Axial \\
+-- & 1 & -1 & -1 & FF \\
$0+0$ & 0 & 1 & 0 & Axial \\
000 & 0 & 0 & 0 & Center-Ax \\
000 & 0 & 0 & 0 & Center-Ax \\
000 & 0 & 0 & 0 & Center-FF \\
-++ & -1 & 1 & 1 & FF \\
\hline
\end{tabular}

The design points provided in this table represent a "face-centered cube design," similar to that discussed in [10]. The optimal design for a linear model in $x_{1}, x_{2}$, and $x_{3}$ with an intercept term is given by the shaded rows of Table 19. These points make up the fractional factorial part of the face-centered cube design.

\section{Using JMP Version 3.2.2 on a Pentium II Processor Running Windows NT Version 4}

A feature of the JMP Version 3.2.2 software package is its D-Optimal Design routine to choose a set of points (the design) from a candidate list of points [1]. The data from Table 19 were entered into JMP Version 3.2.2 and the D-optimal routine evoked to select the best set of 8 points from the set of 20 points. The results from this process are provided in Exhibit B.11 in Appendix B. Values of the D-Optimality criteria, including D-efficiency, are provided as part of the output from this routine. The JMP Version 3.2.2 spreadsheet resulting from the process is also provided in Exhibit B.11, and it shows the rows selected as "optimal" for a linear model.

\section{Using SAS Version 6.12 on AlphaServer Running Open VMS V7}

Exhibit C.16 in Appendix C provides the results form using PROC OPTEX in SAS to select an optimal design.

\section{Using Statgraphics Version 4.0 on a Pentium II Processor Running Windows NT Version 4}

Exhibit E.10 in Appendix E provides the results from using the D-Optimal Design routine in Statgraphics.

\section{Using JMP Version 4.0 on a Pentium II Processor Running Windows NT Version 4}

This feature is not available in JMP Version 4.0. This is the primary reason for maintaining JMP Version 3.2.2 in the baseline software list.

\section{Optimal Design Summary}

Three different packages were used to generate a set of eight design points from those in Table 19 that would be D-optimal for a linear model. The two data sets resulting from the JMP Version 3.2.2 and SAS procedures were identical. Statgraphics had a mirror image design point (+--) for one of the eight points selected by JMP Version 3.2.2 (-++). However, the design efficiencies are identical. The Statgraphics design was input into JMP Version 3.2.2 and the efficiency statistics reproduced. 


\section{Control Charts}

As a final area of interest in this review of software, a problem in statistical process control is explored. The construction of $x$-bar and $s$ charts will be illustrated using an example from [12] (these data are provided in Table 5.1 on page 83 of [12]). These data (along with summary information) are presented in Table 20.

Table 20: Data in Subgroups Obtained at Regular Intervals (Example 5.1, Table 5.1 of [12])

\begin{tabular}{|ccccccc|}
\hline Subgroup & $\mathrm{x} 1$ & $\mathrm{x} 2$ & $\mathrm{x} 3$ & $\mathrm{x} 4$ & Average & Std Dev \\
1 & 72 & 84 & 79 & 49 & 71.00 & 15.47 \\
2 & 56 & 87 & 33 & 42 & 54.50 & 23.64 \\
3 & 55 & 73 & 22 & 60 & 52.50 & 21.70 \\
4 & 44 & 80 & 54 & 74 & 63.00 & 16.85 \\
5 & 97 & 26 & 48 & 58 & 57.25 & 29.68 \\
6 & 83 & 89 & 91 & 62 & 81.25 & 13.28 \\
7 & 47 & 66 & 53 & 58 & 56.00 & 8.04 \\
8 & 88 & 50 & 84 & 69 & 72.75 & 17.23 \\
9 & 57 & 47 & 41 & 46 & 47.75 & 6.70 \\
10 & 13 & 10 & 30 & 32 & 21.25 & 11.35 \\
11 & 26 & 39 & 52 & 48 & 41.25 & 11.53 \\
12 & 46 & 27 & 63 & 34 & 42.50 & 15.76 \\
13 & 49 & 62 & 78 & 87 & 69.00 & 16.87 \\
14 & 71 & 63 & 82 & 55 & 67.75 & 11.53 \\
15 & 71 & 58 & 69 & 70 & 67.00 & 6.06 \\
16 & 67 & 69 & 70 & 94 & 75.00 & 12.73 \\
17 & 55 & 63 & 72 & 49 & 59.75 & 9.98 \\
18 & 49 & 51 & 55 & 76 & 57.75 & 12.42 \\
19 & 72 & 80 & 61 & 59 & 68.00 & 9.83 \\
20 & 61 & 74 & 62 & 57 & 63.50 & 7.33 \\
\hline
\end{tabular}

\section{x-Bar and s Charts}

The values were entered into Excel, and the summary statistics were computed using the AVERAGE and STDEV functions of Excel. These are the values that appear in the last two columns of Table 20, and they agree with the information in [12]. The data were also entered into JMP Version 3.2.2, and the sample means and standard deviations were computed using JMP's "grouping" feature. Table B.1 in Appendix B provides these values (which agree with Table 20). As an additional check, the data were entered into JMP Version 4.0, and the "summary" feature of this software was used to generate sample means and standard deviations. Table F.1 in Appendix F provides these values (which also agree with Table 20).

\section{Using JMP Version 3.2.2 on a Pentium II Processor Running Windows NT Version 4}

Using the Graph/Control Charts platform of JMP Version 3.2.2, the x-bar and s charts for the data of Table 20 were generated after the values were entered into JMP Version 3.2.2. These charts appear as Exhibit B.12 in Appendix B.

\section{Using SAS Version 6.12 on AlphaServer Running Open VMS V7}

Exhibit C.17 in Appendix C provides the inputs to and results from using PROC SHEWHART in SAS to generate these control charts.

\section{Using Statgraphics Version 4.0 on a Pentium II Processor Running Windows NT Version 4}


Using the Special/Quality Control/Variables Control Charts/X-bar and s option of Statgraphics, the $\mathrm{x}$-bar and s charts for the data in Table 20 were generated using Statgraphics. These charts appear as Exhibit E.11 in Appendix E. 


\section{Using JMP Version 4.0 on a Pentium II Processor Running Windows NT Version 4}

Using the Graph/Control Charts platform of JMP Version 4.0, the $\mathrm{x}$-bar and s charts for the data of Table 20 were generated after the values were entered into JMP Version 4.0. These charts appear as Exhibit F.11 in Appendix F.

\section{Control Chart Summary Table}

Some of the critical information from the control charts generated by the software packages reviewed above is provided in Table 21 along with the results from [12].

Table 21: Control Chart Summary Statistics for Each Software Package

\begin{tabular}{|c|c|c|c|c|}
\hline $\begin{array}{l}\text { Source of Information/ } \\
\text { Software Package }\end{array}$ & $\begin{array}{c}\text { Center-line } \\
\text { for } \\
\text { X-bar Chart }\end{array}$ & $\begin{array}{c}\text { Upper } \\
\text { Control } \\
\text { limit for } x- \\
\text { bar Chart }\end{array}$ & $\begin{array}{c}\text { Center- line } \\
\text { for } \\
\text { s Chart }\end{array}$ & $\begin{array}{l}\text { Upper } \\
\text { Control } \\
\text { limit for } \\
\text { s Chart }\end{array}$ \\
\hline As discussed in [12] pages $83-96$ & 59.4 & 82.1 & 13.9 & 31.5 \\
\hline MP Version 3.2.2 on a PC running Windows NT Version 4 --- Fit Model & 59.4 & 82.1 & 13.9 & 31.5 \\
\hline $\begin{array}{l}\text { MP Version } 4.0 \text { on a PC running Windows NT Version } 4 \text {--- Fit Model } \\
\text { AS/QC Version } 6.12 \text { on AlphaServer Running OpenVMS V7 }\end{array}$ & 59.4 & 82.1 & 13.9 & 31.5 \\
\hline PROC SHEWHART & 59.4 & 82.1 & 13.9 & 31.5 \\
\hline tatgraphics Version 4.0 on a PC running for Windows Version 4.0 & 59.4 & 82.1 & 13.9 & 31.5 \\
\hline
\end{tabular}

Table 21 summarizes what is revealed in the exhibits covering this example: a consistent set of control charts from these software packages across these computer platforms for the data of Table 20. 


\section{CONCLUSIONS AND RECOMMENDATIONS}

The statistical analyses completed in this study provide an important verification and validation of the statistical software and computer platforms utilized by the members of SCS. The IBM Personal Computer 300PL and 300XL are both Pentium II based desktops. Therefore, the software v\&v in this report is valid interchangeably between both platforms.

Problems frequently encountered by members of SCS are identified; an example of each problem is selected from a well-established statistical textbook; the example is analyzed using a feature or features of the software (as appropriate) described in the previous section; and the results generated by the various software packages are compared to the information from the textbook and/or to each other for validation and verification. Little discussion is provided regarding the details of the problems, the underlying statistical theory, the statistical routines, or the statistical results. Information about the statistical packages, their capabilities, and details regarding their outputs can be found in their respective published documentation. These references along with those cited as the sources of the problems may be used to provide these details.

This report has shown that these statistical packages, when used appropriately, provide reliable results over a broad range of problem types. This effort is not intended to diminish the importance of the technical review process. As seen in the discussion above, selecting the appropriate statistical approach and model for the problem at hand and the appropriate feature of the available software for its solution are important issues. An important part of the technical review process is to confirm the appropriateness of these decisions.

The software considered in this report is commercial software (some of which is site-licensed), and these packages are considered to have a Level D software classification (as defined in the WSRC 1Q Quality Assurance Manual, QAP 20-1, Revision 6) in that they are important to day to day operation of the business and analyses conducted by SCS, but their failure to perform as intended at in any point in time will not affect the safety or reliability of SRS facilities.

Software configuration control for SCS is the responsibility of each member of SCS, and this document is to serve as the central repository for the software baseline list. When the QA requirements for the work being conducted include software validation and verification, the commercial software packages used to support the analyses should be clearly identified as part of the SCS deliverable. This identification should include the name of the software, the version number, and the vendor. A reference to the appropriate revision of this document may also be included in the deliverable, if this is seen as beneficial. 


\section{REFERENCES}

[1] SAS Institute, JMP ${ }^{\circledR}$ Statistics and Graphics Guide: Version 3 of JMP, SAS Institute, Inc., Cary, NC, 1995.

[2] SAS Institute, SAS Procedures Guide, Version 6, Third Edition, SAS Institute, Inc., Cary, NC, 1990.

[3] SAS Institute, SAS/QC ${ }^{\circledR}$ Software: Reference, Version 6, First Edition, SAS Institute, Inc., Cary, NC, 1989.

[4] SAS Institute, SAS/STAT ${ }^{\circledR}$ User's Guide, Version 6, Fourth Edition, Volume 1, SAS Institute, Inc., Cary, NC, 1990.

[5] SAS Institute, SAS/STAT ${ }^{\circledR}$ User's Guide, Version 6, Fourth Edition, Volume 2, SAS Institute, Inc., Cary, NC, 1990.

[6] SAS Institute, SAS/IML ${ }^{\circledR}$ Software: Usage and Reference, Version 6, First Edition, SAS Institute, Inc., Cary, NC, 1990.

[7] Piepel, G.F., MIXSOFT_-Software for the Design and Analysis of Mixture and Other Constrained Region Experiments, User's Guide Version 2.3, MIXSOFT-Mixture Experiment Software, Richland, Washington, 1998.

[8] Manugistics, Inc., Statgraphics Plus ${ }^{\circledR}$ Standard Edition, Version 4.0, Manugistics, Inc., Rockville, MD, 1998.

[9] Neter, John, William Wasserman, and Michael H. Kutner, Applied Linear Statistical Models: Regression, Analysis of Variance, and Experimental Designs, Third Edition, Richard D. Irwin, Inc., Homewood, IL, 1990.

[10] Mason, Robert L., Richard F. Gunst, and James L. Hess, Statistical Design and Analysis of Experiments With Applications to Engineering and Science, John Wiley \& Sons, Inc., New York, 1989.

[11] Khuri, Andre' I. And John A. Cornell, Response Surfaces: Designs and Analyses, Marcel Dekker, Inc., New York, 1987.

[12] Ryan, Thomas P., Statistical Methods for Quality Improvement, John Wiley \& Sons, Inc., New York, 1989.

[13] Hayes, W.L., Statistics, third edition. New York: Holt, Rinehart and Winston, 1981.

[14] SAS Institute, JMP ${ }^{\circledR}$ Statistics and Graphics Guide: Version 4 of JMP, SAS Institute, Inc., Cary, NC, 2000. 


\section{APPENDICES}

\section{Appendix A: Excel Results}

Table A.1a: Excel Descriptive Statistics for Lot-Size Values in Table 2

Table A.1b: Excel Functions for Lot-Size Values in Table 2

Table A.2: Excel Regression of Information in Table 2

Table A.3: Excel Matrix Handling Capabilities Used to Conduct Regression Analysis for Information in Table 2

Table A.4: Excel ANOVA

Table A.5: Excel ANOVA: Two-Factor Without Replication

\section{Appendix B: JMP Version 3.2.2 Results}

Table B.1: JMP Version 3.2.2 Sample Statistics for Data from Table 20

Exhibit B.1: JMP Version 3.2.2 Output for Descriptive Statistics of Lot Size Information in Table 2

Exhibit B.2: JMP Version 3.2.2 Output for Regression Model for Information in Table 2 Using Fit $\mathrm{Y}$ by $\mathrm{X}$

Exhibit B.3: JMP Version 3.2.2 Output for Regression Model for Information in Table 2 Using Fit Model

Exhibit B.4: JMP Version 3.2.2 Output for ANOVA of Information in Table 5 Using Fit Model

Exhibit B.5: JMP Version 3.2.2 Output for ANOVA of Information in Table 8 Using Fit Model with Random Factor

Exhibit B.6: JMP Version 3.2.2 Output for ANOVA of Information in Table 8 Using Fit Model with Two Factors

Exhibit B.7: JMP Version 3.2.2 Output for Nested ANOVA of Information in Table 13

Using Fit Model with A Nested Factor

Exhibit B.8: JMP Version 3.2.2 Output for Nested ANOVA of Information in Table 13

Using Fit Model with Random Factors

Exhibit B.9: JMP Version 3.2.2 Output for a Fractional Factorial Experiment using the Design Experiment Feature

Exhibit B.10: JMP Version 3.2.2 Output for Mixture Problem Defined by Equation (2)

Exhibit B.11: JMP Version 3.2.2's D-Optimality Results

Exhibit B.12: JMP Version 3.2.2 Results for x-Bar and s Charts for Data in Table 20

\section{Appendix C: SAS Results}

Exhibit C.1: SAS Input for and Results from Descriptive Statistics for Lot Size Values in Table 2

Exhibit C.2: SAS Input for and Results from Proc Reg for Table 2 Data

Exhibit C.3: SAS Input for and Results from SAS/IML Program for Regression of Table 2 Data

Exhibit C.4: SAS Input for and Results from SAS/STAT Proc ANOVA for Analyzing of Table 5 Data

Exhibit C.5: SAS Input for and Results from SAS/STAT Proc GLM for Analyzing of Table 5 Data

Exhibit C.6: SAS Input for and Results from SAS/STAT Proc GLM for Analyzing of Table 8 Data

Exhibit C.7: SAS Input for and Results from SAS/STAT Proc VARCOMP for Analyzing of Table 8 Data

Exhibit C.8: SAS Input for and Results from SAS/STAT Proc ANOVA for Analyzing of Table 8 Data

Exhibit C.9: SAS Input for and Results from SAS/STAT Proc GLM for Analyzing of Table 8 Data

Exhibit C.10: SAS Input for and Results from SAS/STAT Proc ANOVA for Analyzing of Table 13 Data 


\section{APPENDICES}

Exhibit C.11: SAS Input for and Results from SAS/STAT Proc GLM for Analyzing of Table 13 Data

Exhibit C.12: SAS Input for and Results from SAS/STAT Proc GLM for Analyzing of Table 13 Data

Exhibit C.13: SAS Input for and Results from SAS/STAT Proc VARCOMP for Analyzing of Table 13 Data

Exhibit C.14: SAS Input for and Results from SAS/QC Proc Factex for Experimental Design Exhibit C.15: SAS Input and Output for Mixture Problem Defined by Equation (2) Exhibit C.16: SAS Input for and Results from SAS/QC Proc Optex for D-Optimality Exhibit C.17: SAS Input and Output for Control Chart Example from Table 20

\section{Appendix D: Mixsoft Results}

Exhibit D.1: Mixsoft Output for a Fractional Factorial Experiment using the Design Experiment Feature

Exhibit D.2: Mixsoft Input and Output for Mixture Problem Defined by Equation (2)

\section{Appendix E: Statgraphics Results}

Exhibit E.1: Statgraphics Output for Statistics of Lot Size Information in Table 2

Exhibit E.2: Statgraphics Output for Table 2 Data Using Simple Regression Exhibit E.3: Statgraphics Output for Table 5 Data Using One-Way ANOVA

Exhibit E.4: Statgraphics Output for Table 8 Data using Variance Components Analysis Exhibit E.5: Statgraphics Output for Table 10 Data using Two Factor ANOVA

Exhibit E.6: Statgraphics Output for Table 13 Data using a Nested Exhibit E.7: Statgraphics Output for Table 13 Data using Variance Component Analysis Exhibit E.8: Statgraphics Output for Fractional Factorial Design Exhibit E.9: Statgraphics Output for Extreme Vertices Exhibit E.10: Statgraphics D-Optimality Results Exhibit E.11: Statgraphics X-bar and S Charts - X

\section{Appendix F: JMP Version 4.0 Results}

Table F.1: JMP Version 4.0 Sample Statistics for Data from Table 20

Exhibit F.1: JMP Version 4.0 Output for Descriptive Statistics of Lot Size Information in Table 2

Exhibit F.2: JMP Version 4.0 Output for Regression Model for Information in Table 2 Using Fit $\mathrm{Y}$ by $\mathrm{X}$

Exhibit F.3: JMP Version 4.0 Output for Regression Model for Information in Table 2 Using Fit Model

Exhibit F.4: JMP Version 4.0 Output for ANOVA of Information in Table 5 Using Fit Model

Exhibit F.5: JMP Version 4.0 Output for ANOVA of Information in Table 8 Using Fit Model with Random Factor

Exhibit F.6: JMP Version 4.0 Output for ANOVA of Information in Table 8 Using Fit Model with Two Factors

Exhibit F.7: JMP Version 4.0 Output for Nested ANOVA of Information in Table 13 Using Fit Model with A Nested Factor

Exhibit F.8: JMP Version 4.0 Output for Nested ANOVA of Information in Table 13 Using Fit Model with Random Factors

Exhibit F.9: JMP Version 4.0 Output for a Fractional Factorial Experiment using the Design Experiment Feature

Exhibit F.10: JMP Version 4.0 Output for Mixture Problem Defined by Equation (2)

Exhibit F.11: JMP Version 4.0 Results for x-Bar and s Charts for Data in Table 20 
Table A.1a: Excel Descriptive Statistics for Lot-Size Values in Table 2

\begin{tabular}{|cc|}
\hline \multicolumn{2}{|c|}{ Lot Size $\left(X_{i}\right)$} \\
\hline & 50 \\
Mean & 6.146362972 \\
Standard Error & 55 \\
Median & 60 \\
Mode & 19.43650632 \\
Standard Deviation & 377.7777778 \\
Sample Variance & -1.066608997 \\
Kurtosis & -0.113491711 \\
Skewness & 60 \\
Range & 20 \\
Minimum & 80 \\
Maximum & 500 \\
Sum & 10 \\
Count & 80 \\
Largest $(1)$ & 20 \\
Smallest $(1)$ & 13.90404962 \\
Confidence Level $(95.0 \%)$ &
\end{tabular}

Table A.1b: Excel Functions for Lot-Size Values in Table 2

\begin{tabular}{|c|c|}
\hline EXCEL Function & Description \\
\hline Count & 10 Number of data \\
\hline Average & 50 Average of data \\
\hline Sum & 500 Sum of data \\
\hline Minimum & 20 Minimum of data \\
\hline Maximum & 80 Maximum of data \\
\hline Median & 55 Median of data \\
\hline Mode & 60 Mode of data \\
\hline DEVSQ & 3400 Sum of Squares of Deviations about the Mean \\
\hline Std Dev & 19.43650632 Standard deviation of data \\
\hline Skew & -0.11349171 Skewness of data \\
\hline Kurt & -1.06660900 Kurtosis of data \\
\hline Geomean & 46.12054471 Geometric mean of data \\
\hline Harmean & 41.93709436 Harmonic mean of data \\
\hline
\end{tabular}


Table A.2: Excel Regression of Information in Table 2

\begin{tabular}{|c|c|c|c|c|c|c|c|c|}
\hline \multicolumn{9}{|c|}{ SUMMARY OUTPUT } \\
\hline \multicolumn{2}{|c|}{ Regression Statistics } & & & & & & & \\
\hline Multiple R & 0.997801 & & & & & & & \\
\hline R Square & 0.995608 & & & & & & & \\
\hline Adjusted R Square & 0.995059 & & & & & & & \\
\hline Standard Error & 2.738613 & & & & & & & \\
\hline Observations & 10 & & & & & & & \\
\hline \multicolumn{9}{|l|}{ ANOVA } \\
\hline & $d f$ & $S S$ & $M S$ & $F$ & Signific & cance $F$ & & \\
\hline Regression & 1 & 13600 & 13600 & 1813.333 & $1.02 \mathrm{E}-10$ & & & \\
\hline Residual & 8 & 60 & 7.5 & & & & & \\
\hline \multirow[t]{2}{*}{ Total } & 9 & 13660 & & & & & & \\
\hline & Coefficients & $\begin{array}{c}\text { Standard } \\
\text { Error }\end{array}$ & tStat & $P$-value & Lower 95\% & Upper $95 \%$ & $\begin{array}{l}\text { Lower } \\
95.0 \% \\
\end{array}$ & $\begin{array}{l}\text { Upper } \\
95.0 \% \\
\end{array}$ \\
\hline Intercept & 10 & 2.502939 & 3.995302 & 0.003976 & 4.228208 & 15.77179 & 4.228208 & 15.77179 \\
\hline Lot Size (Xi) & 2 & 0.046967 & 42.58325 & $1.02 \mathrm{E}-10$ & 1.891694 & 2.108306 & 1.891694 & 2.108306 \\
\hline
\end{tabular}


Table A.3: Excel Matrix Handling Capabilities Used to Conduct Regression Analysis for Information in Table 2

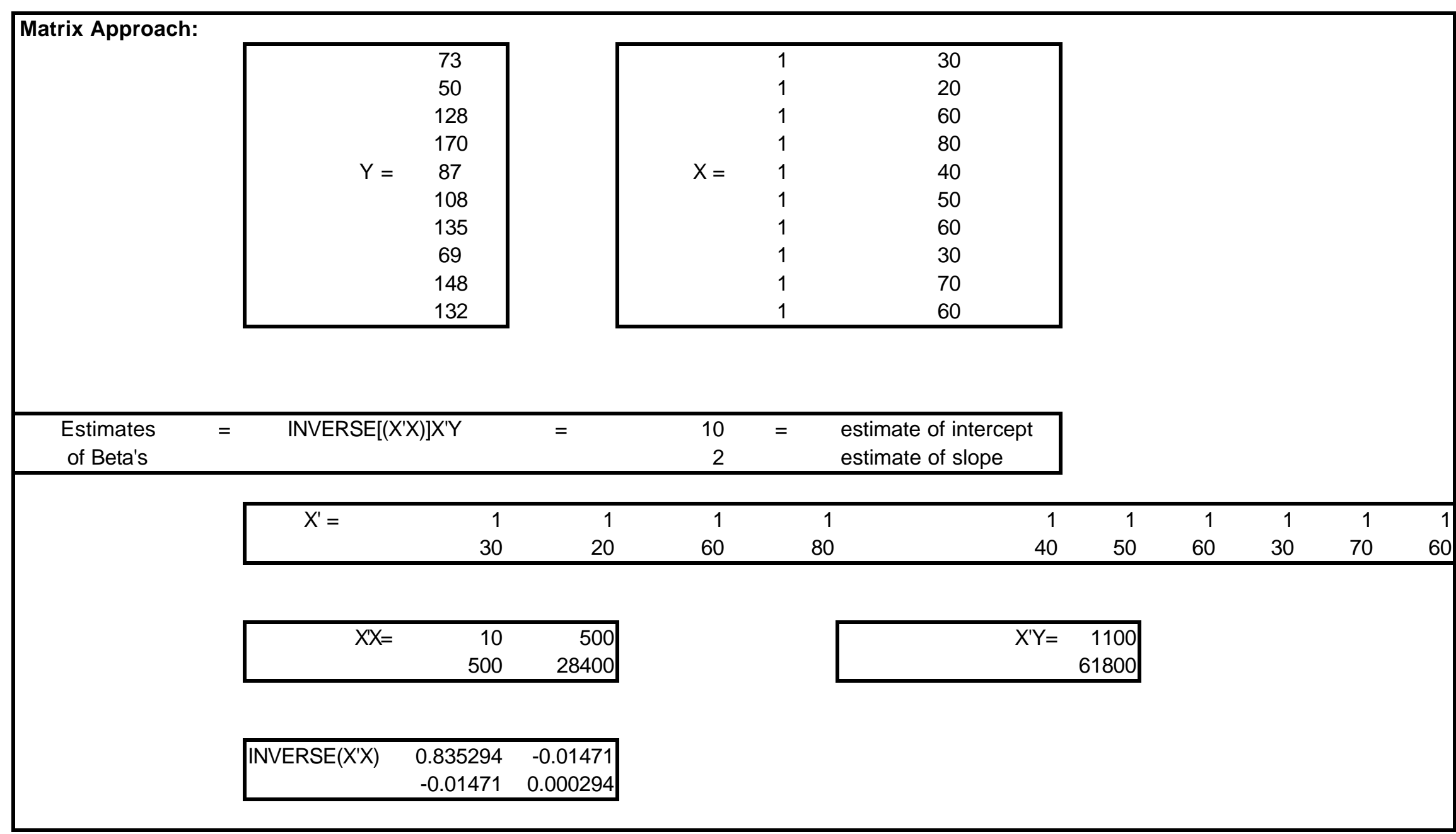


WSRC-RP-99-draft

Revision 1

Appendix A: Excel Results 
Appendix A: Excel Results

Table A.4: Excel ANOVA

Anova: Single Factor

SUMMARY

\begin{tabular}{crrrrr}
\hline Groups & \multicolumn{1}{c}{ Count } & \multicolumn{1}{c}{ Sum } & Average & Variance \\
\hline & 1 & 2 & 30 & 15 & 18 \\
& 2 & 3 & 39 & 13 & 1 \\
& 3 & 3 & 57 & 19 & 4 \\
& 4 & 2 & 54 & 27 & 18 \\
\hline
\end{tabular}

ANOVA

\begin{tabular}{|c|c|c|c|c|c|c|}
\hline Source of Variation & $S S$ & $d f$ & $M S$ & $F$ & $P$-value & F crit \\
\hline Between Groups & 258 & 3 & 86 & 11.21739 & 0.007135 & 4.757055 \\
\hline Within Groups & 46 & 6 & 7.666667 & & & \\
\hline Total & 304 & 9 & & & & \\
\hline
\end{tabular}




\section{Appendix A: Excel Results}

Table A.5: Excel ANOVA: Two-Factor Without Replication

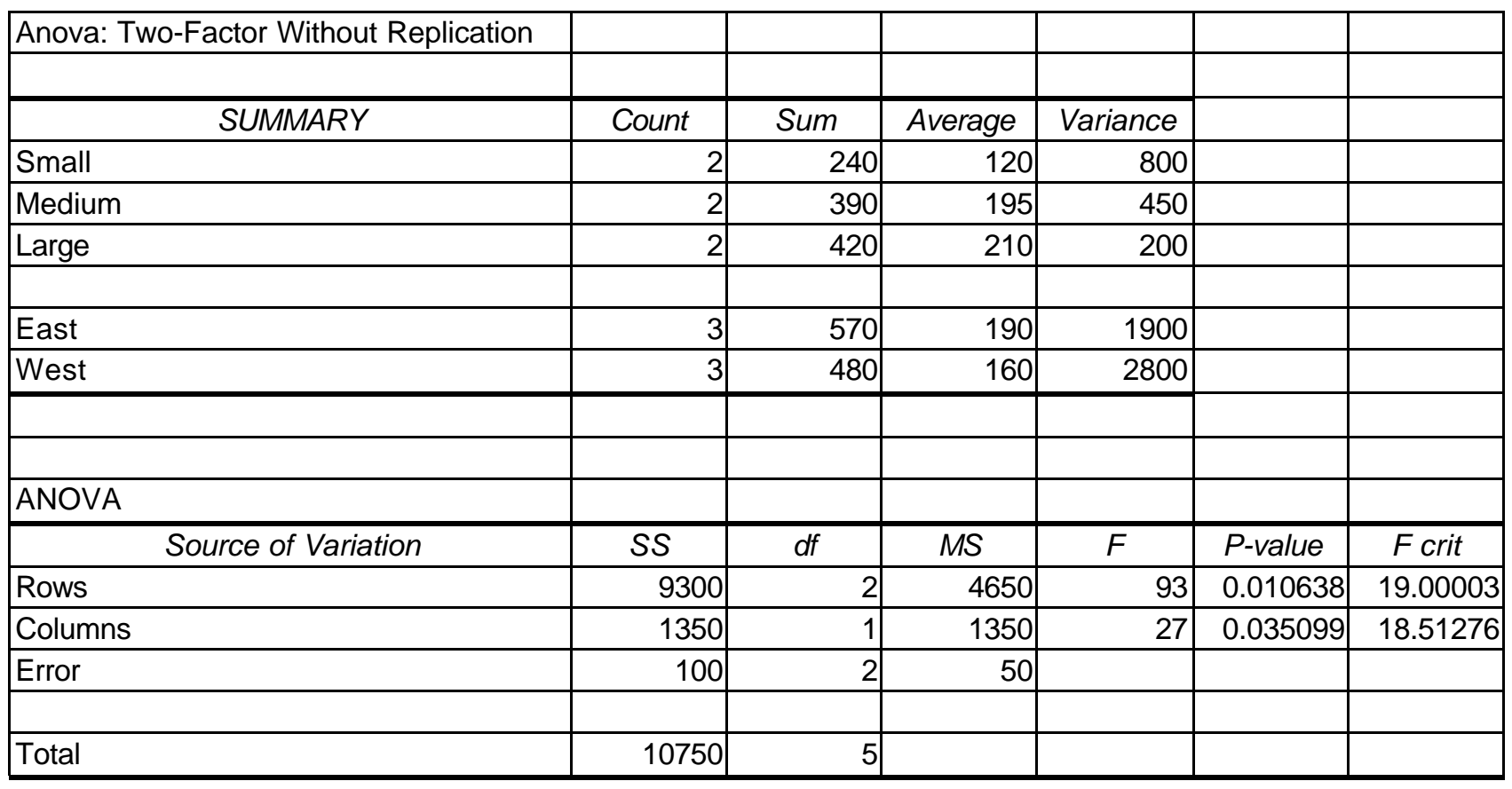


Appendix B: JMP Version 3.2.2 Results

Table B.1: JMP Version 3.2.2 Sample Statistics for Data from Table 18

\begin{tabular}{|cccc|}
\hline Subgroup & N Rows & Mean (x) & Std Dev(x) \\
1 & 4 & 71 & 15.4704 \\
2 & 4 & 54.5 & 23.64318 \\
3 & 4 & 52.5 & 21.70253 \\
4 & 4 & 63 & 16.8523 \\
5 & 4 & 57.25 & 29.68024 \\
6 & 4 & 81.25 & 13.27592 \\
7 & 4 & 56 & 8.041559 \\
8 & 4 & 72.75 & 17.23127 \\
9 & 4 & 47.75 & 6.70199 \\
10 & 4 & 21.25 & 11.35415 \\
11 & 4 & 41.25 & 11.52895 \\
12 & 4 & 42.5 & 15.7586 \\
13 & 4 & 69 & 16.87207 \\
14 & 4 & 67.75 & 11.52895 \\
15 & 4 & 67 & 6.055301 \\
16 & 4 & 75 & 12.72792 \\
17 & 4 & 59.75 & 9.979145 \\
18 & 4 & 57.75 & 12.41974 \\
19 & 4 & 68 & 9.831921 \\
20 & 4 & 63.5 & 7.325754 \\
\hline
\end{tabular}


Appendix B: JMP Version 3.2.2 Results

Exhibit B.1: $\quad$ JMP Version 3.2.2 Output for Descriptive Statistics of Lot Size Information in Table 2

Lot Size (Xi)

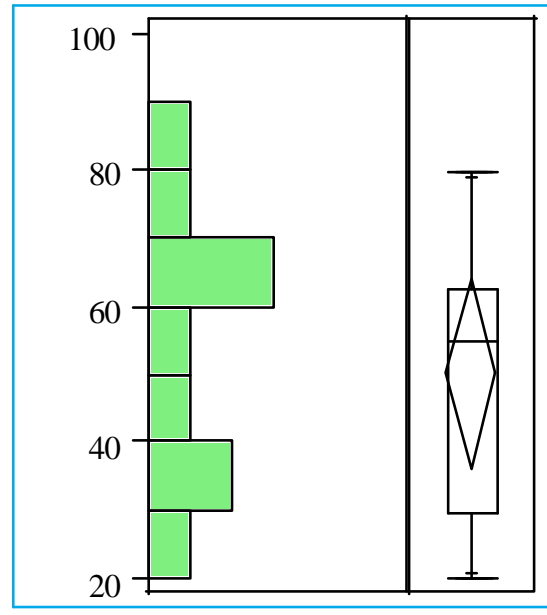

Quantiles

$\begin{array}{lll}\text { maximum } & 100.0 \% & 80.000 \\ & 99.5 \% & 80.000 \\ & 97.5 \% & 80.000 \\ & 90.0 \% & 79.000 \\ \text { quartile } & 75.0 \% & 62.500 \\ \text { median } & 50.0 \% & 55.000 \\ \text { quartile } & 25.0 \% & 30.000 \\ & 10.0 \% & 21.000 \\ & 2.5 \% & 20.000 \\ \text { minimum } & 0.5 \% & 20.000 \\ & 0.0 \% & 20.000\end{array}$

\section{Moments}

Mean

50.00000

Std Dev

19.43651

Std Error Mean

6.14636

Upper 95\% Mean

63.90416

Lower 95\% Mean

36.09584

$\mathrm{N}$

10.00000

Sum Weights

10.00000 


\section{Appendix B: JMP Version 3.2.2 Results}

Exhibit B.1: $\quad$ JMP Version 3.2.2 Output for Descriptive Statistics of Lot Size Information in Table 2 (continued)

\section{Stem and Leaf}

\begin{tabular}{|rll|}
\hline Stem & Leaf & Count \\
8 & 0 & 1 \\
7 & 0 & 1 \\
6 & 000 & 3 \\
5 & 0 & 1 \\
4 & 0 & 1 \\
3 & 00 & 2 \\
2 & 0 & 1 \\
\hline
\end{tabular}

Multiply Stem.Leaf by 10

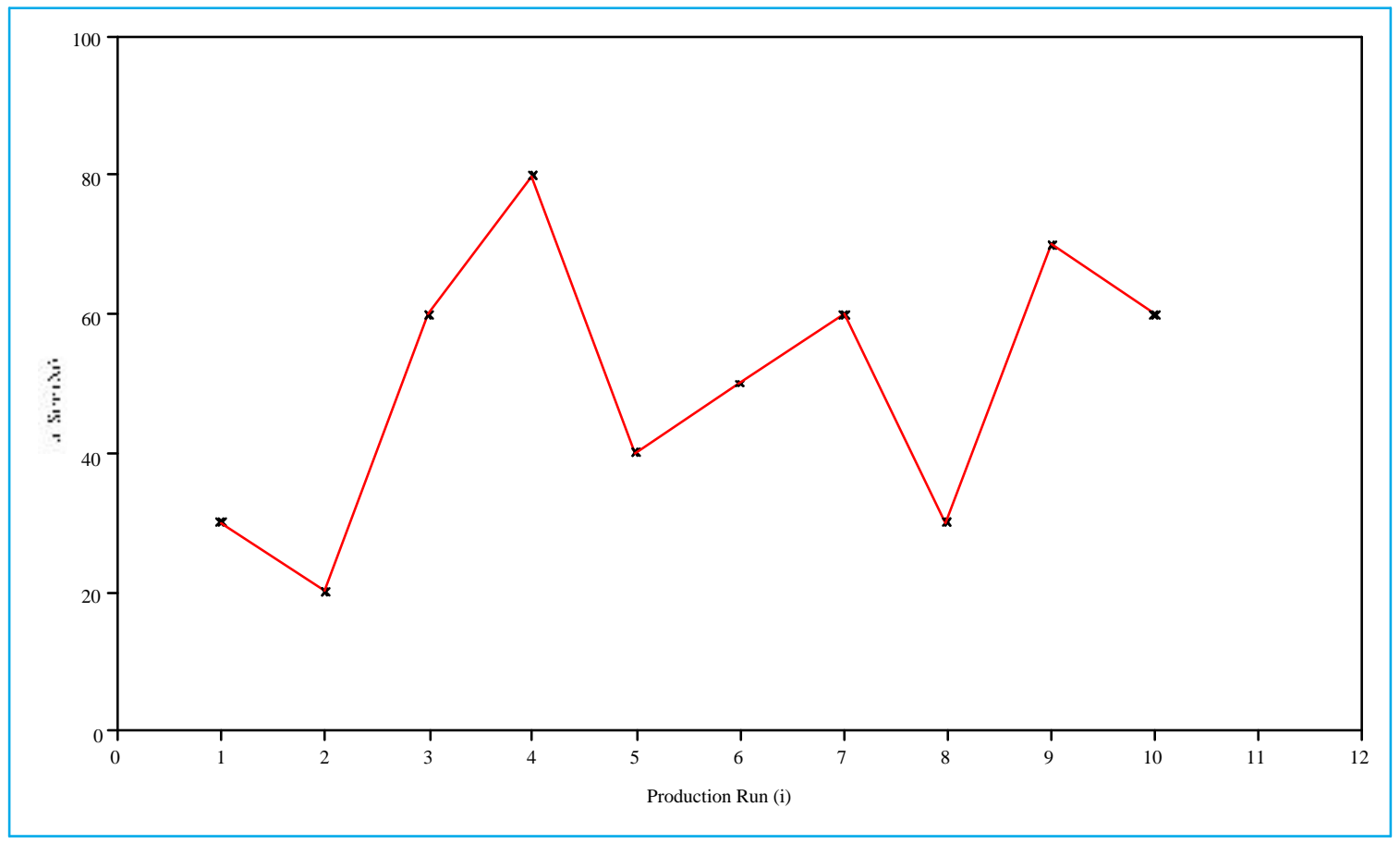


Appendix B: JMP Version 3.2.2 Results

Exhibit B.2: JMP Version 3.2.2 Output for Regression Model for Information in Table 2 Using Fit Y by $X$

\section{Man-Hours (Yi) By Lot Size (Xi)}

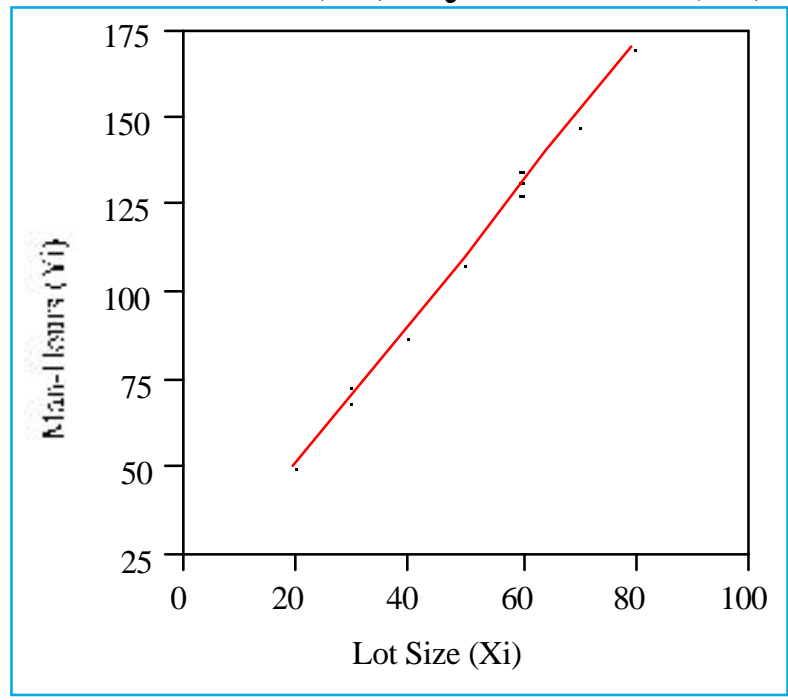

- Linear Fit

\section{Linear Fit}

Man-Hours (Yi) $=10+2$ Lot Size (Xi)

Summary of Fit

$\begin{array}{lr}\text { RSquare } & 0.995608 \\ \text { RSquare Adj } & 0.995059 \\ \text { Root Mean Square Error } & 2.738613 \\ \text { Mean of Response } & 110 \\ \text { Observations (or Sum Wgts) } & 10\end{array}$

Analysis of Variance

Source

Model

Error

C Total

Term

Intercept

Lot Size (Xi)

\section{Sum of Squares}

13600.000

60.000

13660.000

$\begin{array}{rr}\text { Mean Square } & \text { F Ratio } \\ 13600.0 & 1813.333 \\ 7.5 & \text { Prob }>\text { F } \\ <.0001\end{array}$

t Ratio

Prob $>|\mathbf{t}|$

4.00

0.0040

42.58

$<.0001$ 
Appendix B: JMP Version 3.2.2 Results

Exhibit B.3: JMP Version 3.2.2 Output for Regression Model for Information in Table 2 Using Fit Model

Response: Man-Hours (Yi)
$\quad$ Summary of Fit

Lack of Fit

Source

Lack of Fit

Pure Error

Total Error

Max RSq

0.9976

Term

Intercept

Lot Size (Xi)

\section{DF}

5

3

8
Mean Square

5.4667

10.8889

.7.333333

32.666667

60.000000
F Ratio

0.5020

Prob $>$ F

0.7662

Parameter Estimates

Estimate

10

2
Std Error

2.502939

0.046967

\section{Effect Test}

Source

Lot Size (Xi)
Nparm

1
DF

1

Sum of Squares

13600.000 t Ratio

4.00

42.58

Prob $>|\mathbf{t}|$

0.0040

$<.0001$

\section{F Ratio Prob $>$ F \\ $1813.333<.0001$}


Appendix B: JMP Version 3.2.2 Results

\section{Whole-Model Test}

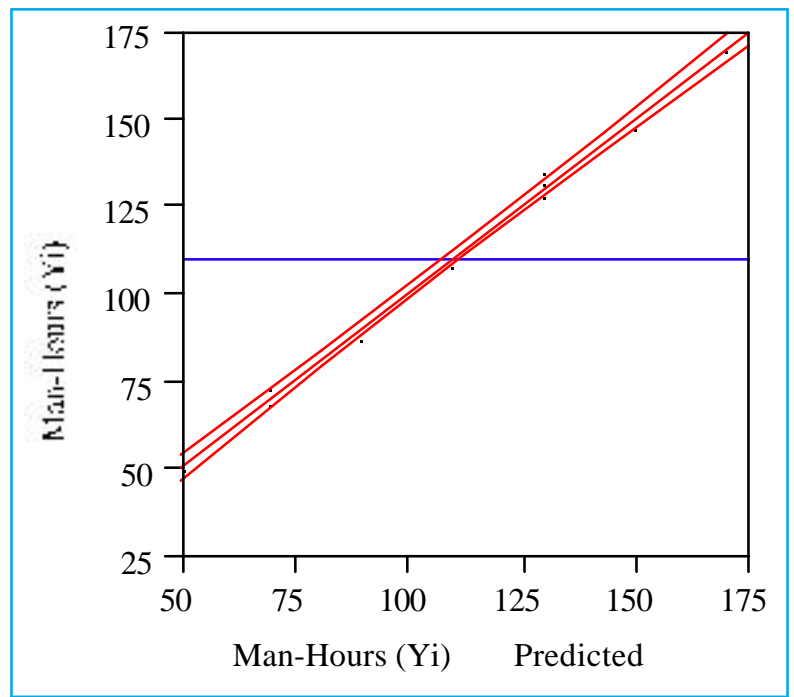

Exhibit B.3: JMP Version 3.2.2 Output for Regression Model for Information in Table 2 Using Fit Model (continued)

$\begin{array}{lrrrr}\text { Source } & \text { DF } & \text { Sum of Squares } & \text { Mean Square } & \text { F Ratio } \\ \text { Model } & 1 & 13600.000 & 13600.0 & 1813.333 \\ \text { Error } & 8 & 60.000 & 7.5 & \text { Prob }>\text { F } \\ \text { C Total } & 9 & 13660.000 & & <.0001\end{array}$

Lot Size (Xi)

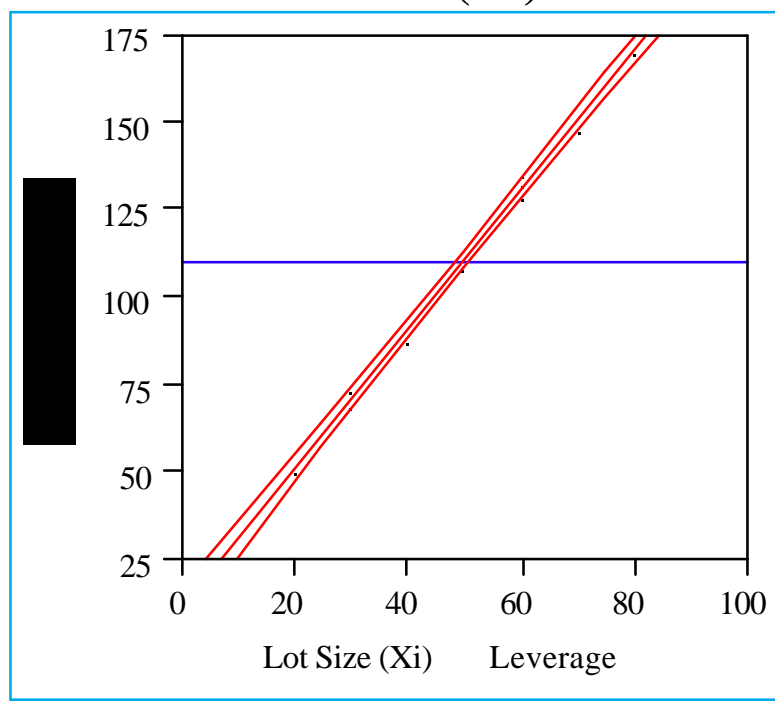

\section{Effect Test}

Sum of Squares F Ratio DF Prob>F 
WSRC-RP-99-00422

Revision 0

Appendix B: JMP Version 3.2.2 Results

$\begin{array}{llll}13600.000 & 1813.333 & 1 & <.0001\end{array}$ 
Appendix B: JMP Version 3.2.2 Results

Exhibit B.4: JMP Version 3.2.2 Output for ANOVA of Information in Table 5 Using Fit Model

\section{Response: Case Sold Summary of Fit}

RSquare

RSquare Adj

Root Mean Square Error

Mean of Response

Observations (or Sum Wgts)
0.848684

0.773026

2.768875

18

10

\section{Term}

Intercept

Package [1-4]

Package [2-4]

Package [3-4]

Source

Package Design

\section{Parameter Estimates}

Estimate

18.5

$-3.5$

$-5.5$

0.5
Std Error

0.89365

1.64781

1.440968

1.440968 t Ratio

20.70

$-2.12$

$-3.82$

0.35
Prob $>|\mathbf{t}|$

$<.0001$

0.0778

0.0088

0.7404

\section{Effect Test}

Nparm DF Sum of Squares F Ratio Prob>F
3
3
258.00000
11.2174
0.0071

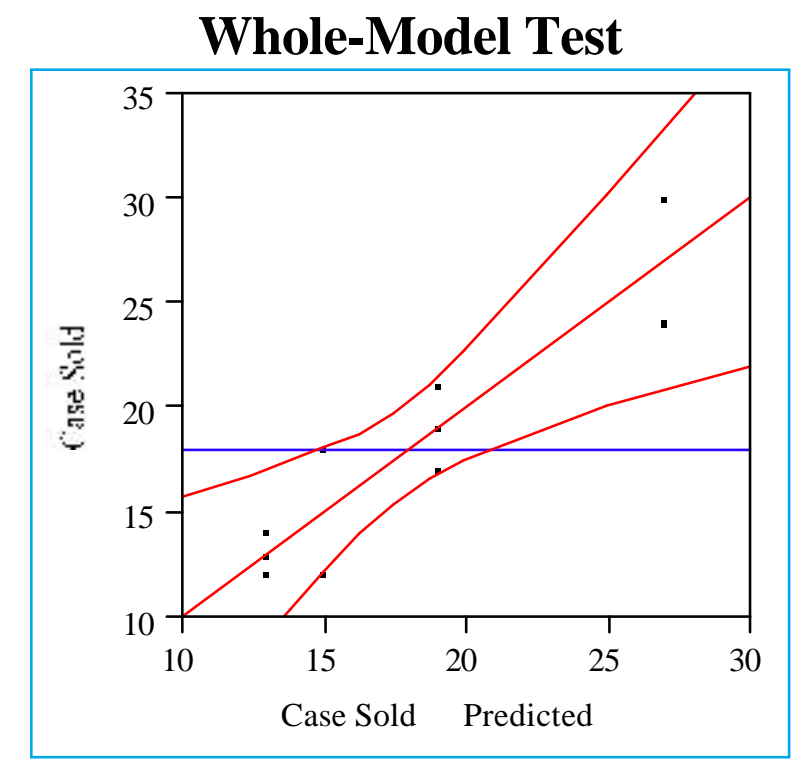


Appendix B: JMP Version 3.2.2 Results

Analysis of Variance

Source

Model

Sum of Squares

258.00000

Error

46.00000

C Total

DF

3

6

304.00000

Mean Square F Ratio

$86.0000 \quad 11.2174$

7.6667 Prob $>$ F

0.0071 
Appendix B: JMP Version 3.2.2 Results

Exhibit B.4: JMP Version 3.2.2 Output for ANOVA of Information in Table 5 Using Fit Model (continued)

\section{Package Design}

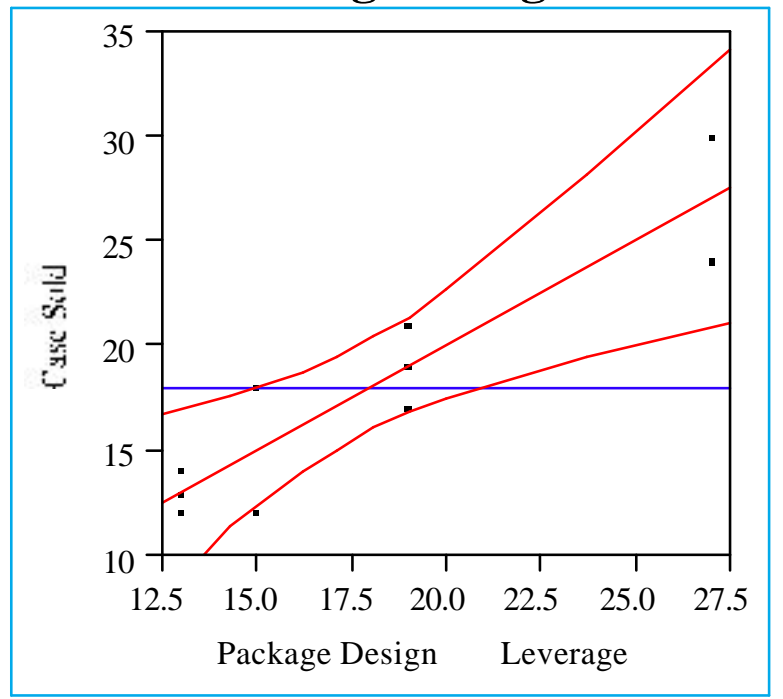

Effect Test

$\begin{array}{rrrr}\text { Sum of Squares } & \text { F Ratio } & \text { DF } & \text { Prob>F } \\ 258.00000 & 11.2174 & 3 & 0.0071\end{array}$

\section{Least Squares Means}

$\begin{array}{lrrr}\text { Level } & \text { Least Sq Mean } & \text { Std Error } & \text { Mean } \\ 1 & 15.00000000 & 1.957890021 & 15.0000 \\ 2 & 13.00000000 & 1.598610508 & 13.0000 \\ 3 & 19.00000000 & 1.598610508 & 19.0000 \\ 4 & 27.00000000 & 1.957890021 & 27.0000\end{array}$



(continued)

\begin{tabular}{lr}
\multicolumn{2}{c}{ Response: Rating } \\
Summary of Fit
\end{tabular}

\section{Term}

Intercept

Officer [A-E]

Officer [B-E]

Officer [C-E]

Officer [D-E]

\section{Parameter Estimates}

$\begin{array}{rrrr}\text { Estimate } & \text { Std Error } & \text { t Ratio } & \text { Prob }>|\mathbf{t}| \\ 71 & 1.944222 & 36.52 & <.0001 \\ 4 & 3.888444 & 1.03 & 0.3199 \\ -1 & 3.888444 & -0.26 & 0.8005 \\ -16 & 3.888444 & -4.11 & 0.0009 \\ 9 & 3.888444 & 2.31 & 0.0352\end{array}$

\section{Expected Mean Squares}

The Mean Square per row by the Variance Component per column

$\begin{array}{lrr}\text { EMS } & \text { Intercept } & \text { Officer (i) } \\ \text { Intercept } & 0 & 0 \\ \text { Officer (i) } & 0 & 4\end{array}$

plus 1.0 times Residual Error Variance

Variance Component Estimates

\section{Component}

Officer (i)

Residual
Var Comp Est

73.6

75.6

These estimates based on equating Mean Squares to Expected Value.

\section{Test Denominator Synthesis}

Source

Officer (i)

Source

Officer (i)
MS Den

75.6
DF Den Denom MS Synthesis

15 Residual

\section{Tests wrt Random Effects}

$\begin{array}{rrrrr}\text { SS } & \text { MS Num } & \text { DF Num } & \text { F Ratio } & \text { Prob }>\text { F } \\ 1480 & 370 & 4 & 4.8942 & 0.0100\end{array}$


Appendix B: JMP Version 3.2.2 Results

Exhibit B.5: JMP Version 3.2.2 Output for ANOVA of Information in Table 8 Using Fit Model with Random Factor (continued)

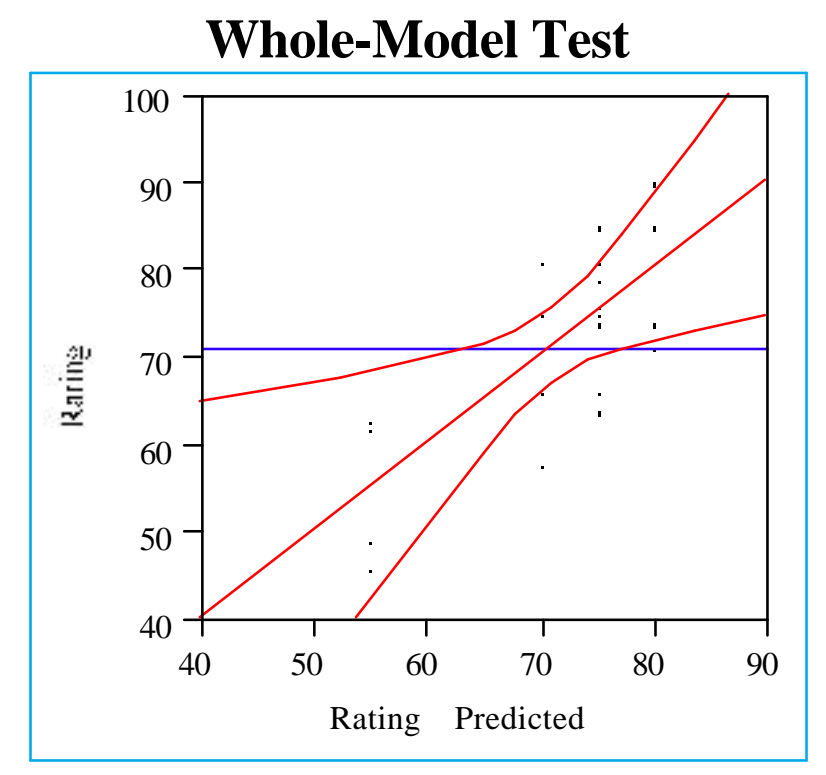

\section{Source}

Model

Error

C Total
Analysis of Variance
DF

4

15

19
Sum of Squares

1480.0000

1134.0000

2614.0000
Mean Square F Ratio

370.000

75.600 4.8942

Prob $>$ F
0.0100

Officer (i)

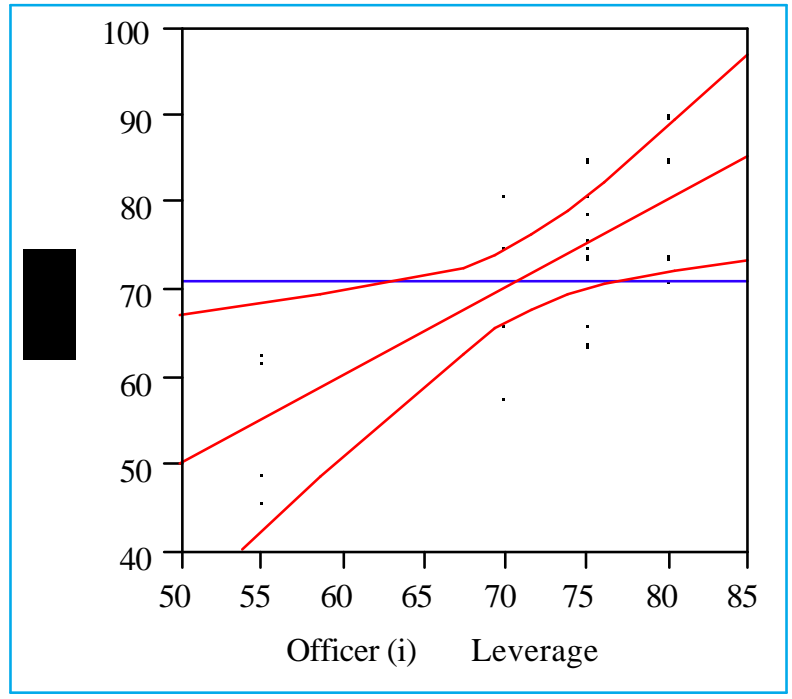


Appendix B: JMP Version 3.2.2 Results

Exhibit B.5: JMP Version 3.2.2 Output for ANOVA of Information in Table 8 Using Fit Model with Random Factor (continued)

\begin{tabular}{rrrr}
\multicolumn{2}{c}{ Effect Test } & & \\
Sum of Squares & F Ratio & DF & Prob>F \\
1480.0000 & 4.8942 & 4 & 0.0100
\end{tabular}

Denominator MS Synthesis: Residual

\section{Least Squares Means}

\section{Level}

A

B

C

D

E
Least Sq Mean

75.00000000

70.00000000

55.00000000

80.00000000

75.00000000
Std Error Mean

$4.347413024 \quad 75.0000$

$4.347413024 \quad 70.0000$

$4.347413024 \quad 55.0000$

$4.347413024 \quad 80.0000$

$4.347413024 \quad 75.0000$

Warning: Std Err calculated with respect to Synthetic Denominator. 
Appendix B: JMP Version 3.2.2 Results

Exhibit B.6: JMP Version 3.2.2 Output for ANOVA of Information in Table 10 Using Fit Model with Two Factors

\section{Response: Premium (\$) Summary of Fit}

RSquare

RSquare Adj

Root Mean Square Error

Mean of Response

Observations (or Sum Wgts)
0.990698

0.976744

7.071068

175

6

\section{Term}

Intercept

Size of [Large-Small]

Size of [Medium-Small]

Region[East-West]

\section{Parameter Estimates} Estimate

Std Error

2.886751

4.082483

4.082483

2.886751 t Ratio

60.62

8.57

4.90

5.20
Prob $>|\mathbf{t}|$

0.0003

0.0133

0.0392

0.0351

\section{Effect Test}

Source

Size of City

Region

Nparm DF Sum of Squares

9300.0000

1350.0000

$\begin{array}{rr}\text { F Ratio } & \text { Prob }>\text { F } \\ 93.0000 & 0.0106 \\ 27.0000 & 0.0351\end{array}$

Whole-Model Test

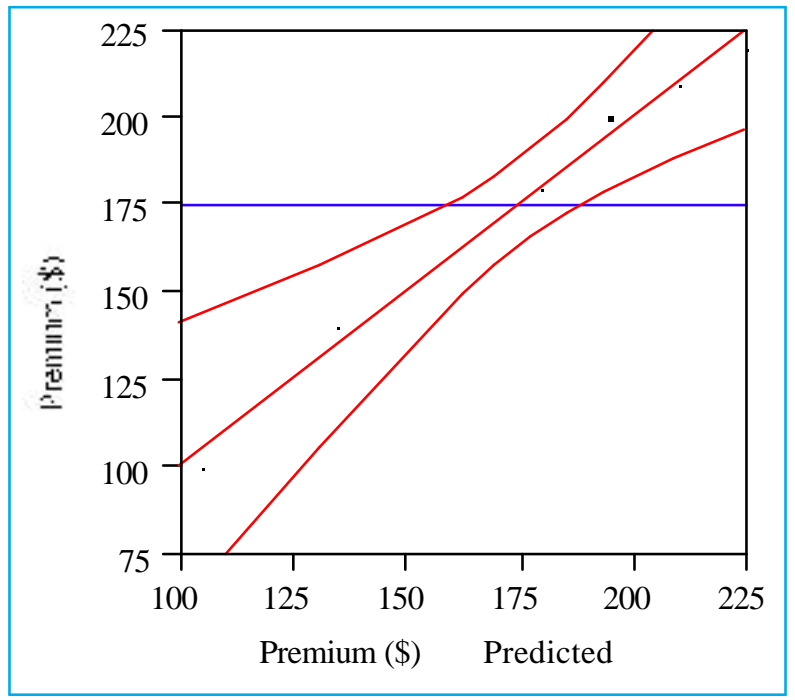


Appendix B: JMP Version 3.2.2 Results

Exhibit B.6: JMP Version 3.2.2 Output for ANOVA of Information in Table 10 Using Fit Model with Two Factors (continued)

Source

Model

Error

C Total
Analysis of Variance

$\begin{array}{rr}\text { DF } & \text { Sum of Squares } \\ 3 & 10650.000 \\ 2 & 100.000 \\ 5 & 10750.000\end{array}$

Mean Square

3550.00

50.00

10750.000

\section{F Ratio \\ 71.0000 \\ Prob $>$ F \\ 0.0139}

Size of City

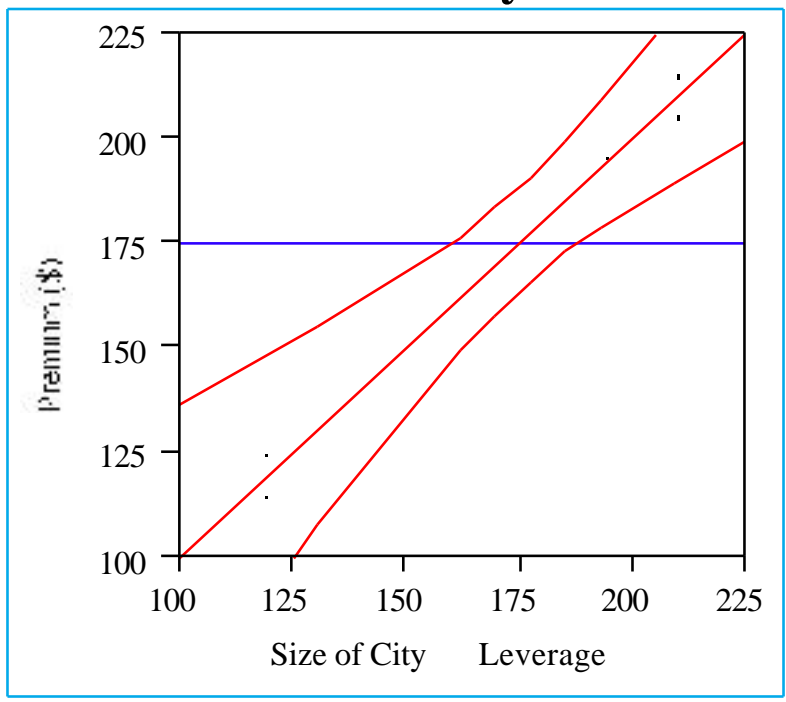

Effect Test

$\begin{array}{rrrr}\text { Sum of Squares } & \text { F Ratio } & \text { DF } & \text { Prob>F } \\ 9300.0000 & 93.0000 & 2 & 0.0106\end{array}$

Least Squares Means

Level

Large

Medium

Least Sq Mean

Std Error

Mean

210.0000000

5.000000000

210.000

195.0000000

5.000000000

195.000

120.0000000

120.000 
Appendix B: JMP Version 3.2.2 Results

Exhibit B.6: JMP Version 3.2.2 Output for ANOVA of Information in Table 10 Using Fit Model with Two Factors (continued)

Region

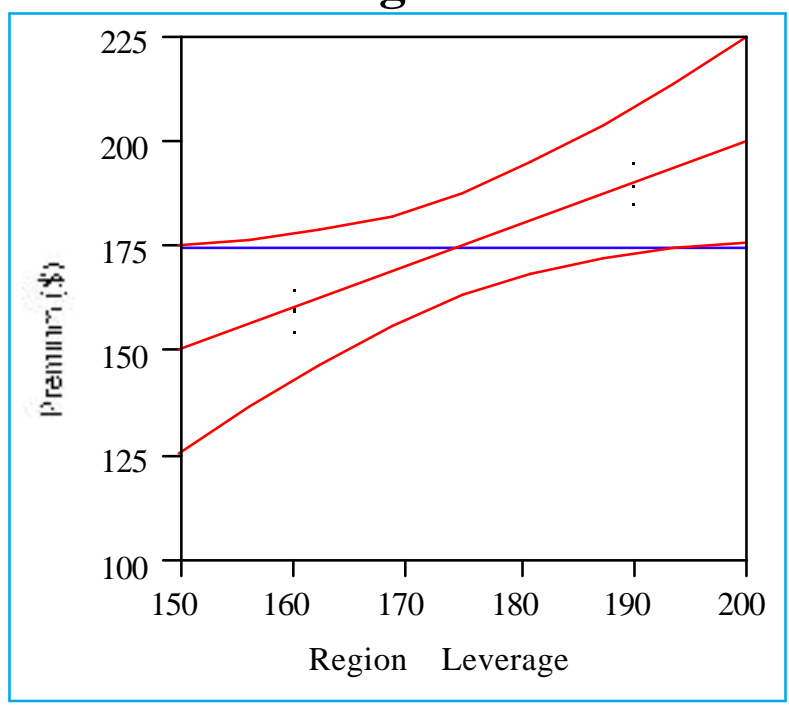

Effect Test

$\begin{array}{rrrr}\text { Sum of Squares } & \text { F Ratio } & \text { DF } & \text { Prob>F } \\ 1350.0000 & 27.0000 & 1 & 0.0351\end{array}$

\section{Least Squares Means}

Level

East

West
Least Sq Mean

190.0000000

160.0000000
Std Error Mean

$4.082482905 \quad 190.000$

$4.082482905 \quad 160.000$ 
Appendix B: JMP Version 3.2.2 Results

Exhibit B.7: JMP Version 3.2.2 Output for Nested ANOVA of Information in Table 13 Using Fit Model with A Nested Factor

\section{Response: Class Learning Scores (coded) Summary of Fit}

RSquare

RSquare Adj

0.899478

Root Mean Square Error

2.645751

Mean of Response

Observations (or Sum Wgts)

\section{Parameter Estimates}

\section{Term}

Intercept

School[Atlanta-San Fra]

School[Chicago-San Fra]

School[Atlanta]:Instruct[1-2]

School[Chicago]:Instruct[1-2]

School[San Fra]:Instruct[1-2]
Estimate Std Error

15

4.75

$-0.75$

7.25

$-5.75$

7.5
0.763763

1.080123

1.080123

1.322876

1.322876

1.322876 t Ratio

19.64

4.40

$-0.69$

5.48

$-4.35$

5.67
Prob $>|\mathbf{t}|$

$<.0001$

0.0046

0.5134

0.0015

0.0048

0.0013

\section{Effect Test}

\section{Source}

School

Instructor[School]
Nparm

2

3
DF Sum of Squares

156.50000

567.50000

\section{F Ratio Prob>F \\ $11.1786 \quad 0.0095$ \\ 27.0238 \\ 0.0007}

\section{Whole-Model Test}

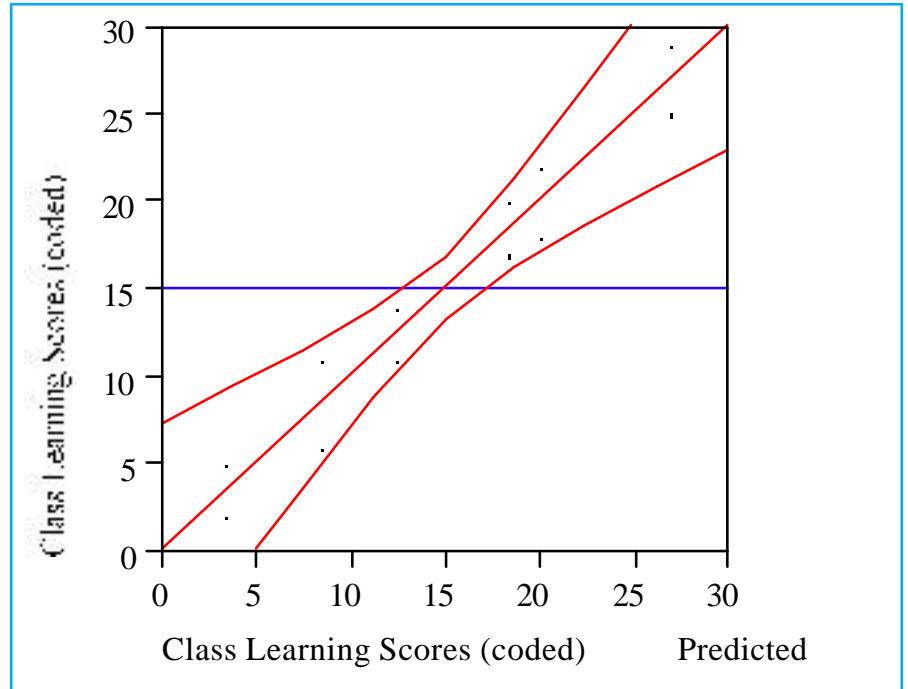


Appendix B: JMP Version 3.2.2 Results

Exhibit B.7: JMP Version 3.2.2 Output for Nested ANOVA of Information in Table 13 Using Fit Model with A Nested Factor (continued)

\begin{tabular}{lrrrr}
\multicolumn{3}{c}{ Analysis of Variance } & & \\
Source & DF & Sum of Squares & Mean Square & F Ratio \\
Model & 5 & 724.00000 & 144.800 & 20.6857 \\
Error & 6 & 42.00000 & 7.000 & Prob>F \\
C Total & 11 & 766.00000 & & 0.0010
\end{tabular}

Level

Atlanta

Chicago

San Francisco
School

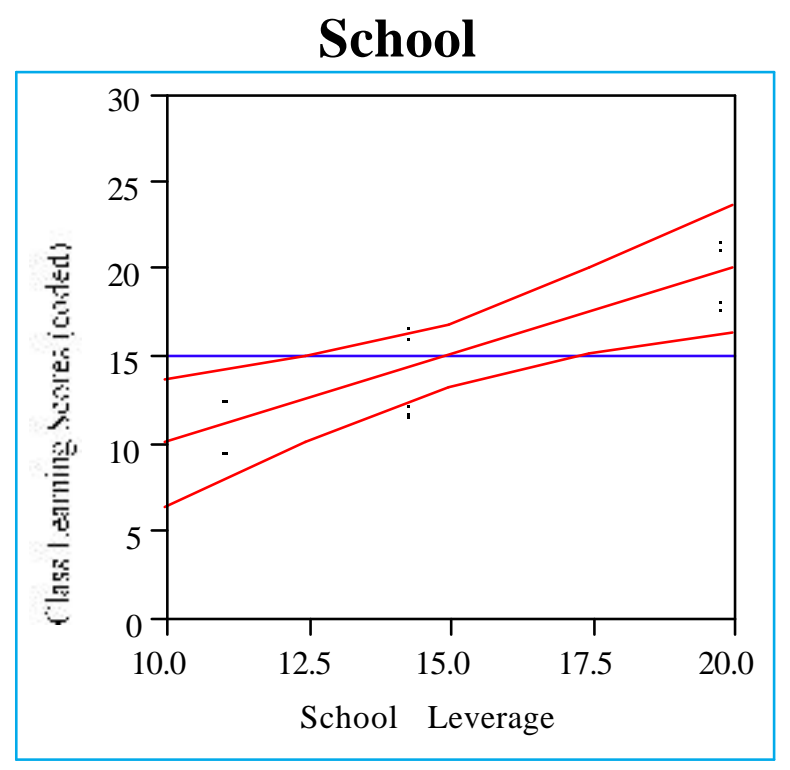

\section{Effect Test \\ Sum of Squares F Ratio DF Prob>F \\ $\begin{array}{llll}156.50000 & 11.1786 & 2 & 0.0095\end{array}$}

Least Squares Means

Least Sq Mean

19.75000000

14.25000000

11.00000000
Std Error

1.322875656

1.322875656

1.322875656
Mean

19.7500

14.2500

11.0000 
Appendix B: JMP Version 3.2.2 Results

Exhibit B.7: JMP Version 3.2.2 Output for Nested ANOVA of Information in Table 13 Using Fit Model with A Nested Factor (continued)

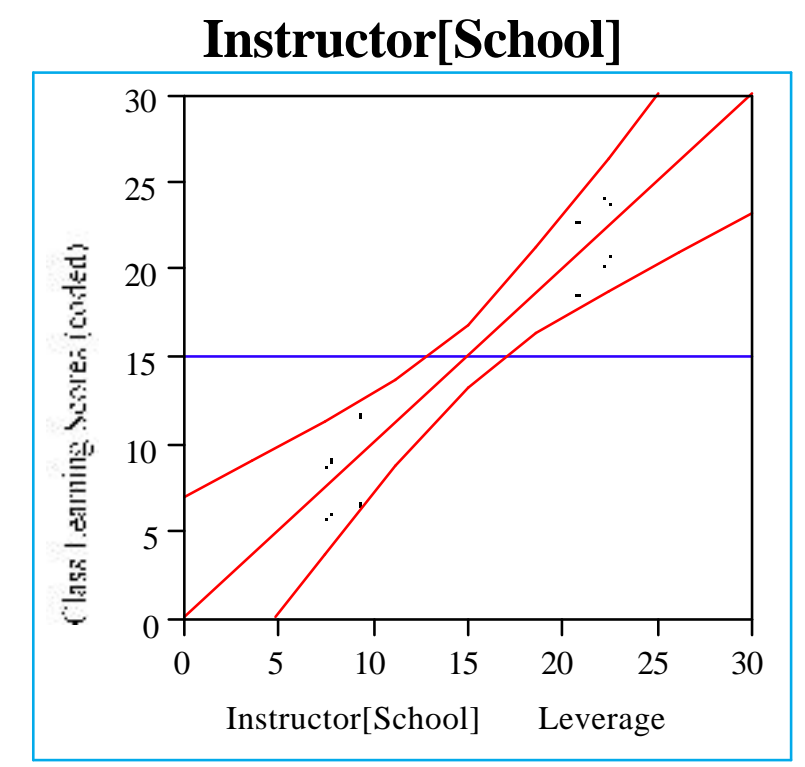

\section{Effect Test Sum of Squares F Ratio DF Prob $>$ F $\begin{array}{llll}567.50000 & 27.0238 & 3 & 0.0007\end{array}$}

\section{Level}

[Atlanta]1

[Atlanta]2

[Chicago]1

[Chicago]2

[San Francisco]1

[San Francisco]2

\section{Least Squares Means}

Least Sq Mean

27.00000000

12.50000000

8.50000000

20.00000000

18.50000000

3.50000000
Std Error

1.870828693

1.870828693

1.870828693

1.870828693

1.870828693

1.870828693 
Appendix B: JMP Version 3.2.2 Results

Exhibit B.8: JMP Version 3.2.2 Output for Nested ANOVA of Information in Table 13

Using Fit Model with Random Factors

$\begin{array}{lr}\text { Response: Class Learning Scores (coded) } \\ \quad \text { Summary of Fit } \\ \text { RSquare } & 0.94517 \\ \text { RSquare Adj } & 0.899478 \\ \text { Root Mean Square Error } & 2.645751 \\ \text { Mean of Response } & 15 \\ \text { Observations (or Sum Wgts) } & 12\end{array}$

\section{Term}

Intercept

School[Atlanta-San Fra]

School[Chicago-San Fra]

School[Atlanta]:Instruct[1-2]

School[Chicago]:Instruct[1-2]

School[San Fra]:Instruct[1-2]

\section{Parameter Estimates}

\section{Expected Mean Squares}

The Mean Square per row by the Variance Component per column

$\begin{array}{lrrr}\text { EMS } & \text { Intercept } & \text { School } & \text { Instructor[School] } \\ \text { Intercept } & 0 & 0 & 0 \\ \text { School } & 0 & 4 & 2 \\ \text { Instructor[School] } & 0 & 0 & 2\end{array}$

plus 1.0 times Residual Error Variance

$$
\begin{array}{lr}
\text { Variance Component Estimates } \\
\text { Component } & \text { Var Comp Est } \\
\text { School } & -27.7292 \\
\text { Instructor[School] } & 91.08333 \\
\text { Residual } & 7
\end{array}
$$

These estimates based on equating Mean Squares to Expected Value.

\section{Test Denominator Synthesis}

Source

Synthesis

School

Instructor[School]

\section{MS Den DF Den Denom MS}

189.167

7
3 Instructor[School]

6 Residual 
Appendix B: JMP Version 3.2.2 Results

Exhibit B.8: JMP Version 3.2.2 Output for Nested ANOVA of Information in Table 13 Using Fit Model with Random Factors (continued)

\begin{tabular}{lrrrrr} 
& \multicolumn{2}{c}{ Tests wrt Random Effects } & & \\
Source & SS & MS Num & DF Num & F Ratio & Prob $>$ F \\
School & 156.5 & 78.25 & 2 & 0.4137 & 0.6940 \\
Instructor[School] & 567.5 & 189.167 & 3 & 27.0238 & 0.0007
\end{tabular}

Whole-Model Test

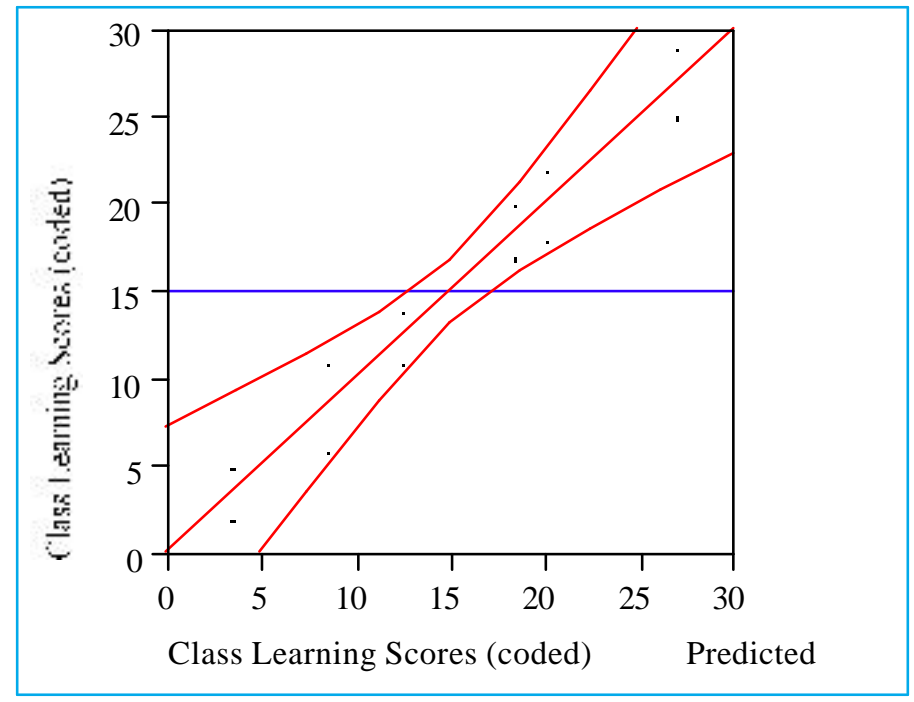

Analysis of Variance

Source

Model DF Sum of Squares Mean Square

F Ratio

20.6857

Error

724.00000

144.800

Prob $>$ F

C Total

42.00000

7.000

0.0010 
Appendix B: JMP Version 3.2.2 Results

Exhibit B.8: JMP Version 3.2.2 Output for Nested ANOVA of Information in Table 13 Using Fit Model with Random Factors (continued)

School

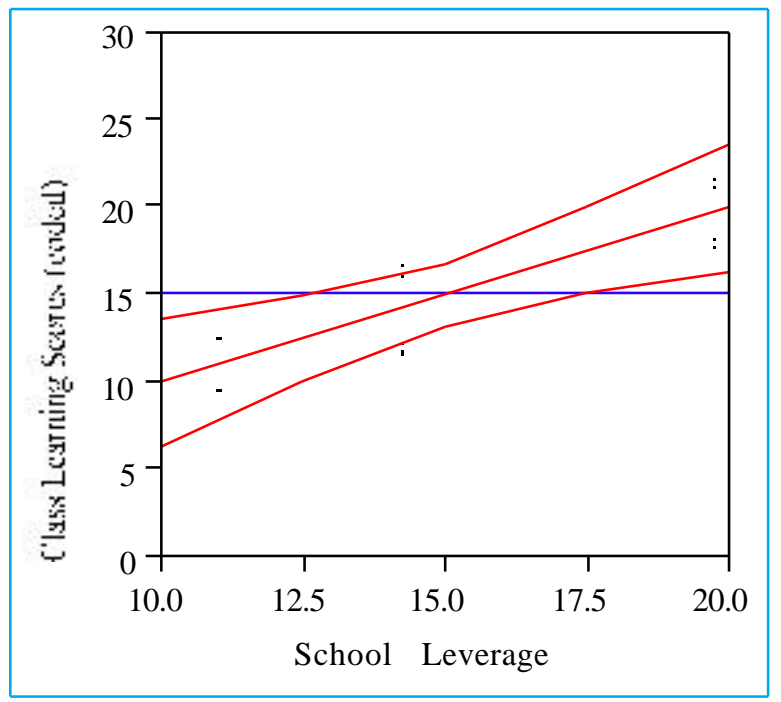

Effect Test

$\begin{array}{rrrr}\text { Sum of Squares } & \text { F Ratio } & \text { DF } & \text { Prob }>\text { F } \\ 156.50000 & 0.4137 & 2 & 0.6940\end{array}$

Denominator MS Synthesis: Instructor[School]

\section{Least Squares Means}

Level

Atlanta

Chicago

San Francisco

\section{Least Sq Mean}

19.75000000

14.25000000

11.00000000
Std Error

6.876893679

6.876893679

6.876893679
Mean

19.7500

14.2500

11.0000

Warning: Std Err calculated with respect to Synthetic Denominator. 


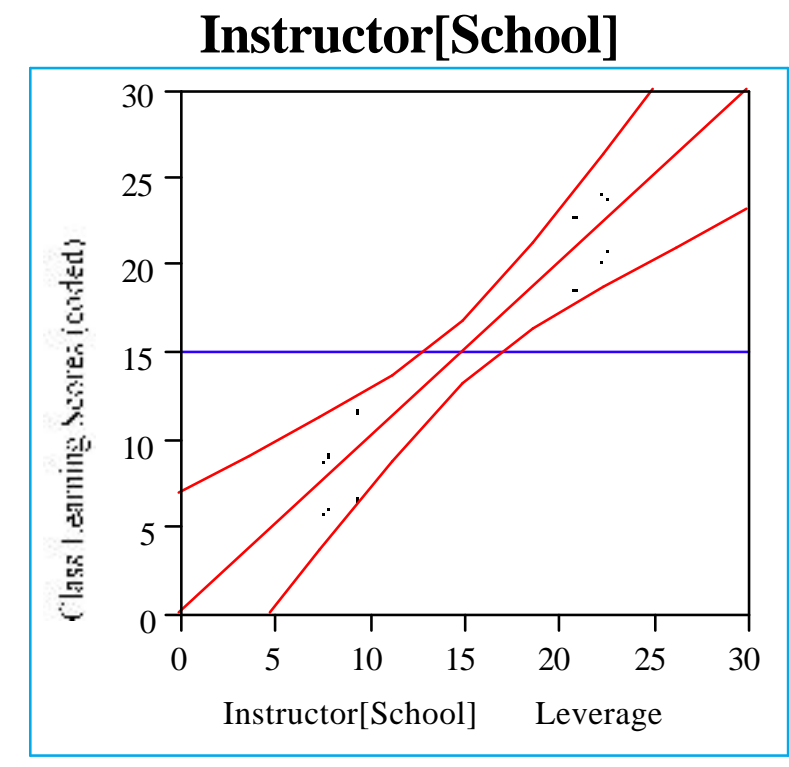

\section{Effect Test \\ Sum of Squares F Ratio DF Prob $>$ F \\ $\begin{array}{llll}567.50000 & 27.0238 & 3 & 0.0007\end{array}$}

Denominator MS Synthesis: Residual

\section{Least Squares Means}

\section{Level}

[Atlanta]1

[Atlanta]2

[Chicago]1

[Chicago] 2

[San Francisco]1

[San Francisco]2
Least Sq Mean

27.00000000

12.50000000

8.50000000

20.00000000

18.50000000

3.50000000
Std Error

1.870828693

1.870828693

1.870828693

1.870828693

1.870828693

1.870828693

Warning: Std Err calculated with respect to Synthetic Denominator. 
Appendix B: JMP Version 3.2.2 Results

Exhibit B.9: JMP Version 3.2.2 Output for a Fractional Factorial Experiment using the Design Experiment Feature

\begin{tabular}{|c|c|c|c|c|c|c|}
\hline Pattern & $\mathbf{X 1}$ & $\mathbf{X 2}$ & $\mathbf{X 3}$ & $\mathbf{X 4}$ & $\mathbf{X 5}$ & $\mathbf{X 6}$ \\
\hline----- & -1 & -1 & -1 & -1 & -1 & -1 \\
\hline---+++ & -1 & -1 & -1 & 1 & 1 & 1 \\
\hline--+-++ & -1 & -1 & 1 & -1 & 1 & 1 \\
\hline--++-- & -1 & -1 & 1 & 1 & -1 & -1 \\
\hline-+--+- & -1 & 1 & -1 & -1 & 1 & -1 \\
\hline-+-+-+ & -1 & 1 & -1 & 1 & -1 & 1 \\
\hline-++-+ & -1 & 1 & 1 & -1 & -1 & 1 \\
\hline-++++- & -1 & 1 & 1 & 1 & 1 & -1 \\
\hline+---+ & 1 & -1 & -1 & -1 & -1 & 1 \\
\hline+--++- & 1 & -1 & -1 & 1 & 1 & -1 \\
\hline+-+-+- & 1 & -1 & 1 & -1 & 1 & -1 \\
\hline+-++-+ & 1 & -1 & 1 & 1 & -1 & 1 \\
\hline++--++ & 1 & 1 & -1 & -1 & 1 & 1 \\
\hline++-+- & 1 & 1 & -1 & 1 & -1 & -1 \\
\hline+++-- & 1 & 1 & 1 & -1 & -1 & -1 \\
\hline++++++ & 1 & 1 & 1 & 1 & 1 & 1 \\
\hline
\end{tabular}

Fractional Factorial structure

Factor Confounding Rules

$\mathrm{X} 5=\mathrm{X} 2 * \mathrm{X} 3 * \mathrm{X} 4$

$\mathrm{x} 6=\mathrm{x} 1 * \mathrm{x} 3 * \mathrm{x} 4$

Aliasing structure

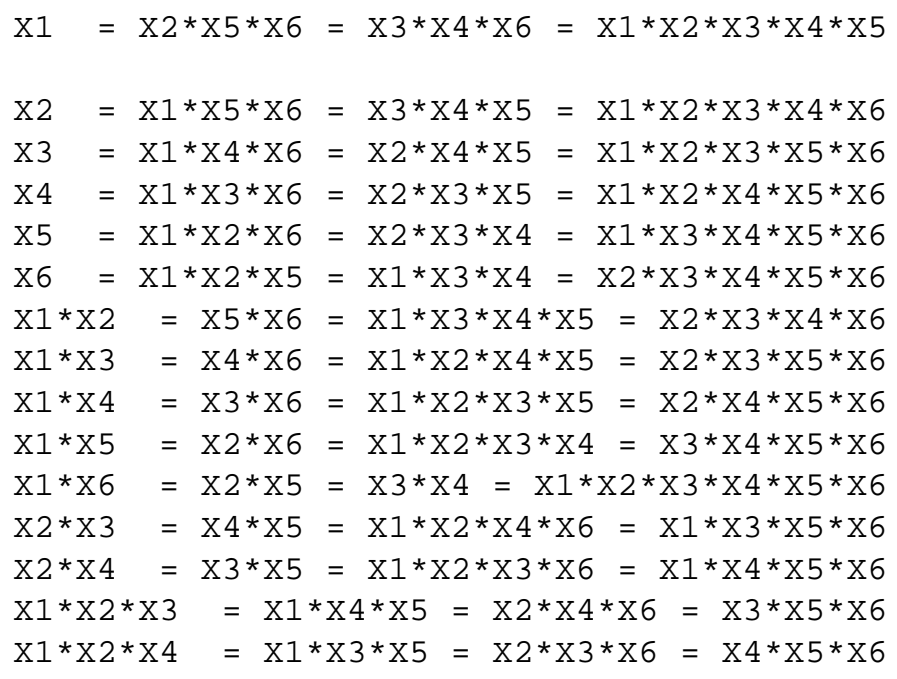


Appendix B: JMP Version 3.2.2 Results

Revision 0 
Exhibit B.10: JMP Version 3.2.2 Output for Mixture Problem Defined by Equation (2)

\begin{tabular}{|c|c|c|c|}
\hline $\mathbf{X}_{\mathbf{1}}$ & $\mathbf{X}_{\mathbf{2}}$ & $\mathbf{X}_{\mathbf{3}}$ & Dimen \\
\hline 0.4 & 0.1 & 0.5 & 0 \\
\hline 0.6 & 0.1 & 0.3 & 0 \\
\hline 0.6 & 0.3 & 0.1 & 0 \\
\hline 0.2 & 0.3 & 0.5 & 0 \\
\hline 0.3 & 0.6 & 0.1 & 0 \\
\hline 0.2 & 0.6 & 0.2 & 0 \\
\hline 0.2 & 0.45 & 0.35 & 1 \\
\hline 0.6 & 0.2 & 0.2 & 1 \\
\hline 0.5 & 0.1 & 0.4 & 1 \\
\hline 0.25 & 0.6 & 0.15 & 1 \\
\hline 0.45 & 0.45 & 0.1 & 1 \\
\hline 0.3 & 0.2 & 0.5 & 1 \\
\hline 0.383333 & 0.333333 & 0.283333 & 2 \\
\hline
\end{tabular}

JMP Version 3.2.2 is capable of evaluating more than just the extreme vertices of this region. A value of 0 for Dimen column indicates that the row corresponds to an extreme vertex of the mixture region, a value of 1 indicates an edge of the region, and finally, a 2 value indicates the centroid of the region. This centroid is computed as part of the discussion in [1], and the value that is reported there (on page 358$)$ is $(0.384,0.333,0.283)-$ the same value as shown in the table above. 
Appendix B: JMP Version 3.2.2 Results

Revision 0

Exhibit B.11: JMP Version 3.2.2's D-Optimality Results

\section{Optimal Design Controls}

\section{N Desired 8 \\ N Random 3 \\ K Value 3 \\ Trips

$\begin{array}{ll}\text { N } & 8 \\ \text { Trips } & 1\end{array}$ \\ Best Design}

D-efficiency

A-efficiency

G-efficiency

AvgPredSE

$\mathrm{N}$

Correlations

Corr

Intercept

X1

$\mathrm{X} 2$

$\mathrm{X} 3$

\section{Intercept}

1.0000

0.0000

0.0000

0.0000
100

100

100

0.5590

8.0000 
Appendix B: JMP Version 3.2.2 Results

Revision 0 


\section{x-bar chart}

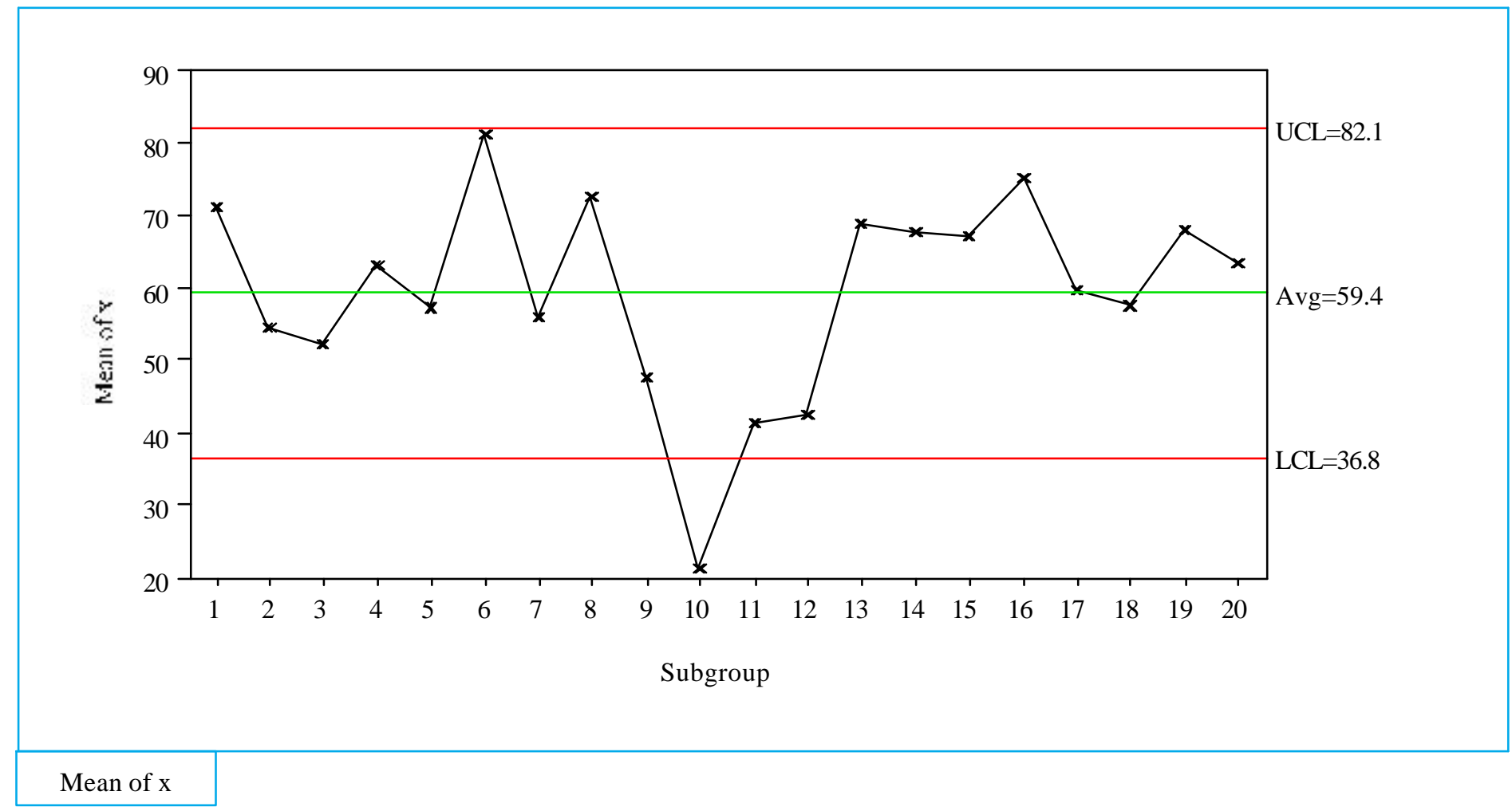


Exhibit B.12: JMP Version 3.2.2 Results for $\mathrm{x}$-Bar and s Charts for Data in Table 18 (continued)

\section{s chart}

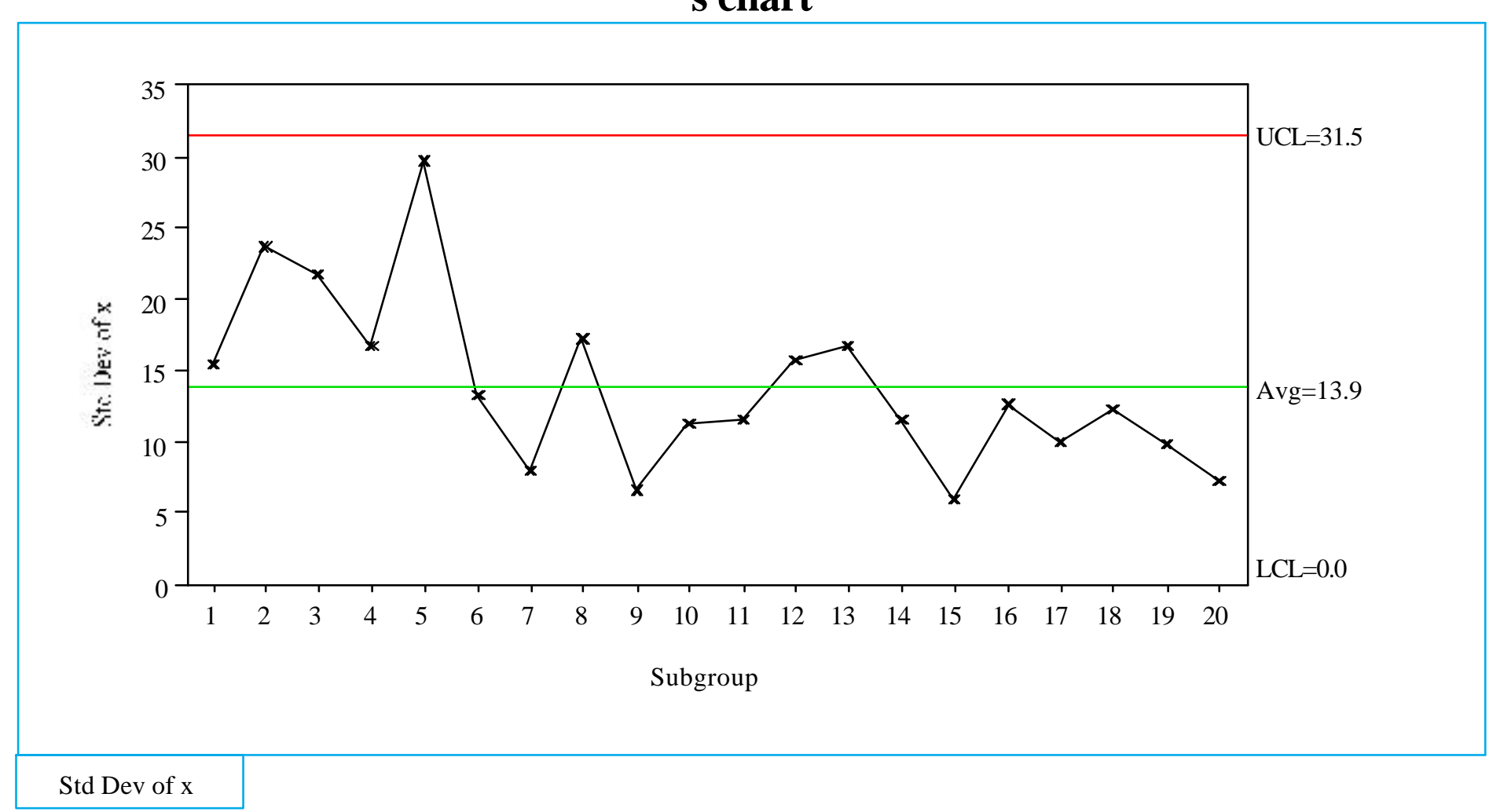




\section{Appendix C: SAS Results}

Exhibit C.1: SAS Input for and Results from Descriptive Statistics for Lot Size Values in Table 2

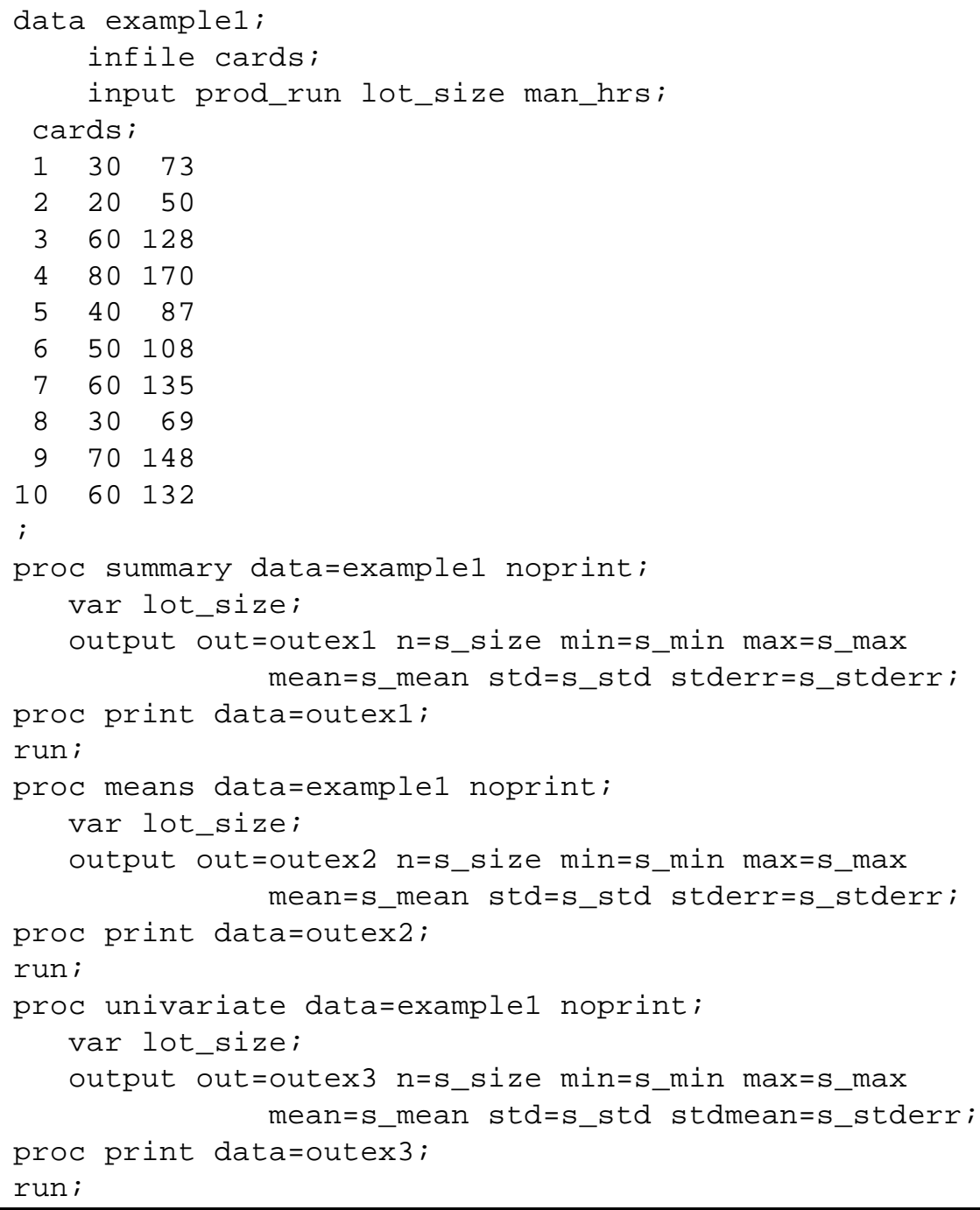

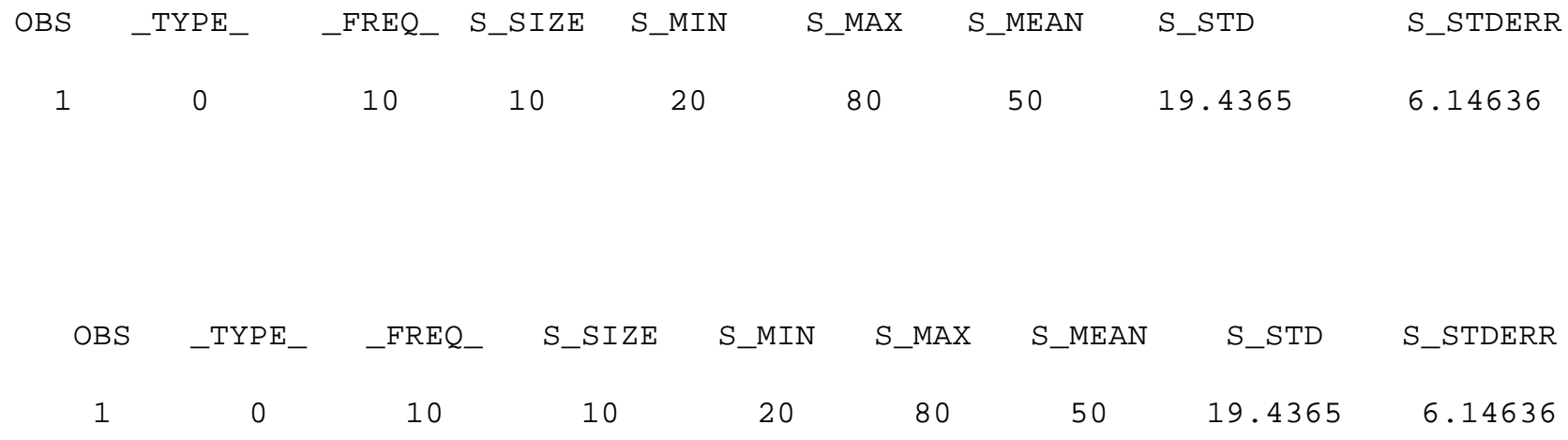


WSRC-RP-99-00422

Revision 1

Appendix C: SAS Results

\begin{tabular}{|c|c|c|c|c|c|c|}
\hline OBS & S_SIZE & S_MEAN & S_STD & S_STDERR & S_MAX & S_MIN \\
\hline 1 & 10 & 50 & 19.4365 & 6.14636 & 80 & 20 \\
\hline
\end{tabular}




\section{Appendix C: SAS Results}

Exhibit C.2: SAS Input for and Results from PROC REG for Table 2 Data

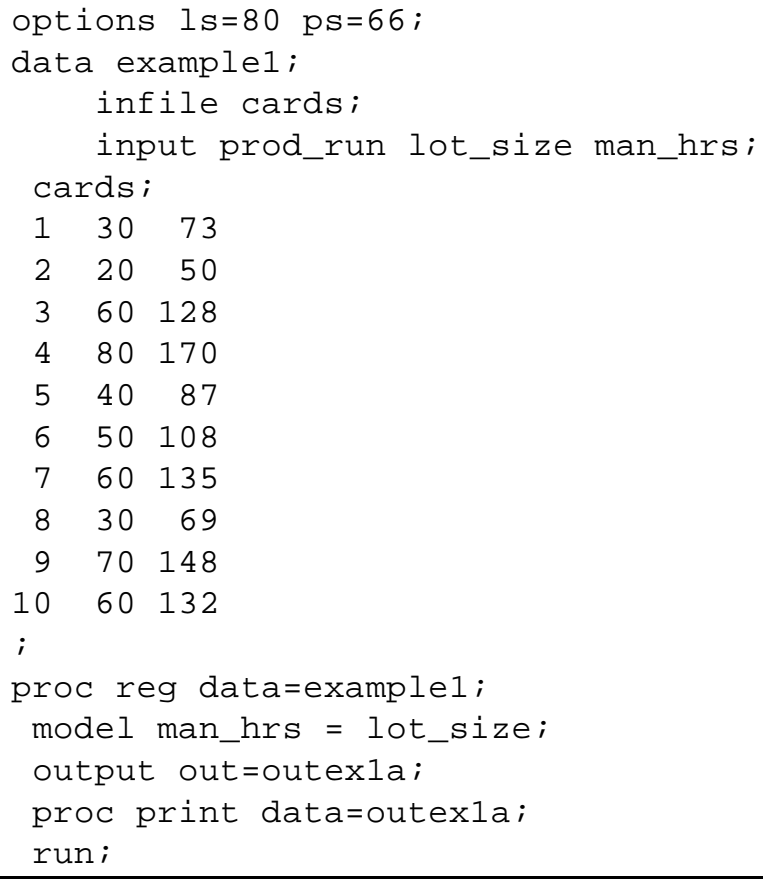

Source

Model

Error

C Total

Root MSE
Dep Mean
C.V.

Sum of

Squares

113600.00000

$8 \quad 60.00000$

$9 \quad 13660.00000$

1360
600.00000
7.50000

Mean

Square

F Value

1813.333

2.73861

110.00000

2.48965
0.9956

0.9951

Parameter Estimates

$\begin{array}{lcr}\text { Variable } & \text { DF } & \begin{array}{r}\text { Parameter } \\ \text { Estimate }\end{array} \\ \text { INTERCEP } & 1 & 10.000000 \\ \text { LOT_SIZE } & 1 & 2.000000\end{array}$

$$
\text { Standard }
$$

Error

2.50293945

0.04696682
$\mathrm{T}$ for $\mathrm{HO}$ :

Parameter $=0$

3.995

42.583
0.0040
0.0001 


\section{Appendix C: SAS Results}

Exhibit C.3: SAS Input for and Results from SAS/IML Program for Regression of Table 2 Data

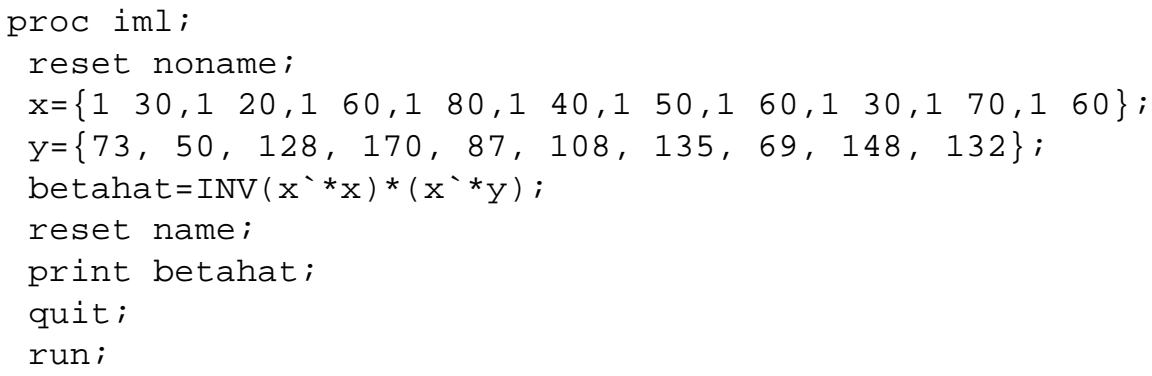




\section{Appendix C: SAS Results}

Exhibit C.4: SAS Input for and Results from SAS/STAT PROC ANOVA for Analyzing of Table 5 Data

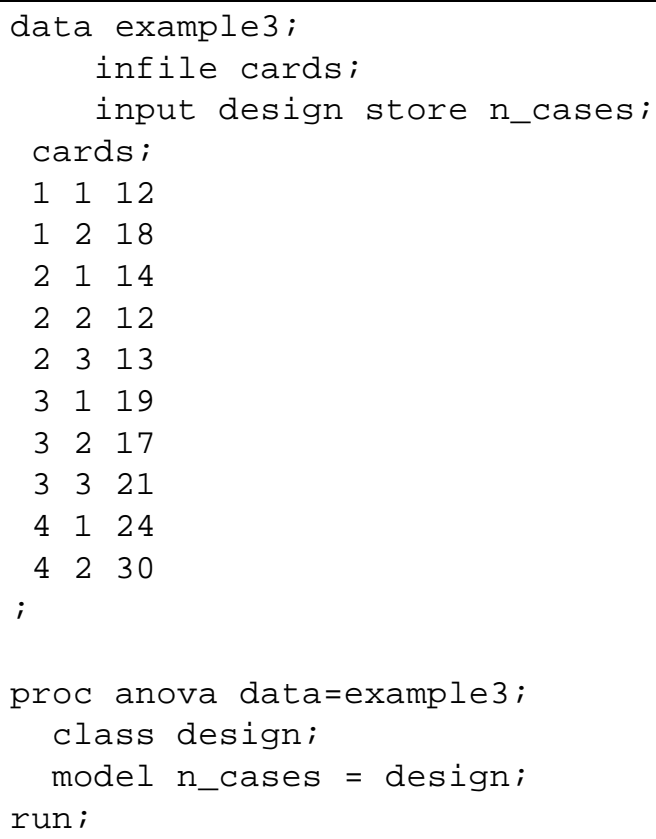


WSRC-RP-99-00422

\author{
Revision 1
}

Appendix C: SAS Results

DESIGN

3

258.00000000

86.00000000

11.22

0.0071 


\section{Appendix C: SAS Results}

Exhibit C.5: SAS Input for and Results from SAS/STAT PROC GLM for Analyzing of Table 5 Data

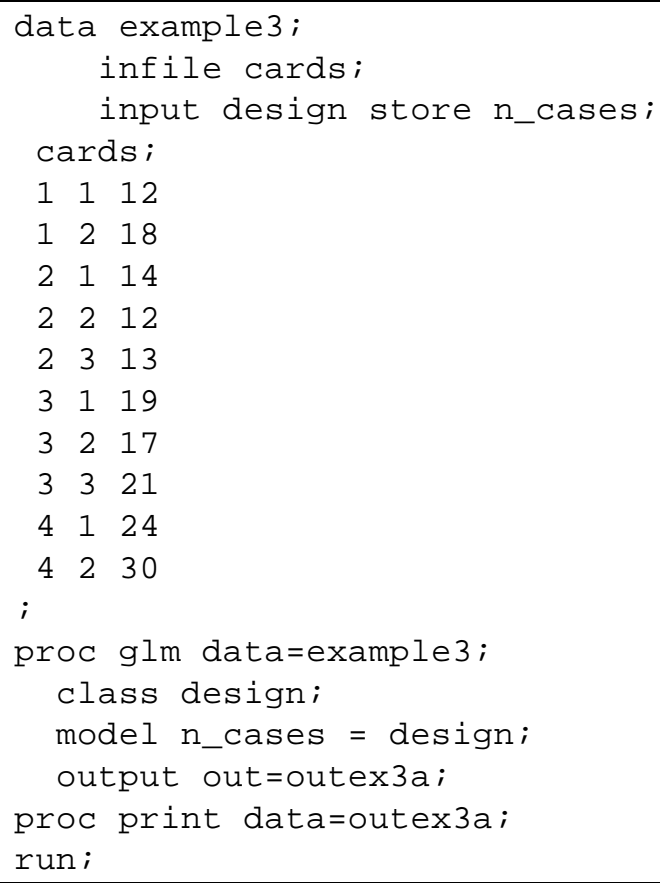


WSRC-RP-99-00422

\section{Appendix C: SAS Results}

Revision 1

DESIGN
Source
DESIGN

258.00000000

86.00000000

11.22

0.0071

$\mathrm{DF}$

Type III SS

Mean Square

F Value

$\operatorname{Pr}>\mathrm{F}$

3

258.00000000

86.00000000

11.22

0.0071 


\section{Appendix C: SAS Results}

Exhibit C.6: SAS Input for and Results from SAS/STAT PROC GLM for Analyzing of Table 8 Data

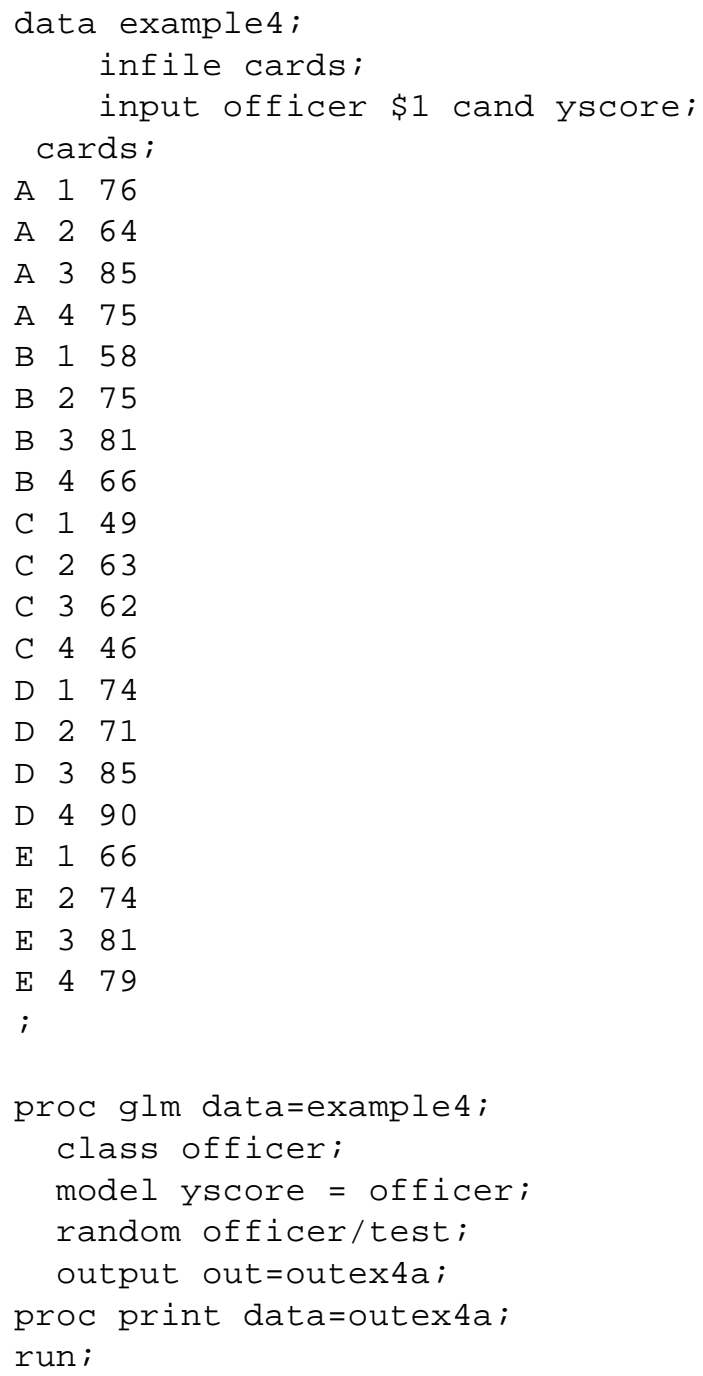


WSRC-RP-99-00422

\section{Appendix C: SAS Results}

Revision 1

$\begin{array}{lccc}\text { Model } & 4 & 1480.0000000 & 370.0000000 \\ \text { Error } & 15 & 1134.0000000 & 75.6000000 \\ \text { Corrected Total } & 19 & 2614.0000000 & \end{array}$




\section{Appendix C: SAS Results}

Exhibit C.6: SAS Input for and Results from SAS/STAT PROC GLM for Analyzing of Table 8 Data (Continued)

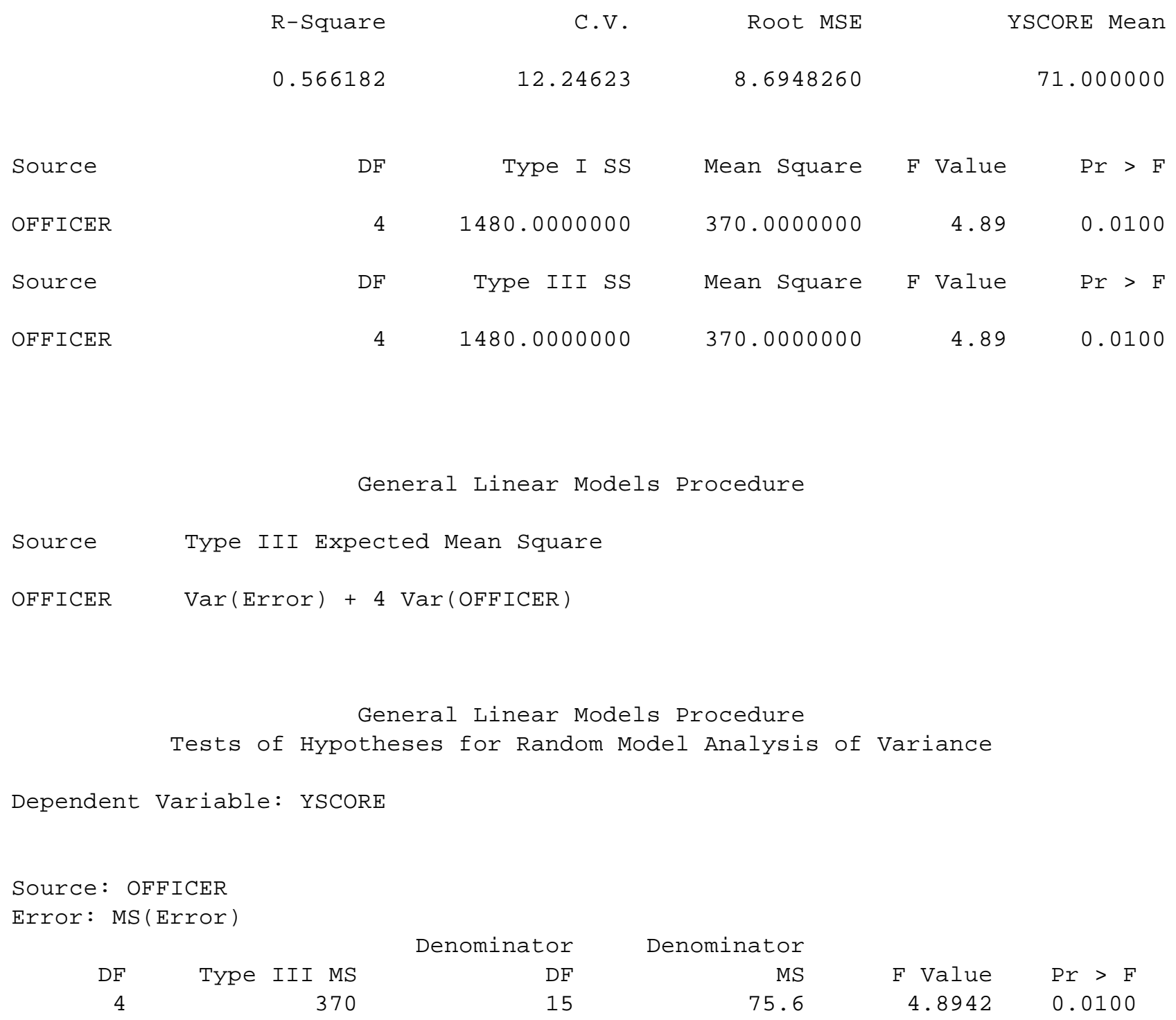




\section{Appendix C: SAS Results}

Exhibit C.7: SAS Input for and Results from SAS/STAT PROC VARCOMP for Analyzing of Table 8 Data

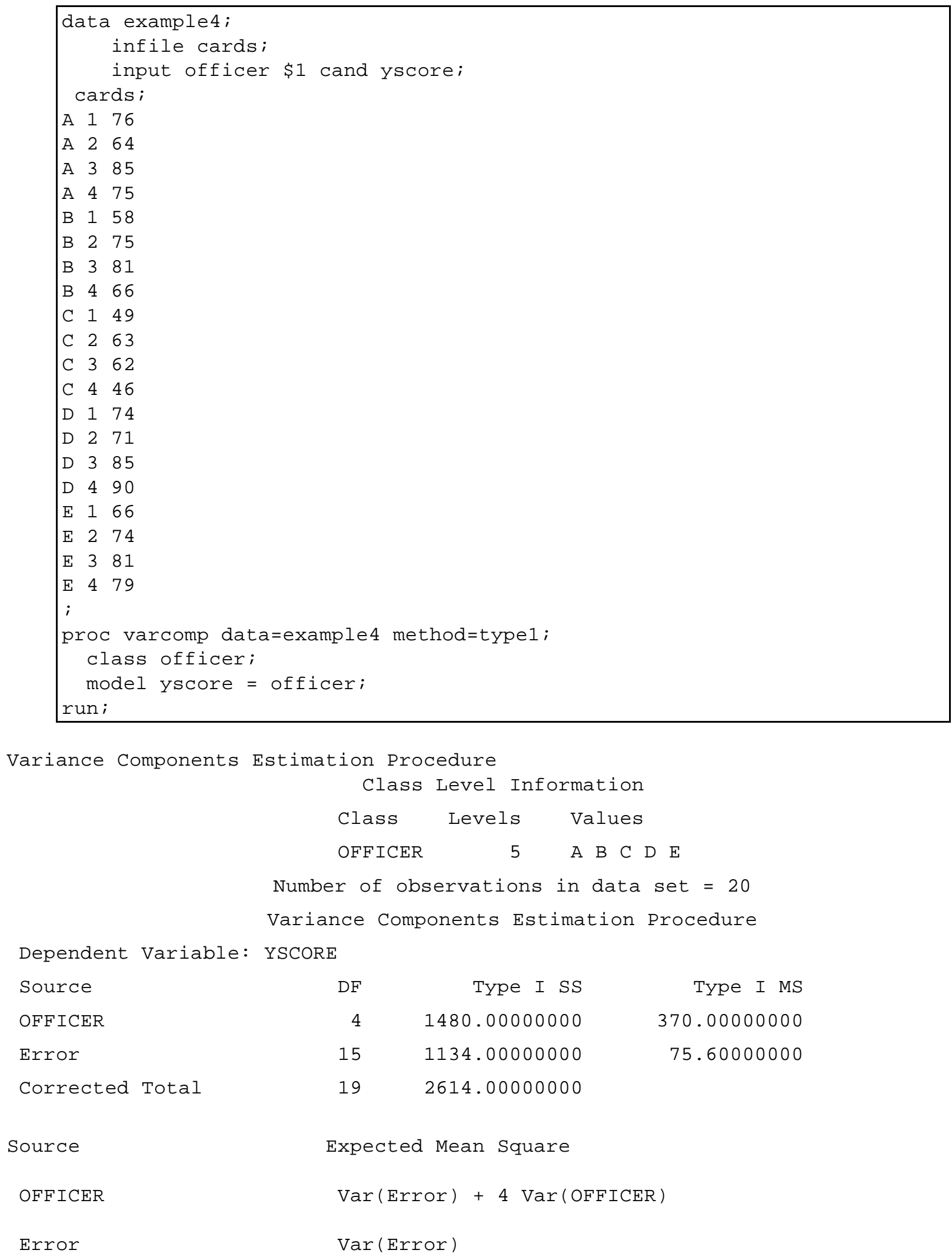




\section{Appendix C: SAS Results}

Revision 1

Variance Component

Estimate

$\operatorname{Var}(\mathrm{OFFICER})$

73.60000000

$\operatorname{Var}$ (Error)

75.60000000 


\section{Appendix C: SAS Results}

Exhibit C.8: SAS Input for and Results from SAS/STAT PROC ANOVA for Analyzing of Table 10 Data

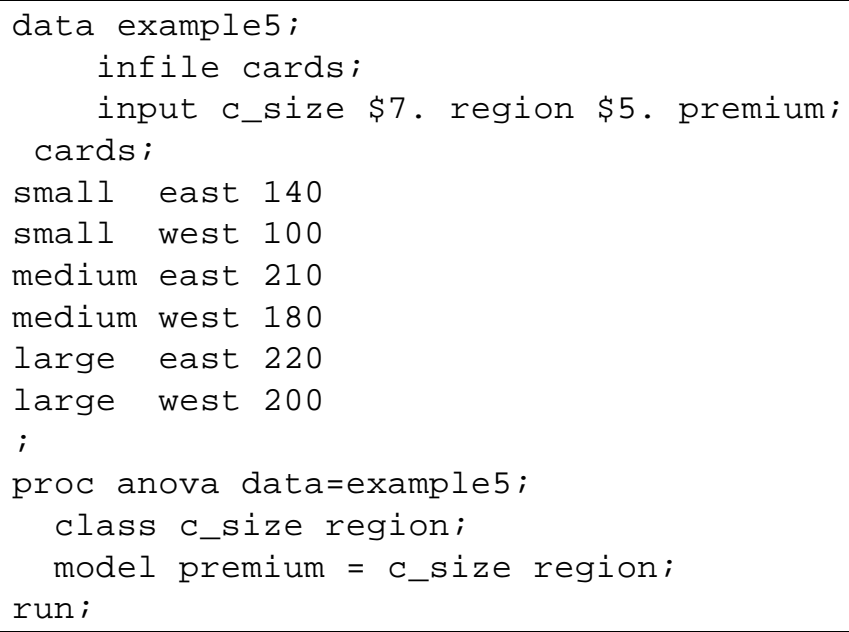


WSRC-RP-99-00422

Revision 1

Appendix C: SAS Results

REGION

1

1350.0000000

1350.0000000

27.00

0.0351 


\section{Appendix C: SAS Results}

Exhibit C.9: SAS Input for and Results from SAS/STAT PROC GLM for Analyzing of Table 10 Data

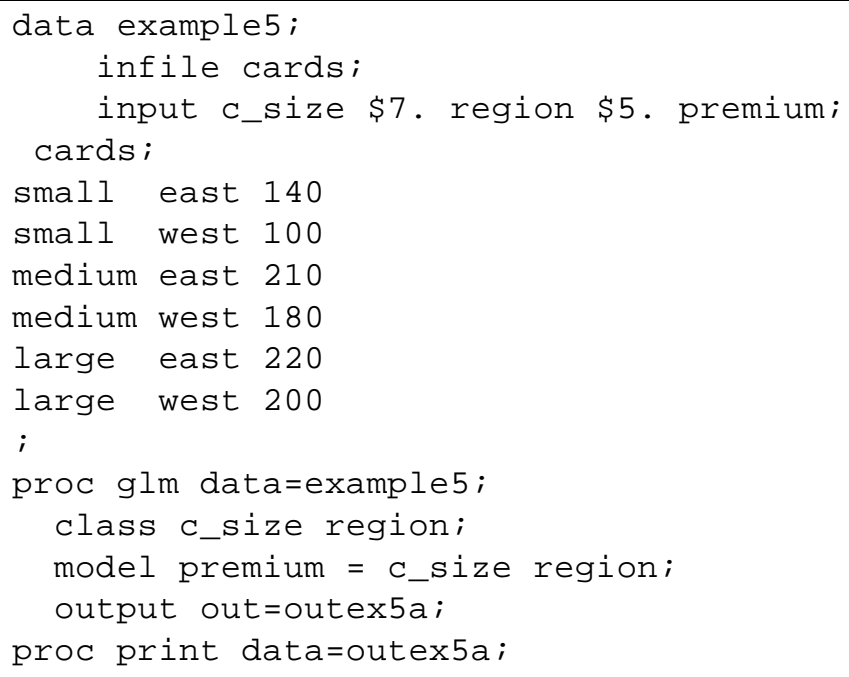

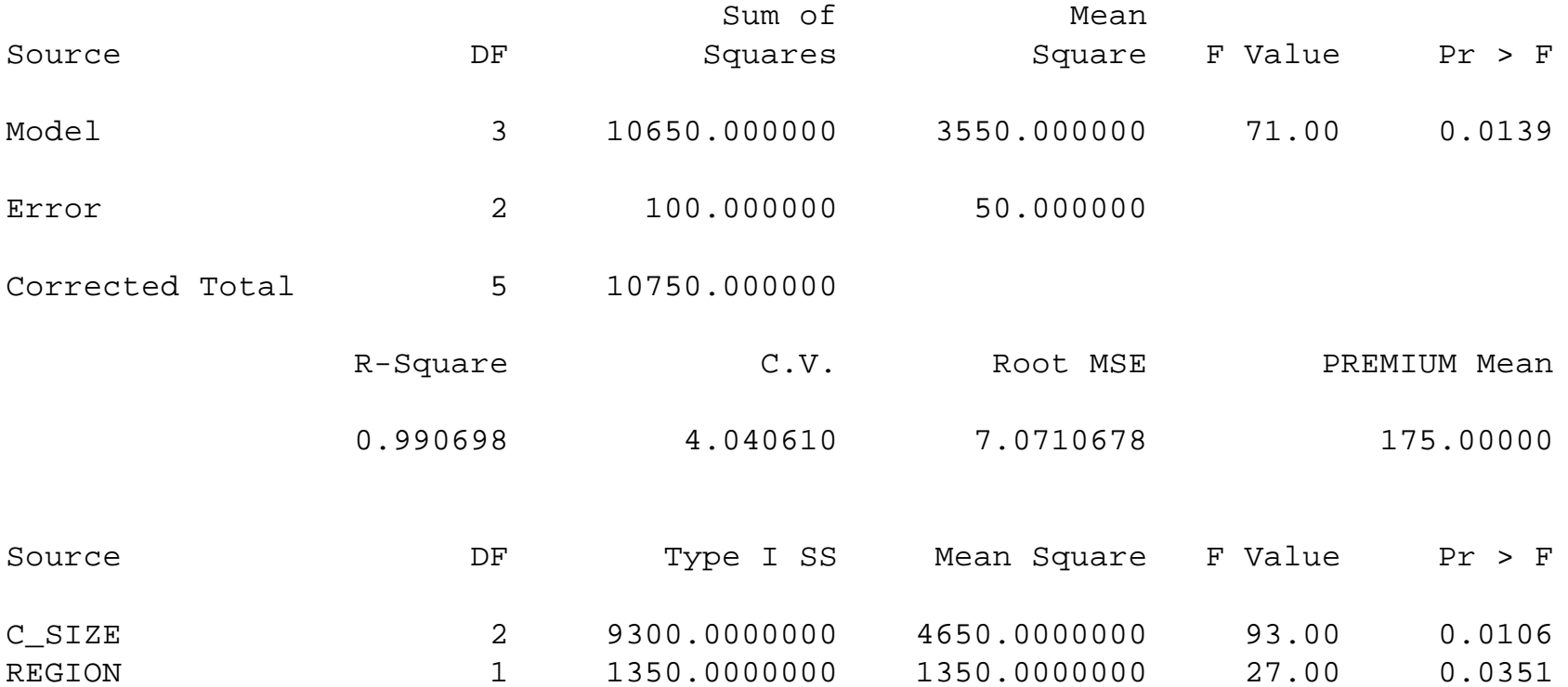


WSRC-RP-99-00422

\section{Appendix C: SAS Results}

\section{Revision 1}

Source
C_SIZE
REGION

DF

2

1
Type III SS

9300.0000000

1350.0000000
Mean Square
4650.0000000
1350.0000000

Value

93.00

27.00
$\operatorname{Pr}>\mathrm{F}$

0.0106

0.0351 


\section{Appendix C: SAS Results}

Exhibit C.10: SAS Input for and Results from SAS/STAT PROC ANOVA for Analyzing of Table 13 Data

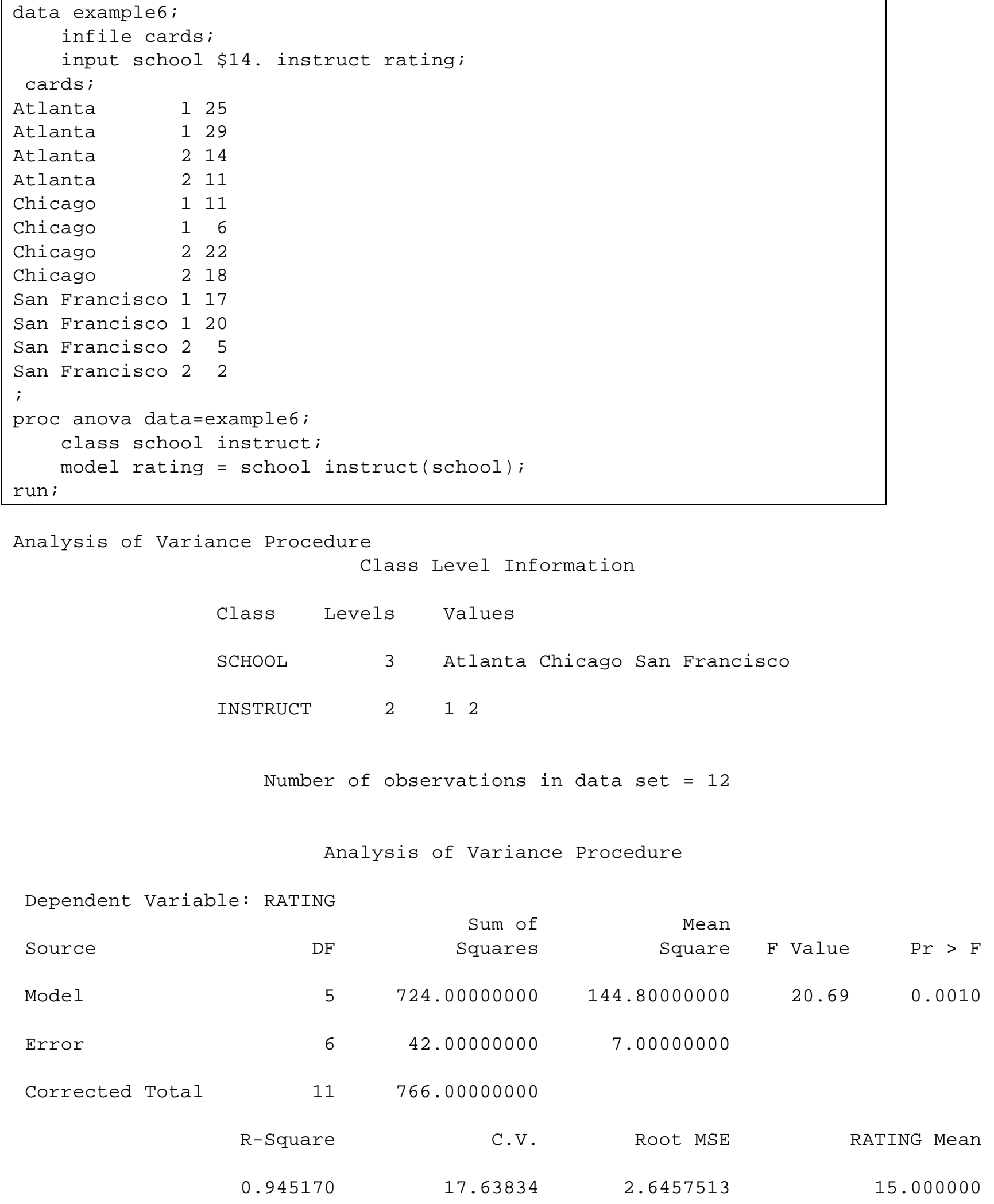


WSRC-RP-99-00422

\section{Revision 1}

Appendix C: SAS Results

Source

DF

Anova SS
156.50000000
567.50000000

Mean Square

F Value

$\operatorname{Pr}>\mathrm{F}$

SCHOOL

INSTRUCT (SCHOOL)

2

78.25000000

189.16666667

11.18

27.02

0.0095

0.0007 


\section{Appendix C: SAS Results}

Exhibit C.11: SAS Input for and Results from SAS/STAT PROC GLM for Analyzing of Table 13 Data

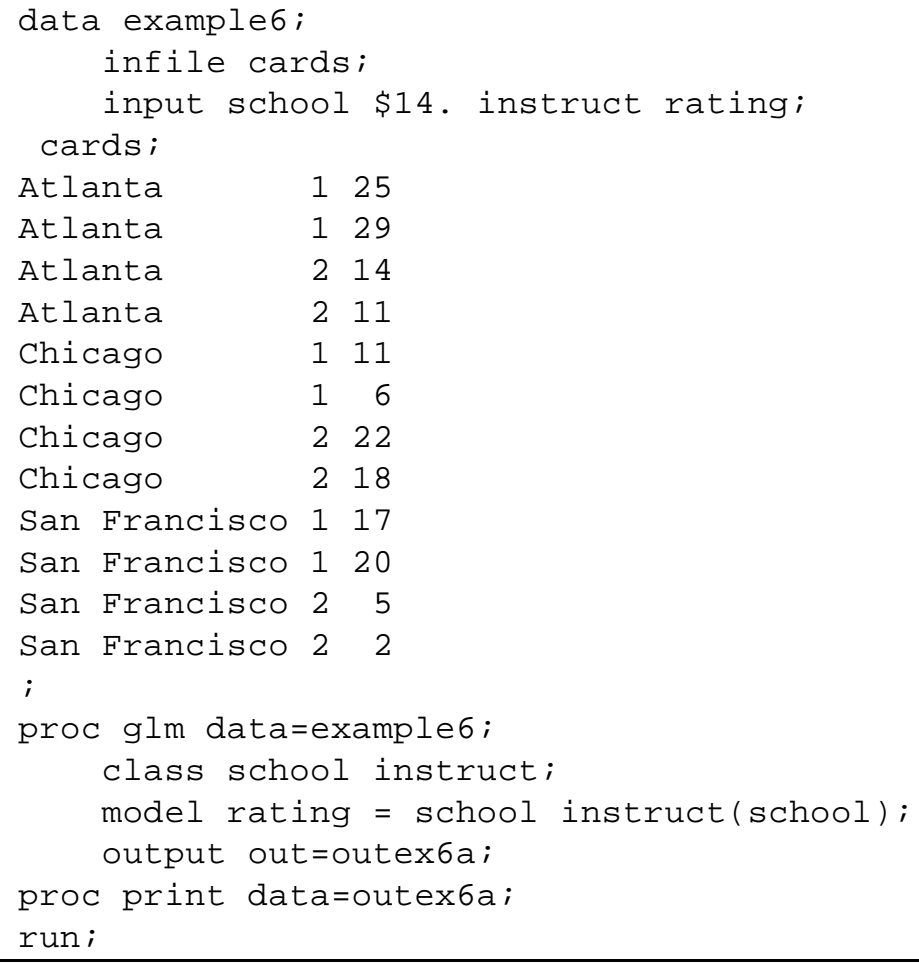


WSRC-RP-99-00422

Revision 1

Appendix C: SAS Results

0.945170

17.63834

2.6457513

15.000000 


\section{Appendix C: SAS Results}

Exhibit C.11: SAS Input for and Results from SAS/STAT PROC GLM for Analyzing of Table 13 Data (continued)

Source
SCHOOL
INSTRUCT (SCHOOL)
SourCe
SCHOOL
INSTRUCT (SCHOOL)

$\mathrm{DF}$
2
3
$\mathrm{DF}$
2
3

$\begin{array}{rrcc}\text { Type I SS } & \text { Mean Square } & \text { F Value } & \text { Pr }>\text { F } \\ 156.50000000 & 78.25000000 & 11.18 & 0.0095 \\ 567.50000000 & 189.16666667 & 27.02 & 0.0007 \\ \text { Type III SS } & \text { Mean Square } & \text { F Value } & \text { Pr }>\text { F } \\ 156.50000000 & 78.25000000 & 11.18 & 0.0095 \\ 567.50000000 & 189.16666667 & 27.02 & 0.0007\end{array}$




\section{Appendix C: SAS Results}

Exhibit C.12: SAS Input for and Results from SAS/STAT PROC GLM for Analyzing of Table 13 Data

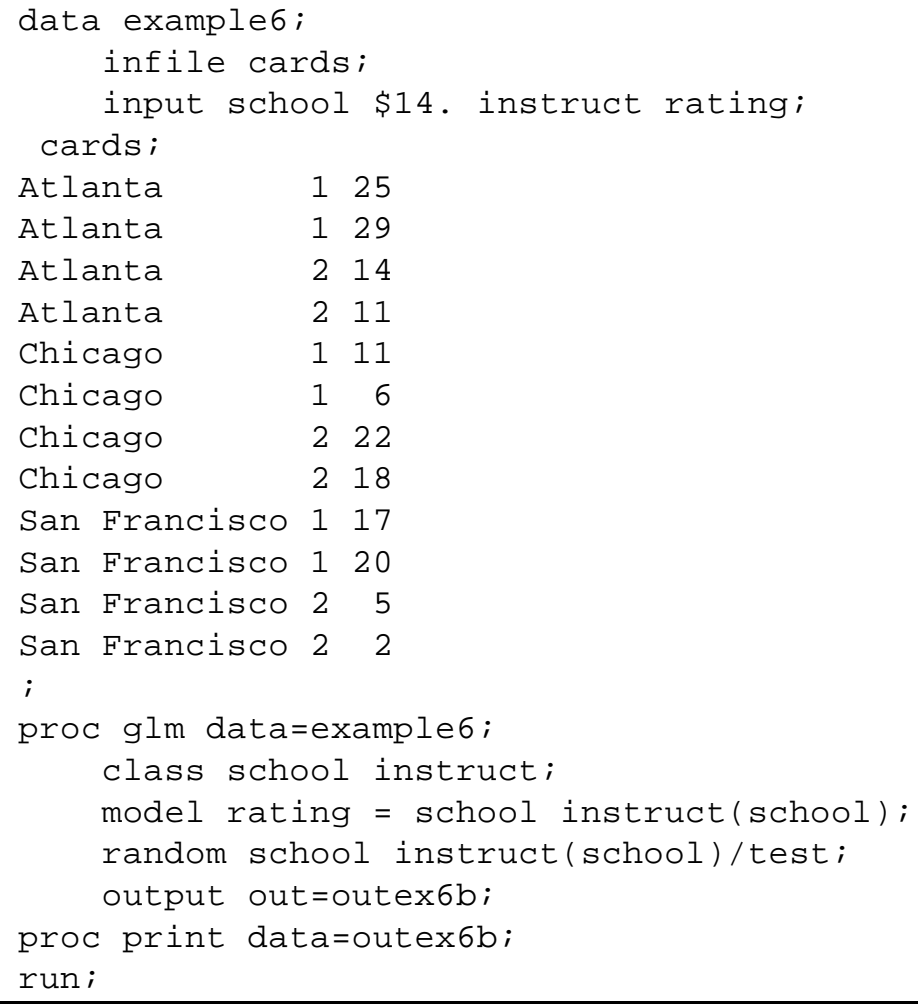


WSRC-RP-99-00422

Revision 1

Appendix C: SAS Results

R-Square

C.V.

Root MSE

RATING Mean

0.945170

17.63834

2.6457513

15.000000 


\section{Appendix C: SAS Results}

Exhibit C.12: SAS Input for and Results from SAS/STAT PROC GLM for Analyzing of Table 13 Data (continued)

\begin{tabular}{|c|c|c|c|c|c|c|}
\hline Source & $\mathrm{DF}$ & Type I SS & Mean Square & $\mathrm{F}$ & Value & $\operatorname{Pr}>\mathrm{F}$ \\
\hline SCHOOL & 2 & 156.50000000 & 78.25000000 & & 11.18 & 0.0095 \\
\hline INSTRUCT (SCHOOL) & 3 & 567.50000000 & 189.16666667 & & 27.02 & 0.0007 \\
\hline Source & $\mathrm{DF}$ & Type III SS & Mean Square & $\mathrm{F}$ & Value & $\operatorname{Pr}>\mathrm{F}$ \\
\hline SCHOOL & 2 & 156.50000000 & 78.25000000 & & 11.18 & 0.0095 \\
\hline INSTRUCT (SCHOOL) & 3 & 567.50000000 & 189.16666667 & & 27.02 & 0.0007 \\
\hline
\end{tabular}

General Linear Models Procedure

Source $\quad$ Type III Expected Mean square

SCHOOL $\operatorname{Var}($ Error $)+2 \operatorname{Var}($ INSTRUCT (SCHOOL) $)+4 \operatorname{Var}(\mathrm{SCHOOL})$

INSTRUCT (SCHOOL) Var(Error) + $2 \operatorname{Var}($ INSTRUCT (SCHOOL))

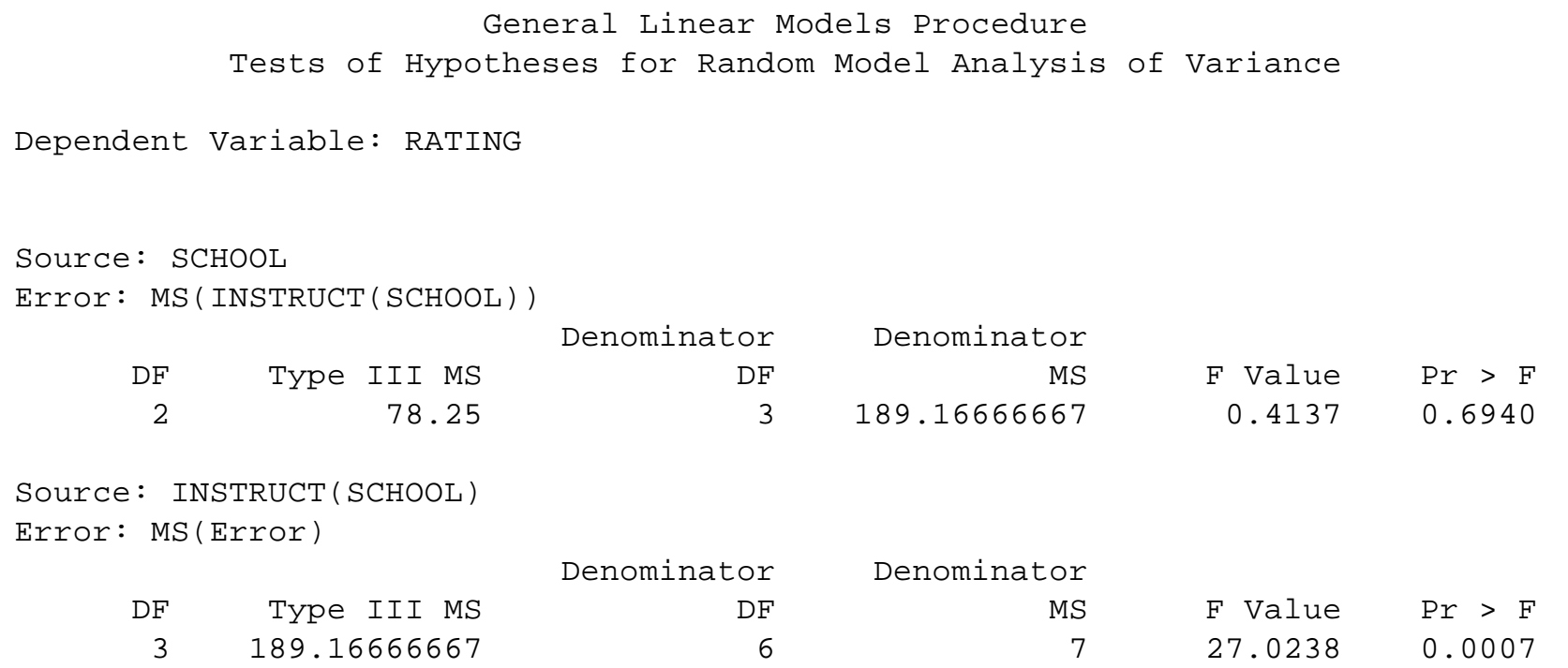




\section{Appendix C: SAS Results}

Exhibit C.13: SAS Input for and Results from SAS/STAT PROC VARCOMP for Analyzing of Table 13 Data

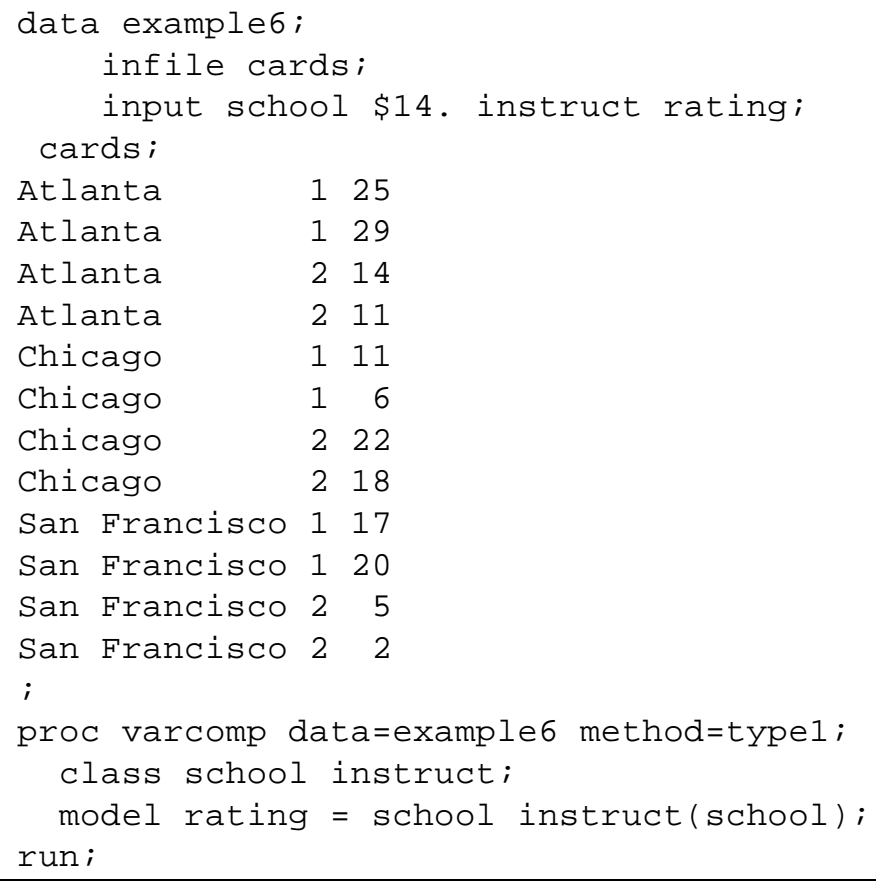


Appendix C: SAS Results

Revision 1

$\operatorname{Var}$ (Error)

7.00000000 


\section{Appendix C: SAS Results}

Exhibit C.14: SAS Input for and Results from SAS/QC PROC FACTEX for Experimental Design

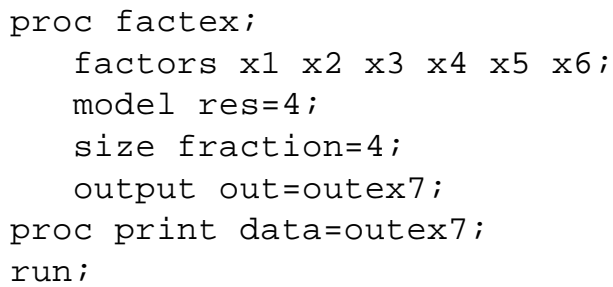

$\begin{array}{rrrrrrr}\text { OBS } & \text { X1 } & \text { X2 } & \text { X3 } & \text { X4 } & \text { X5 } & \text { X6 } \\ 1 & -1 & -1 & -1 & -1 & -1 & -1 \\ 2 & -1 & -1 & -1 & 1 & 1 & 1 \\ 3 & -1 & -1 & 1 & -1 & 1 & 1 \\ 4 & -1 & -1 & 1 & 1 & -1 & -1 \\ 5 & -1 & 1 & -1 & -1 & 1 & -1 \\ 6 & -1 & 1 & -1 & 1 & -1 & 1 \\ 7 & -1 & 1 & 1 & -1 & -1 & 1 \\ 8 & -1 & 1 & 1 & 1 & 1 & -1 \\ 9 & 1 & -1 & -1 & -1 & -1 & 1 \\ 10 & 1 & -1 & -1 & 1 & 1 & -1 \\ 11 & 1 & -1 & 1 & -1 & 1 & -1 \\ 12 & 1 & -1 & 1 & 1 & -1 & 1 \\ 13 & 1 & 1 & -1 & -1 & 1 & 1 \\ 14 & 1 & 1 & -1 & 1 & -1 & -1 \\ 15 & 1 & 1 & 1 & -1 & -1 & -1 \\ 16 & 1 & 1 & 1 & 1 & 1 & 1\end{array}$




\section{Appendix C: SAS Results}

Exhibit C.15: SAS Input and Output for Mixture Problem Defined by Equation (2)

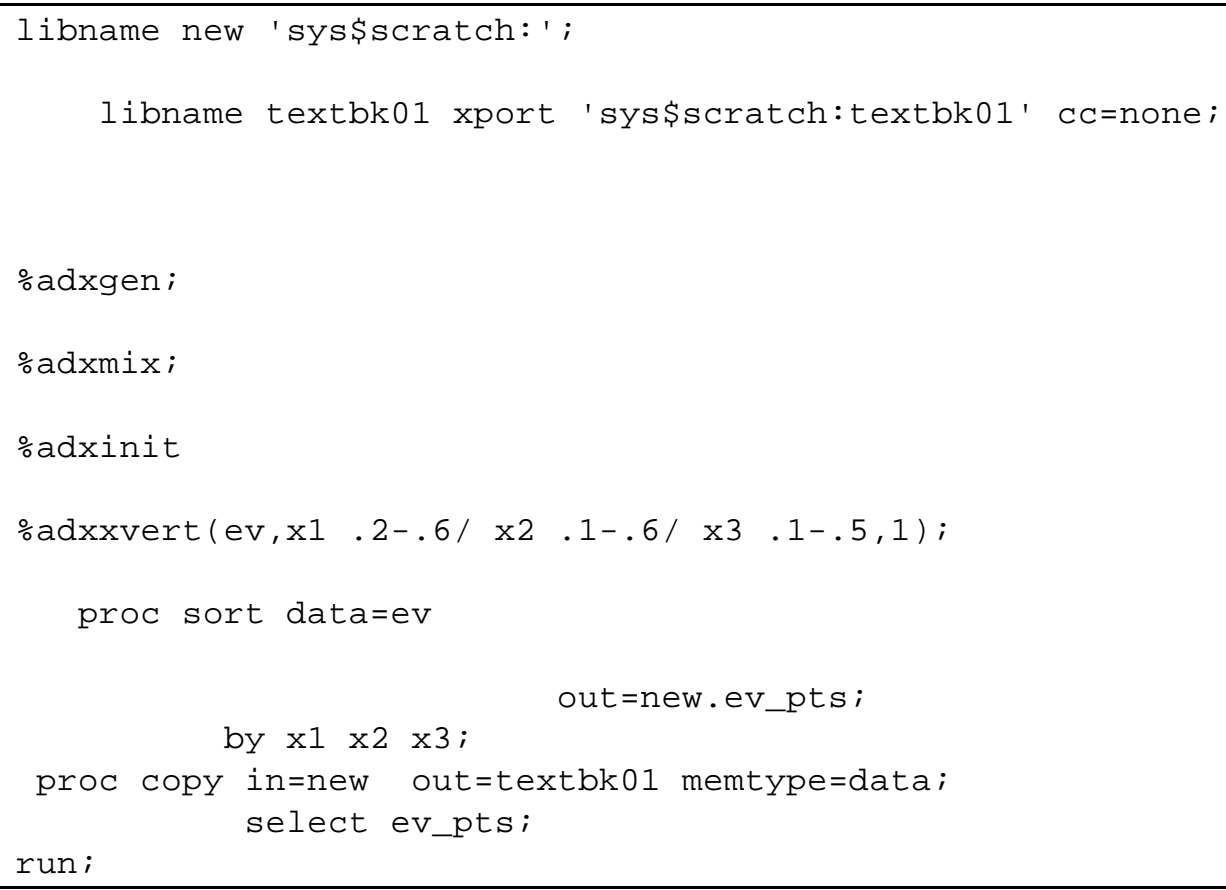

Extreme Vertices (Dimen=0) and Centroid (Dimen=2)

\begin{tabular}{|c|c|c|c|}
\hline $\mathbf{x}_{\mathbf{1}}$ & $\mathbf{x}_{\mathbf{2}}$ & $\mathbf{x}_{\mathbf{3}}$ & $\mathbf{D I M E N}$ \\
\hline 0.2 & 0.3 & 0.5 & 0 \\
\hline 0.2 & 0.6 & 0.2 & 0 \\
\hline 0.3 & 0.6 & 0.1 & 0 \\
\hline 0.383333 & 0.333333 & 0.283333 & 2 \\
\hline 0.4 & 0.1 & 0.5 & 0 \\
\hline 0.6 & 0.1 & 0.3 & 0 \\
\hline 0.6 & 0.3 & 0.1 & 0 \\
\hline
\end{tabular}

The output from this SAS run was "FTP'd" to the IBM PC using WS_FTP32 Version 3.00 by Ipswitch, Inc., 1996, as a SAS transport file. The file was then imported into JMP and copy and pasted into this document. 


\section{Appendix C: SAS Results}

Exhibit C.16: SAS Input for and Results from SAS/QC PROC OPTEX for D-Optimality

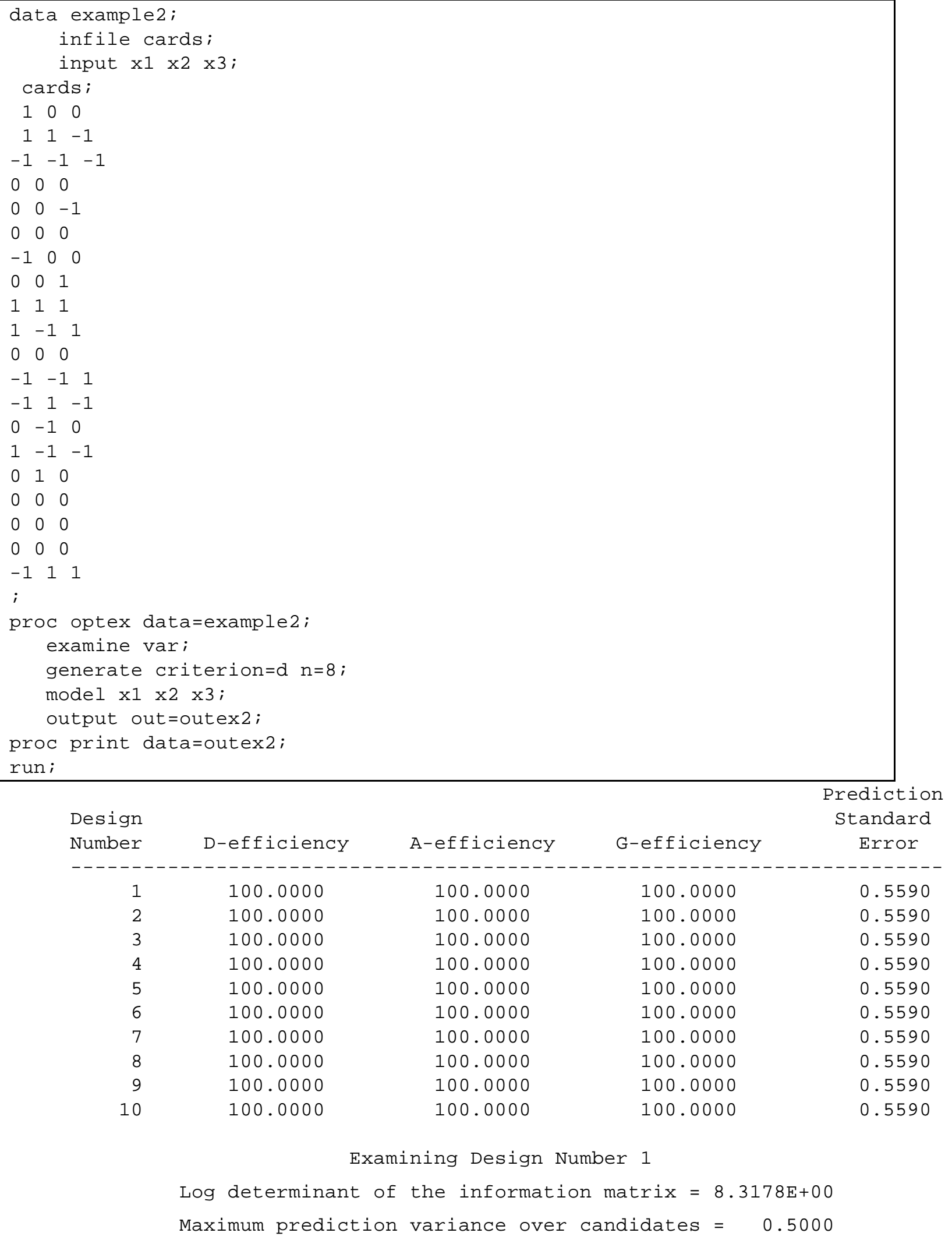


WSRC-RP-99-00422

Revision 1

Appendix C: SAS Results

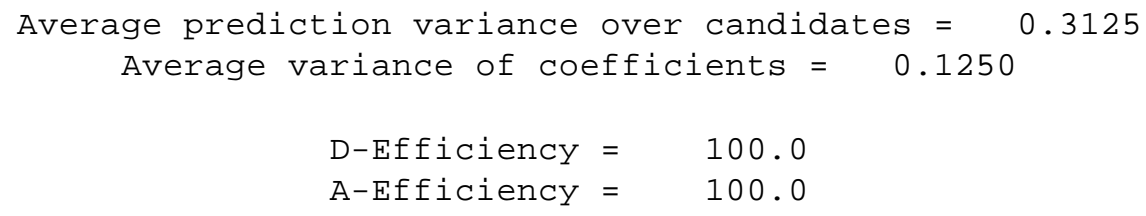




\section{Appendix C: SAS Results}

Exhibit C.16: SAS Input for and Results from SAS/QC PROC OPTEX for D-Optimality

(Continued)

\begin{tabular}{|c|c|c|c|c|c|c|}
\hline & & ianc & Mat 1 & & & \\
\hline & INTERCEPT & & $\mathrm{X} 1$ & & $\mathrm{x} 2$ & X3 \\
\hline INTERCEPT & 0.125 & & 000 & & 0.000 & 0.000 \\
\hline $\mathrm{X} 1$ & 0.000 & & 125 & & 0.000 & 0.000 \\
\hline $\mathrm{x} 2$ & 0.000 & & 000 & & 0.125 & 0.000 \\
\hline X3 & 0.000 & & 000 & & 0.000 & 0.125 \\
\hline & OBS & $\mathrm{X} 1$ & $\mathrm{x} 2$ & X3 & & \\
\hline & 1 & -1 & -1 & -1 & & \\
\hline & 2 & -1 & -1 & 1 & & \\
\hline & 3 & -1 & 1 & -1 & & \\
\hline & 4 & -1 & 1 & 1 & & \\
\hline & 5 & 1 & -1 & -1 & & \\
\hline & 6 & 1 & -1 & 1 & & \\
\hline & 7 & 1 & 1 & -1 & & \\
\hline & 8 & 1 & 1 & 1 & & \\
\hline
\end{tabular}




\section{Appendix C: SAS Results}

Exhibit C.17: SAS Input and Output for Control Chart Example from Table 18

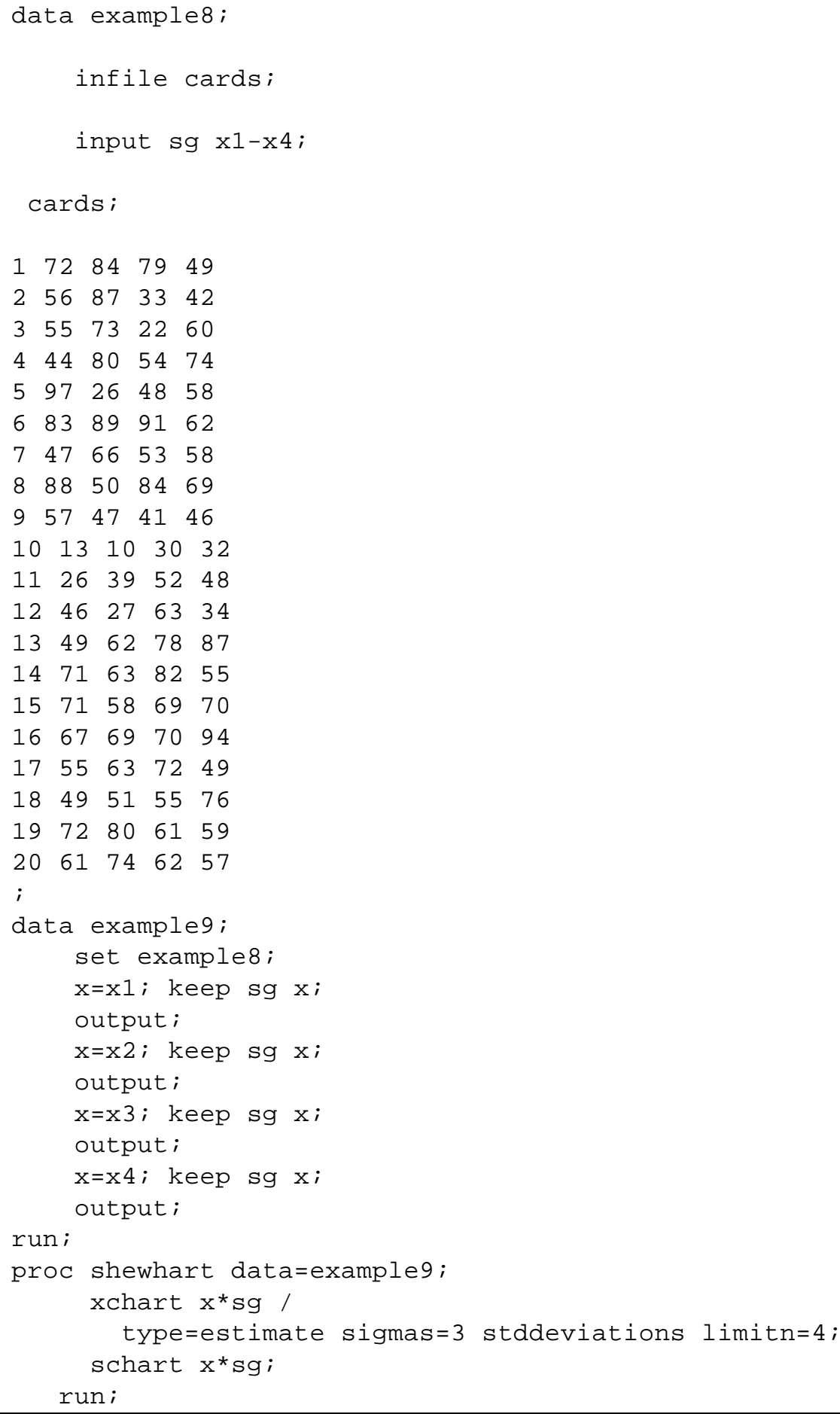




\section{Appendix C: SAS Results}

Exhibit C.17: SAS Input and Output for Control Chart Example from Table 18

(Continued)

3 Sigma Limits

For $\mathrm{n}=4$ :

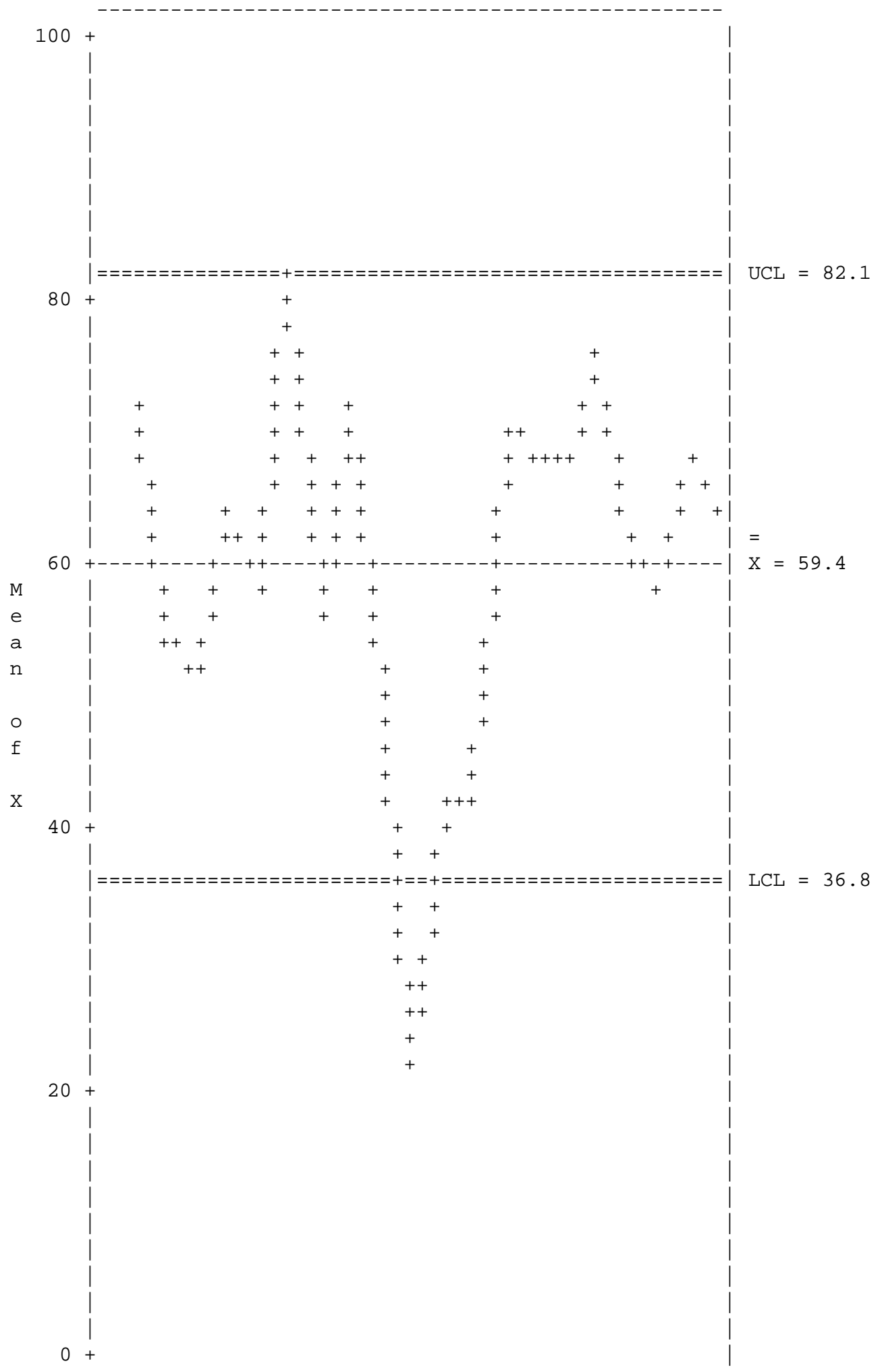




\section{Appendix C: SAS Results}

Revision 1

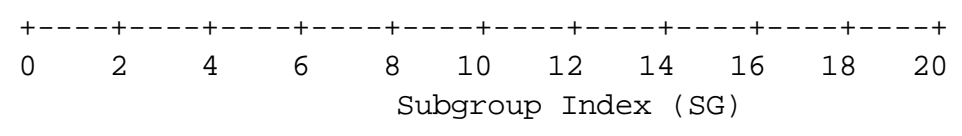

Subgroup Sizes: $n=4$ 
Appendix C: SAS Results

Exhibit C.17: SAS Input and Output for Control Chart Example from Table 18

(Continued)

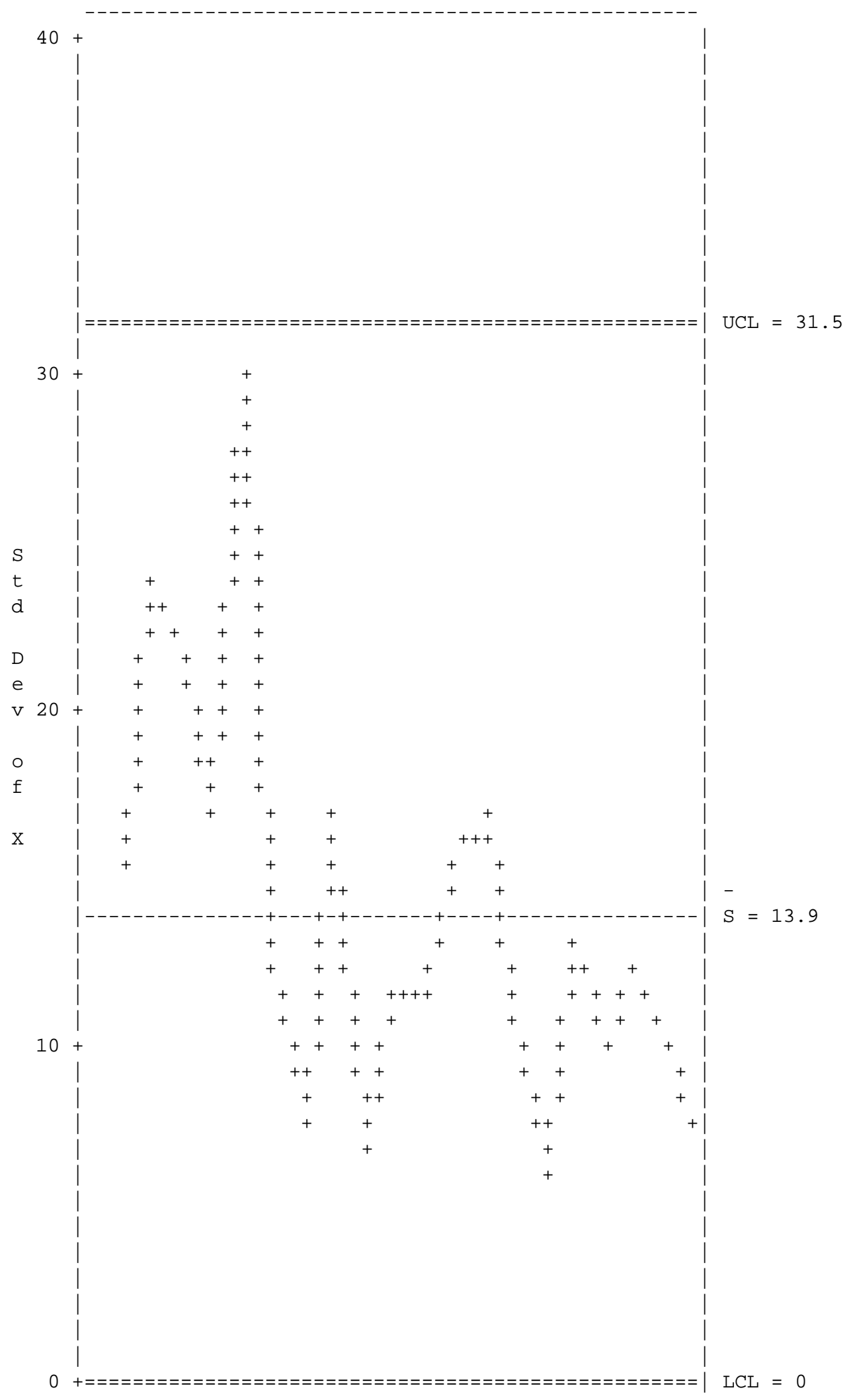


Appendix C: SAS Results

Revision 1

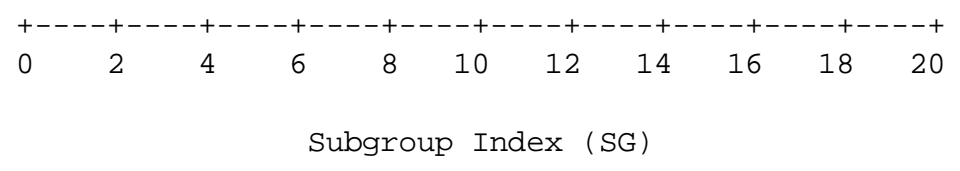

Subgroup Sizes: $n=4$ 
Appendix D: Mixsoft Results

Exhibit D.1: Mixsoft Output for a Fractional Factorial Experiment using the Design Experiment Feature

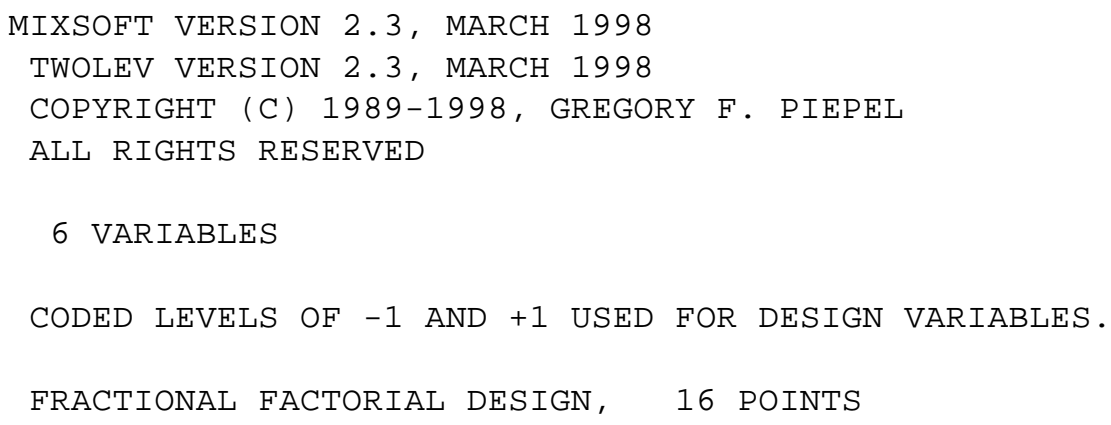

\begin{tabular}{|c|c|c|c|c|c|c|}
\hline Run & $\mathrm{A}$ & $\mathrm{B}$ & $\mathrm{C}$ & $\mathrm{D}$ & $\mathrm{E}$ & $\mathrm{F}$ \\
\hline 1 & -1 & -1 & -1 & -1 & -1 & -1 \\
\hline 2 & 1 & -1 & -1 & -1 & 1 & 1 \\
\hline 3 & -1 & 1 & -1 & -1 & 1 & 1 \\
\hline 4 & 1 & 1 & -1 & -1 & -1 & -1 \\
\hline 5 & -1 & -1 & 1 & -1 & 1 & -1 \\
\hline 6 & 1 & -1 & 1 & -1 & -1 & 1 \\
\hline 7 & -1 & 1 & 1 & -1 & -1 & 1 \\
\hline 8 & 1 & 1 & 1 & -1 & 1 & -1 \\
\hline 9 & -1 & -1 & -1 & 1 & -1 & 1 \\
\hline 10 & 1 & -1 & -1 & 1 & 1 & -1 \\
\hline 11 & -1 & 1 & -1 & 1 & 1 & -1 \\
\hline 12 & 1 & 1 & -1 & 1 & -1 & 1 \\
\hline 13 & -1 & -1 & 1 & 1 & 1 & 1 \\
\hline 14 & 1 & -1 & 1 & 1 & -1 & -1 \\
\hline 15 & -1 & 1 & 1 & 1 & -1 & -1 \\
\hline 16 & 1 & 1 & 1 & 1 & 1 & 1 \\
\hline
\end{tabular}




\section{Appendix D: Mixsoft Results}

Exhibit D.2: Mixsoft Input and Output for Mixture Problem Defined by Equation (2)

\begin{tabular}{|c|c|c|c|}
\hline \multicolumn{4}{|c|}{$\begin{array}{l}\text { MIXSOFT VERSION 2.3, MARCH } 1998 \\
\text { VERT VERSION 2.3, MARCH } 1998\end{array}$} \\
\hline \multicolumn{4}{|c|}{3 COMPONENTS } \\
\hline COMP & ONENT & ER BOUNDS & UPPER BOUNDS \\
\hline---- & ----- & --------- & ------------ \\
\hline & 0.2 & $00000 \mathrm{E}+00$ & $0.600000 \mathrm{E}+00$ \\
\hline & 0.1 & $00000 \mathrm{E}+00$ & $0.600000 \mathrm{E}+00$ \\
\hline & 0.1 & $00000 \mathrm{E}+00$ & $0.500000 \mathrm{E}+00$ \\
\hline \multicolumn{4}{|c|}{ TOLERANCE VALUE $=0.1000 \mathrm{E}-05$} \\
\hline \multicolumn{4}{|c|}{ COMPONENT VALUE TOLERANCE VECTOR } \\
\hline \multicolumn{4}{|c|}{$\operatorname{TOLV}(1)=0.5000 \mathrm{E}-04$} \\
\hline \multicolumn{4}{|c|}{$\operatorname{TOLV}(2)=0.5000 \mathrm{E}-04$} \\
\hline \multicolumn{4}{|c|}{$\operatorname{TOLV}(3)=0.5000 \mathrm{E}-04$} \\
\hline $\mathrm{THE}$ & CONSTRAINT RE & GION HAS & 6 VERTICES. \\
\hline ALL & VERTICES: & 6 OBTAINED & \\
\hline 1 & $0.2000 \mathrm{E}+00$ & $0.6000 \mathrm{E}+00$ & $0.2000 \mathrm{E}+00$ \\
\hline 2 & $0.3000 \mathrm{E}+00$ & $0.6000 \mathrm{E}+00$ & $0.1000 \mathrm{E}+00$ \\
\hline 3 & $0.6000 \mathrm{E}+00$ & $0.3000 \mathrm{E}+00$ & $0.1000 \mathrm{E}+00$ \\
\hline 4 & $0.2000 \mathrm{E}+00$ & $0.3000 \mathrm{E}+00$ & $0.5000 \mathrm{E}+00$ \\
\hline 5 & $0.6000 \mathrm{E}+00$ & $0.1000 \mathrm{E}+00$ & $0.3000 \mathrm{E}+00$ \\
\hline 6 & $0.4000 \mathrm{E}+00$ & $0.1000 \mathrm{E}+00$ & $0.5000 \mathrm{E}+00$ \\
\hline
\end{tabular}


Appendix E: Statgraphics Results

Exhibit E.1: Statgraphics Output for Statistics of Lot Size Information in Table 2

\title{
Analysis Summary
}

Data variable: $\mathrm{X}$

10 values ranging from 20.0 to 80.0

Scatterplot for $\mathrm{X}$

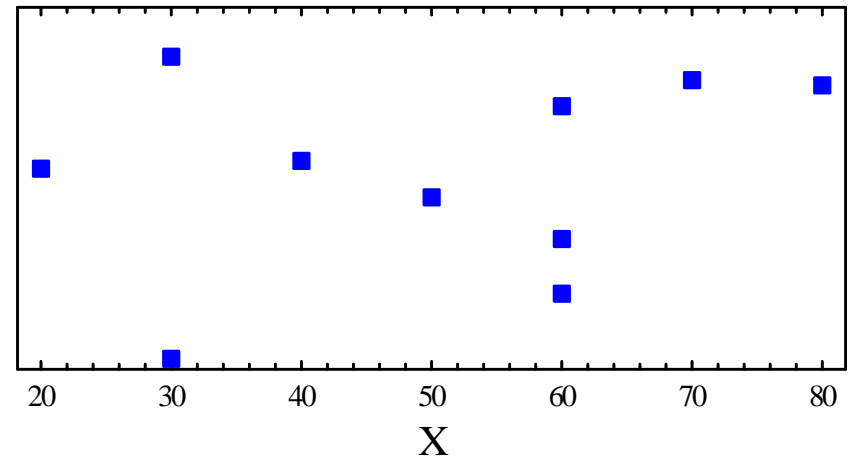

\section{Summary Statistics for $\mathbf{X}$}

\author{
Count $=10$ \\ Average $=50.0$ \\ Median $=55.0$ \\ Mode $=60.0$ \\ Geometric mean $=46.1205$ \\ Variance $=377.778$ \\ Standard deviation $=19.4365$ \\ Standard error $=6.14636$ \\ Minimum $=20.0$ \\ Maximum $=80.0$ \\ Range $=60.0$ \\ Lower quartile $=30.0$ \\ Upper quartile $=60.0$ \\ Interquartile range $=30.0$ \\ Skewness $=-0.113492$ \\ Stnd. skewness $=-0.146517$ \\ Kurtosis $=-1.06661$ \\ Stnd. kurtosis $=-0.688493$ \\ Coeff. of variation $=38.873 \%$ \\ Sum $=500.0$
}


Appendix E: Statgraphics Results

Exhibit E.1: Statgraphics Output for Statistics of Lot Size Information in Table 2

(continued)

Box-and-Whisker Plot

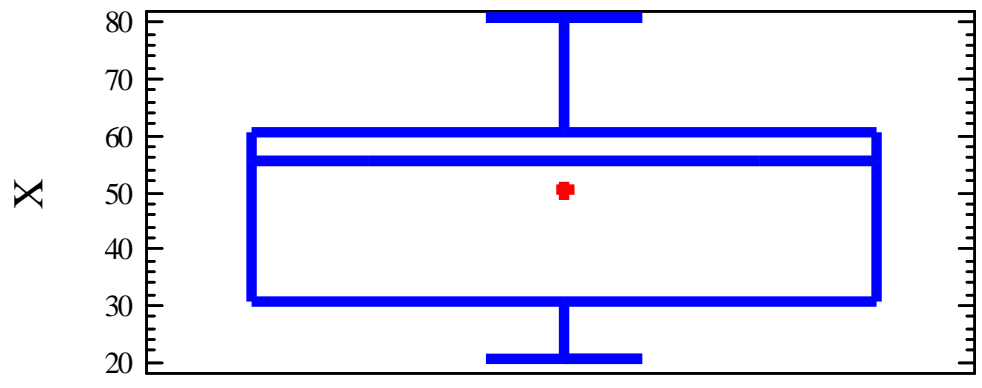

\section{Percentiles for $\mathbf{X}$}

$$
\begin{aligned}
& 0.5 \%=20.0 \\
& 2.5 \%=20.0 \\
& 10.0 \%=25.0 \\
& 25.0 \%=30.0 \\
& 50.0 \%=55.0 \\
& 75.0 \%=60.0 \\
& 90.0 \%=75.0 \\
& 97.5 \%=80.0 \\
& 99.5 \%=80.0
\end{aligned}
$$

Note: There are several ways to determine estimates of quantiles. Statgraphics computes these as outlined in Hayes [13]. The Pth quantile is estimated as $100(\mathrm{i}-0.5) / \mathrm{N}$ where $\mathrm{i}$ is the rank. Linear interpolation is used for other quantiles.

\section{Moments}

Histogram for X

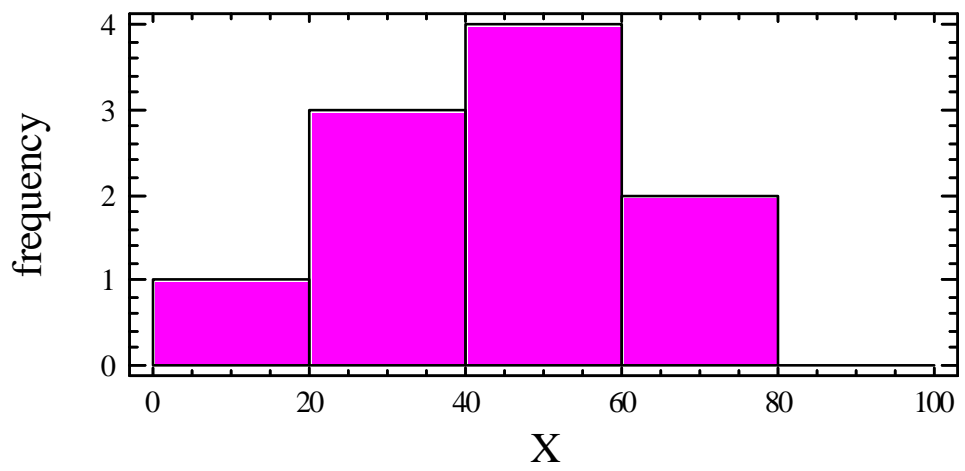


Appendix E: Statgraphics Results

Exhibit E.1: Statgraphics Output for Statistics of Lot Size Information in Table 2 (continued)

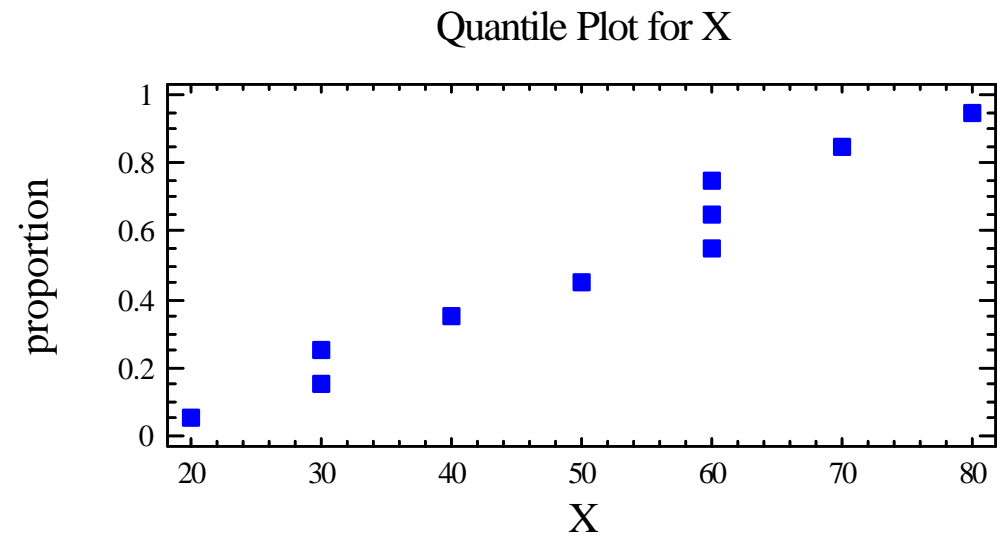

\section{Stem-and-Leaf Display for X: unit $=1.01 \mid 2$ represents 12.0}

$\begin{array}{ll}1 & 2 \mid 0 \\ 3 & 3 \mid 00 \\ 4 & 4 \mid 0 \\ 5 & 5 \mid 0 \\ 5 & 6 \mid 000 \\ 2 & 7 \mid 0 \\ 1 & 8 \mid 0\end{array}$

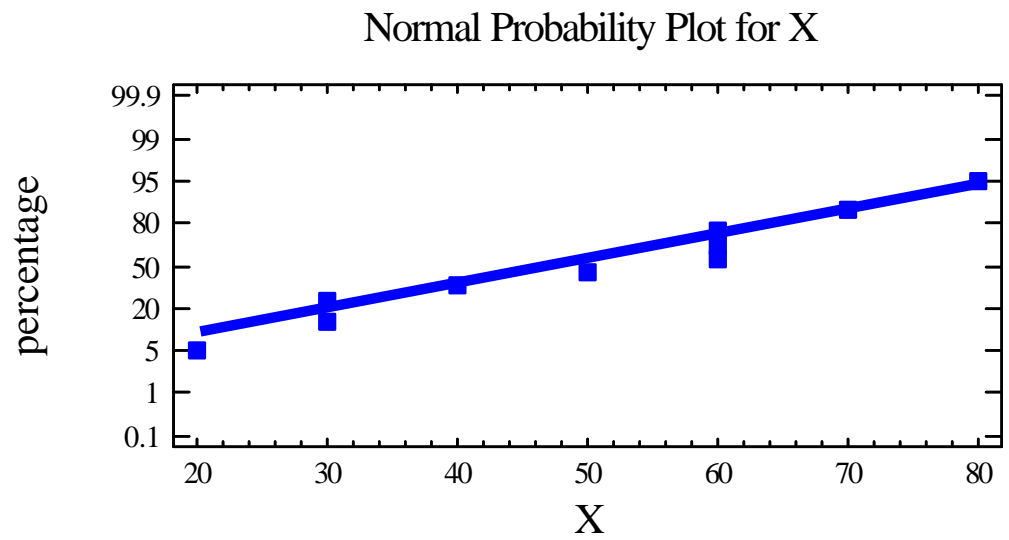

\section{Confidence Intervals for $\mathbf{X}$}

95.0\% confidence interval for mean: $50.0+/-13.9041 \quad[36.0959,63.9041]$

95.0\% confidence interval for standard deviation: [13.3691,35.4835] 
Appendix E: Statgraphics Results

Exhibit E.2: Statgraphics Output for Table 2 Data Using Simple Regression

\section{Regression Analysis - Linear model: $\mathrm{Y}=\mathbf{a}+\mathrm{b}^{*} \mathrm{X}$}

Dependent variable: $\mathrm{Y}$

Independent variable: $\mathrm{X}$

\begin{tabular}{|c|c|c|c|c|}
\hline \multirow[b]{2}{*}{ Parameter } & \multicolumn{2}{|c|}{ Standard } & \multicolumn{2}{|c|}{$\mathrm{T}$} \\
\hline & Estimate & Error & Statistic & P-Value \\
\hline Intercept & 10.0 & 0294 & 3.9953 & 0.0040 \\
\hline Slope & $2.0 \quad 0$. & 9668 & 42.5833 & 0.0000 \\
\hline
\end{tabular}

\section{Analysis of Variance}

\begin{tabular}{lccccc}
\hline Source & Sum of Squares & Df & Mean Square & F-Ratio & P-Value \\
\hline Model & 13600.0 & 1 & 13600.0 & 1813.33 & 0.0000 \\
Residual & 60.0 & 8 & 7.5 & & \\
Total (Corr.) & 13660.0 & 9 & & \\
& & & & \\
Correlation Coefficient $=0.997801$ & & & \\
R-squared $=99.5608$ percent & & & \\
Standard Error of Est. $=2.73861$ &
\end{tabular}

Plot of Fitted Model

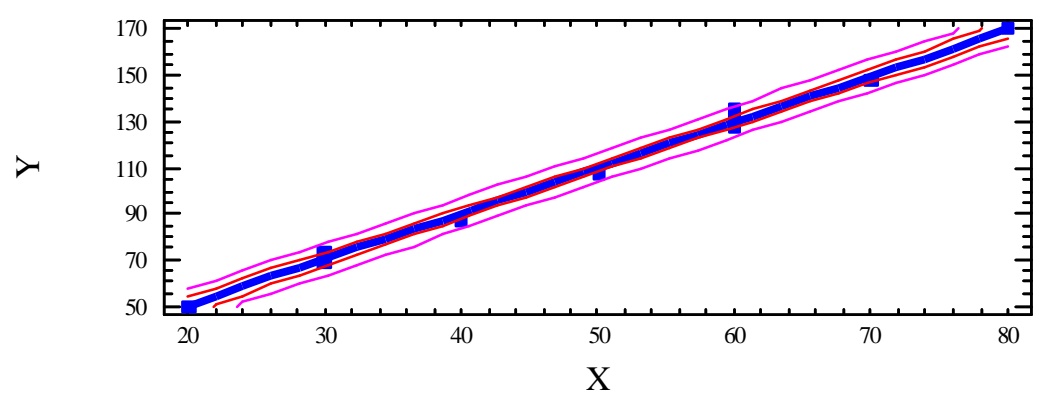

\section{Analysis of Variance with Lack-of-Fit}

\begin{tabular}{|c|c|c|c|c|c|}
\hline Source & Sum of Squares & \multicolumn{2}{|c|}{ Df Mean Square } & \multirow{2}{*}{$\begin{array}{c}\text { F-Ratio } \\
1813.33\end{array}$} & \multirow{2}{*}{$\begin{array}{l}\text { P-Value } \\
0.0000\end{array}$} \\
\hline Model & 13600.0 & 1 & 13600.0 & & \\
\hline Residual & 60.0 & 8 & 7.5 & & \\
\hline Lack-of-Fit & 27.3333 & 5 & 5.46667 & 0.50 & 0.7662 \\
\hline Pure Error & 32.6667 & 3 & 10.8889 & & \\
\hline Total (Corr.) & 13660.0 & 9 & & & \\
\hline
\end{tabular}


Appendix E: Statgraphics Results

Exhibit E.3: Statgraphics Output for Table 5 Data Using One-Way ANOVA

Dependent variable: Sales

Factor: Design

Number of observations: 10

Number of levels: 4

Scatterplot by Level Code

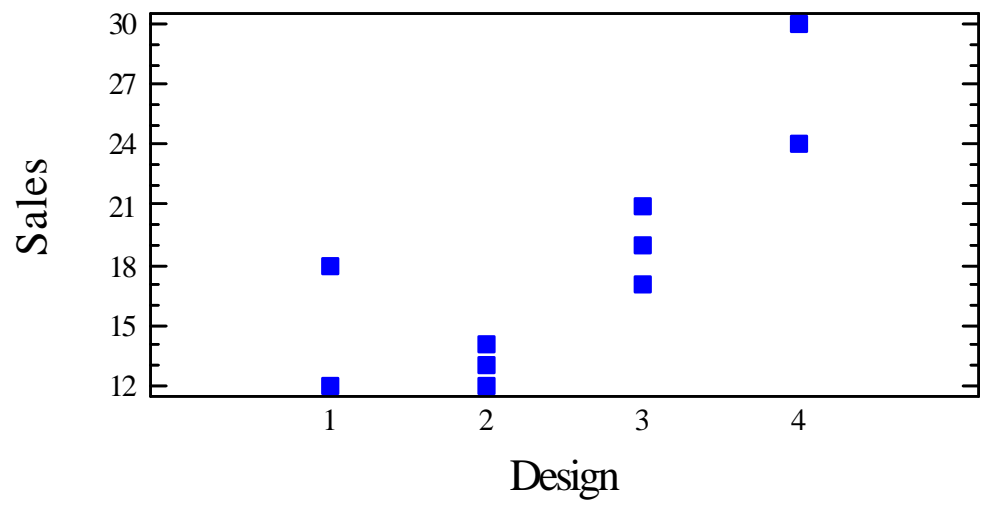

\section{Summary Statistics for Sales}

\begin{tabular}{|c|c|c|c|}
\hline Design & Count & Average & Variance \\
\hline 1 & 2 & 15.0 & 18.0 \\
\hline 2 & 3 & 13.0 & 1.0 \\
\hline 3 & 3 & 19.0 & 4.0 \\
\hline 4 & 2 & 27.0 & 18.0 \\
\hline Total & 10 & 18.0 & 33.7778 \\
\hline
\end{tabular}

\begin{tabular}{|c|c|c|c|}
\hline Design & Standard deviation & Minimum & Maximum \\
\hline 1 & 4.24264 & 12.0 & 18.0 \\
\hline 2 & 1.0 & 12.0 & 14.0 \\
\hline 3 & 2.0 & 17.0 & 21.0 \\
\hline 4 & 4.24264 & 24.0 & 30.0 \\
\hline Total & 5.81187 & 12.0 & 30.0 \\
\hline
\end{tabular}

Design Range Stnd. skewness Stnd. kurtosis

\begin{tabular}{llll}
\hline 1 & 6.0 & & \\
2 & 2.0 & 0.0 & \\
3 & 4.0 & 0.0 & \\
4 & 6.0 & & \\
- \hdashline Total & 18.0 & 1.23305 & 0.358593
\end{tabular}


Appendix E: Statgraphics Results

Exhibit E.3: Statgraphics Output for Table 5 Data Using One-Way ANOVA (continued)

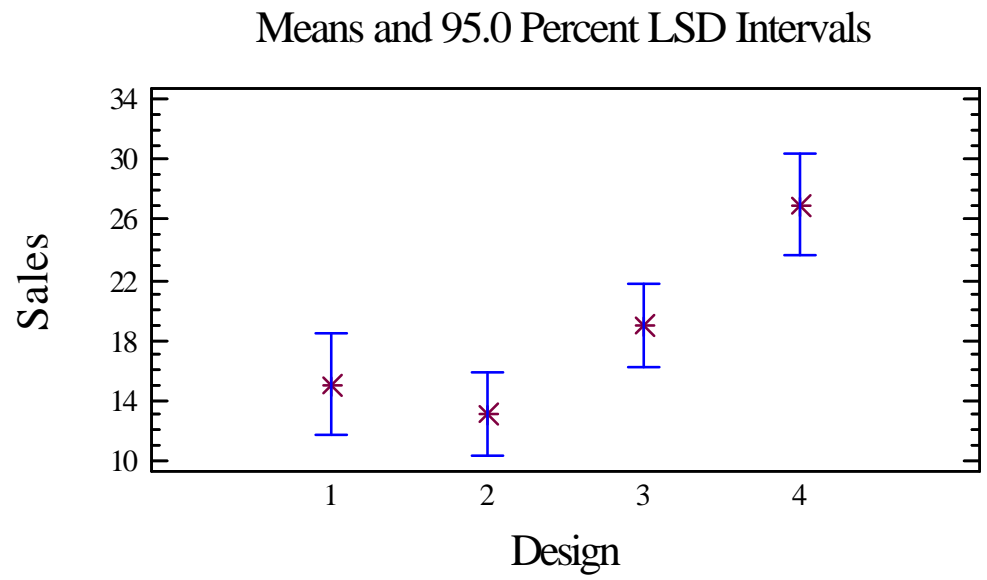

\section{ANOVA Table for Sales by Design}

$\begin{array}{lccccc} & \text { Sum of Squares } & \text { Df } & \text { Mean Square } & \text { F-Ratio } & \text { P-Value } \\ \text { Source } & 258.0 & 3 & 86.0 & 11.22 & 0.0071 \\ \text { Between groups } & 46.0 & 6 & 7.66667 & & \\ \text { Within groups } & 304.0 & 9 & & \end{array}$

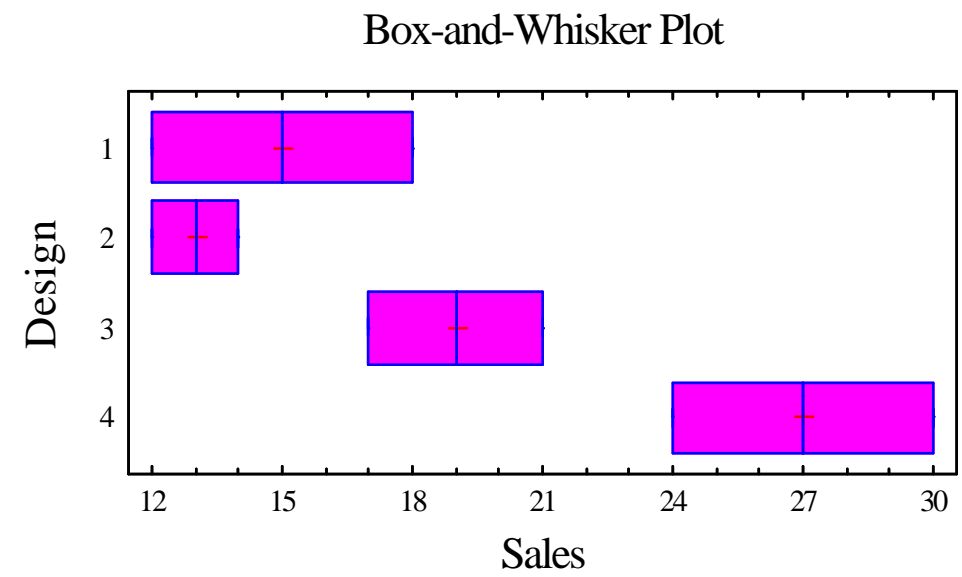


Appendix E: Statgraphics Results

Exhibit E.3: Statgraphics Output for Table 5 Data Using One-Way ANOVA (continued)

\section{Table of Means for Sales by Design with 95.0 percent LSD intervals}

\begin{tabular}{llllll} 
& \multicolumn{5}{c}{ Stnd. error } \\
Design & Count & Mean & (pooled s) & Lower limit & Upper limit \\
\hline 1 & 2 & 15.0 & 1.95789 & 11.6124 & 18.3876 \\
2 & 3 & 13.0 & 1.59861 & 10.234 & 15.766 \\
3 & 3 & 19.0 & 1.59861 & 16.234 & 21.766 \\
4 & 2 & 27.0 & 1.95789 & 23.6124 & 30.3876 \\
- & 2 & 18.0 & & &
\end{tabular}


Appendix E: Statgraphics Results

Exhibit E.4: Statgraphics Output for Table 8 Data using Variance Components Analysis

Dependent variable: $\mathrm{Y}$

Factors: Officer

Number of complete cases: 20

\section{Analysis of Variance for $\mathbf{Y}$}

\begin{tabular}{|c|c|c|c|c|c|c|}
\hline Source & Sum of Squares & Df & Mean Square & Var & Comp. & Percent \\
\hline TOTAL (CORRECTED) & 2614.0 & 19 & & & & \\
\hline Officer & 1480.0 & 4 & 370.0 & 73.6 & 49.33 & \\
\hline ERROR & 1134.0 & 15 & 75.6 & & 75.6 & 50.67 \\
\hline
\end{tabular}

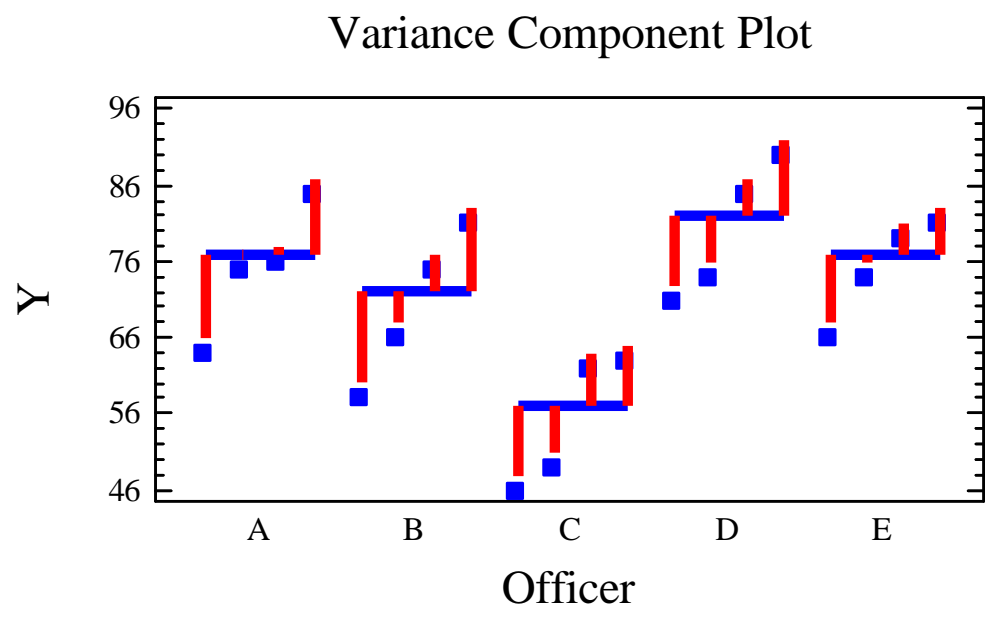

\begin{tabular}{lccc} 
Y & \multicolumn{3}{c}{ Standard } \\
Level & Count & Mean & Deviation \\
GRAND MEAN & 20 & 71.0 & 11.7294 \\
Officer & & & \\
A & 4 & 75.0 & 8.60233 \\
B & 4 & 70.0 & 10.0995 \\
C & 4 & 55.0 & 8.75595 \\
D & 4 & 80.0 & 8.98146 \\
E & 4 & 75.0 & 6.68331
\end{tabular}


Appendix E: Statgraphics Results

Exhibit E.5: Statgraphics Output for Table 10 Data using Two Factor ANOVA

Multifactor ANOVA - Y

Dependent variable: $Y$

Factors:

Size

Region

Number of complete cases: 6

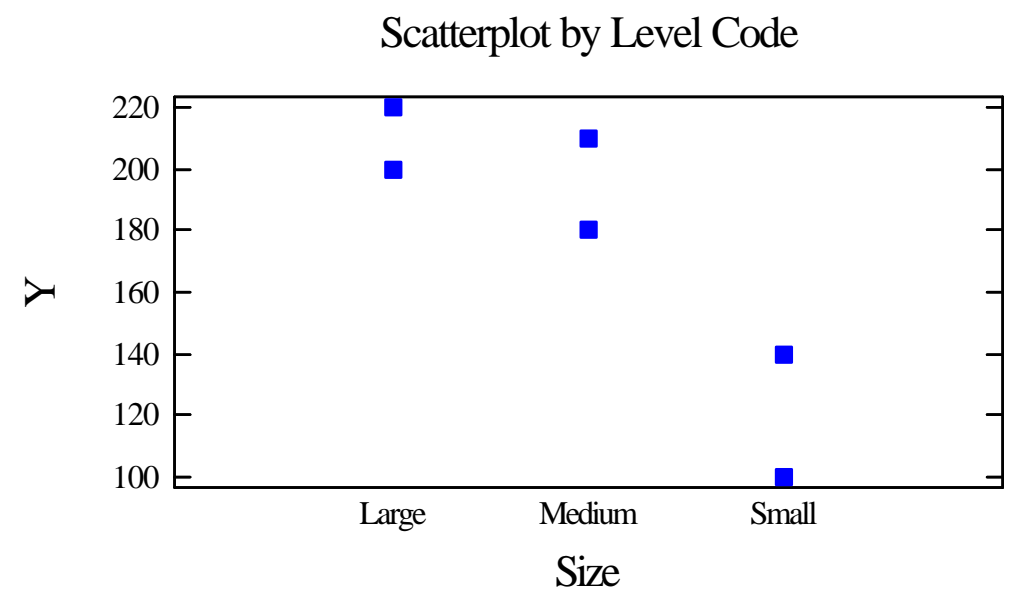

\section{Analysis of Variance for $\mathbf{Y}$}

Type III Sums of Squares

\begin{tabular}{|c|c|c|c|c|c|}
\hline Source & Sum of Squares & Df & Mean Square & F-Ratio & P-Value \\
\hline \multicolumn{6}{|l|}{ MAIN EFFECTS } \\
\hline A:Size & 9300.0 & 2 & 4650.0 & 93.00 & 0.0106 \\
\hline B:Region & 1350.0 & 1 & 1350.0 & 27.00 & 0.0351 \\
\hline RESIDUAL & 100.0 & 50.0 & & & \\
\hline TOTAL (CORRECTED) & 10750.0 & 5 & & & \\
\hline
\end{tabular}

All F-ratios are based on the residual mean square error. 
Appendix E: Statgraphics Results

Exhibit E.5: Statgraphics Output for Table 10 Data using Two Factor ANOVA (continued)

Means and 95.0 Percent LSD Intervals

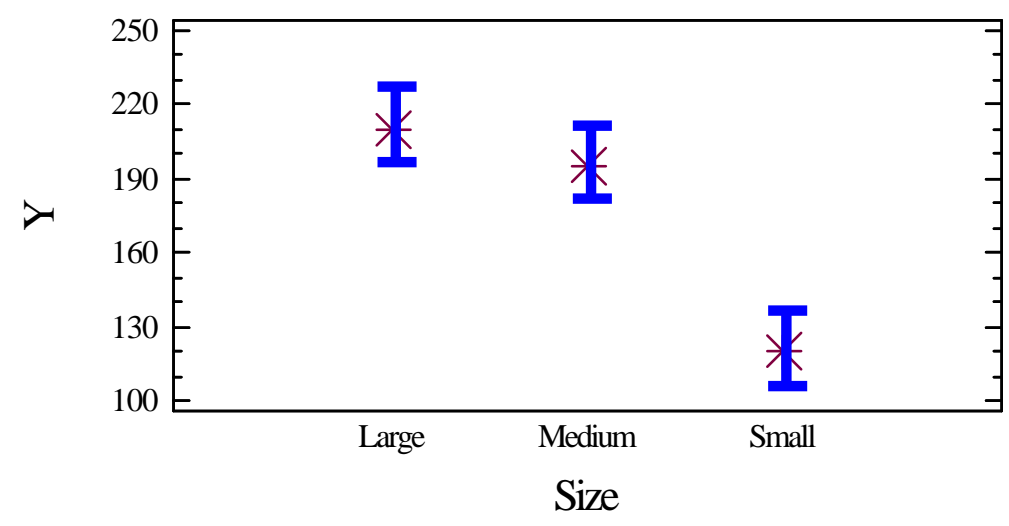

\section{Table of Least Squares Means for $Y$ with 95.0 Percent} Confidence Intervals

\begin{tabular}{|c|c|c|c|c|c|c|c|c|}
\hline \multirow[b]{2}{*}{ Level } & & \multirow[b]{2}{*}{ Count } & \multirow{2}{*}{$\begin{array}{l}\text { Stnd. } \\
\text { Mean }\end{array}$} & \multirow[b]{2}{*}{ Error } & \multirow[t]{2}{*}{ Lower } & \multicolumn{3}{|c|}{ Upper } \\
\hline & & & & & & Limit & & Limit \\
\hline GRAND MEAN & & 6 & 175.0 & & & & & \\
\hline \multicolumn{9}{|l|}{ Size } \\
\hline Large & & 2 & 210.0 & 5.0 & 188.487 & & 231.513 & \\
\hline Medium & 2 & 195.0 & 5.0 & 173.487 & & 216.513 & & \\
\hline Small & & 2 & 120.0 & 5.0 & 98.4867 & & 141.513 & \\
\hline \multicolumn{9}{|l|}{ Region } \\
\hline East & & 3 & 190.0 & 4.08248 & & 172.434 & & 207.566 \\
\hline West & & 3 & 160.0 & 4.08248 & & 142.434 & & 177.566 \\
\hline
\end{tabular}

\section{Multiple Range Tests for Y by Size}

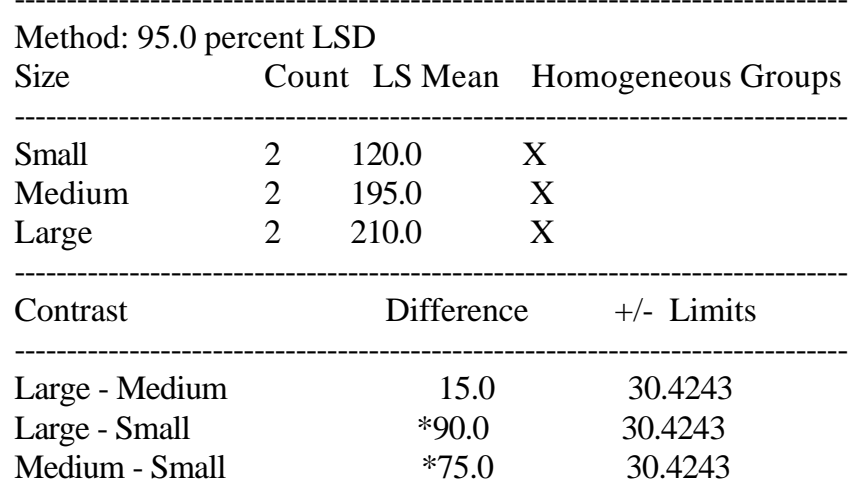

* denotes a statistically significant difference. 
Appendix E: Statgraphics Results

Exhibit E.6: Statgraphics Output for Table 13 Data using a Nested Model

General Linear Models

Number of dependent variables: 1

Number of categorical factors: 2

Number of quantitative factors: 0

\section{Analysis of Variance for $Y$}

\begin{tabular}{|c|c|c|c|c|c|}
\hline Source & Sum of Squares & Df & Mean Square & & F-Ratio \\
\hline Model & 724.0 & 5 & 144.8 & 20.69 & 0.0010 \\
\hline Residual & 42.0 & 6 & 7.0 & & \\
\hline Total (Corr.) & 766.0 & 11 & & & \\
\hline
\end{tabular}

\section{Type III Sums of Squares}

\begin{tabular}{lcccccc}
\hline Source & Sum of Squares & Df & Mean Square & \multicolumn{2}{c}{ F-Ratio } & P-Value \\
School & 156.5 & 2 & 78.25 & & 11.18 & 0.0095 \\
Instructor(School) & 567.5 & 3 & 189.167 & 27.02 & 0.0007 & \\
Residual & 42.0 & 6 & 7.0 & & &
\end{tabular}

Total (corrected) $\quad 766.0 \quad 11$

All F-ratios are based on the residual mean square error.

R-Squared $=94.517$ percent

R-Squared (adjusted for d.f.) $=89.9478$ percent

Standard Error of Est. $=2.64575$

Mean absolute error $=1.83333$

Durbin-Watson statistic $=1.89881$ 
Appendix E: Statgraphics Results

Exhibit E.6: Statgraphics Output for Table 13 Data using a Nested Model (continued)

Scatterplot for Y

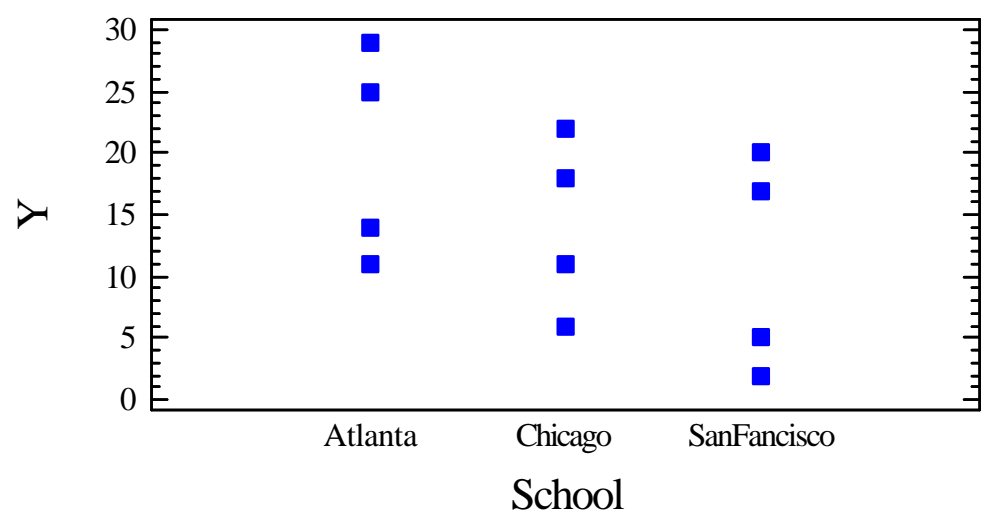

\section{0\% confidence intervals for coefficient estimates ( $(Y)$}

\begin{tabular}{lcccccc} 
& \multicolumn{3}{c}{ Standard } & & & \\
Parameter & Estimate & Error & Lower Limit & Upper Limit & V.I.F. \\
\hline CONSTANT & 15.0 & 0.763763 & 13.1311 & 16.8689 & \\
School & 4.75 & 1.08012 & 2.10703 & 7.39297 & 1.33333 & \\
School & -0.75 & 1.08012 & -3.39297 & 1.89297 & 1.33333 & \\
Instructor(School) & 7.25 & 1.32288 & 4.01303 & 10.487 & 1.0 \\
Instructor(School) & -5.75 & 1.32288 & -8.98697 & -2.51303 & 1.0 \\
Instructor(School) & 7.5 & 1.32288 & 4.26303 & 10.737 & 1.0 \\
- & & &
\end{tabular}

Means and 95.0 Percent LSD Intervals

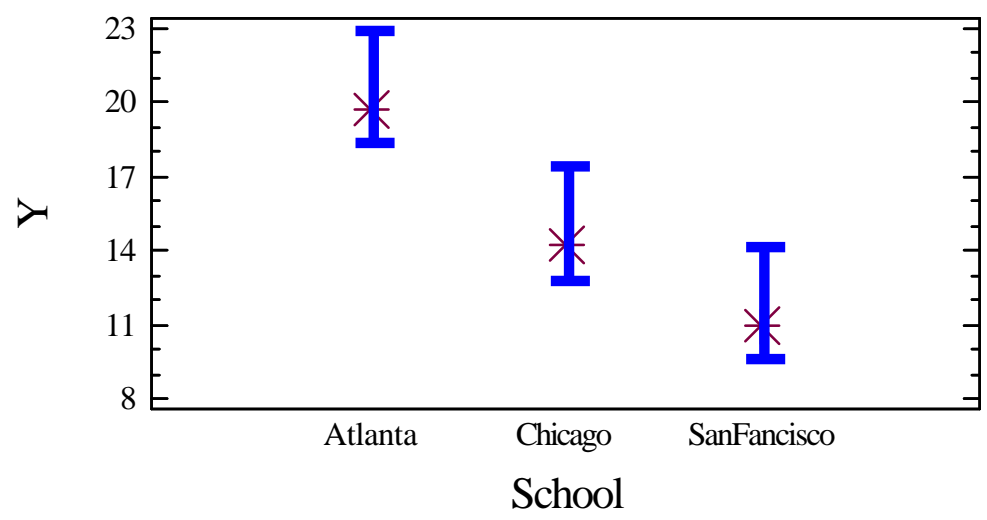


Appendix E: Statgraphics Results

Exhibit E.6: Statgraphics Output for Table 13 Data using a Nested Model (continued)

\section{Table of Least Squares Means for $Y$ with 95.0 Percent Confidence Intervals}

\begin{tabular}{|c|c|c|c|c|c|c|c|c|}
\hline \multicolumn{2}{|c|}{ Level } & Count & Mean & Stnd. & Error & Lower & $\begin{array}{l}\text { Upper } \\
\text { Limit }\end{array}$ & \multirow[t]{2}{*}{ Limit } \\
\hline \multicolumn{2}{|c|}{ GRAND MEAN } & & 12 & 15.0 & 0.763763 & 313.1311 & 16.8689 & \\
\hline \multicolumn{9}{|c|}{ School } \\
\hline & & & 4 & 19.75 & 1.32288 & & 16.513 & 22.987 \\
\hline & go & & 4 & 14.25 & 1.32288 & & 11.013 & 17.487 \\
\hline & ancisco & & 4 & 11.0 & 1.32288 & & 7.76303 & 14.237 \\
\hline \multicolumn{9}{|c|}{ Instructor within School } \\
\hline 1 & Atlanta & & 2 & 27.0 & 1.87083 & & 22.4222 & 31.5778 \\
\hline 1 & Chicago 2 & 2 & 8.5 & 1.87083 & & 3.92224 & 13.0778 & \\
\hline 1 & SanFancisc & & 2 & 18.5 & 1.87083 & & 13.9222 & 23.0778 \\
\hline 2 & Atlanta & & 2 & 12.5 & 1.87083 & & 7.92224 & 17.0778 \\
\hline 2 & Chicago 2 & 2 & 20.0 & 1.87083 & & 15.4222 & 24.5778 & \\
\hline 2 & SanFancisc & & 2 & 3.5 & 1.87083 & & -1.07776 & 8.07776 \\
\hline
\end{tabular}

\section{Multiple Comparisons for Y by School}

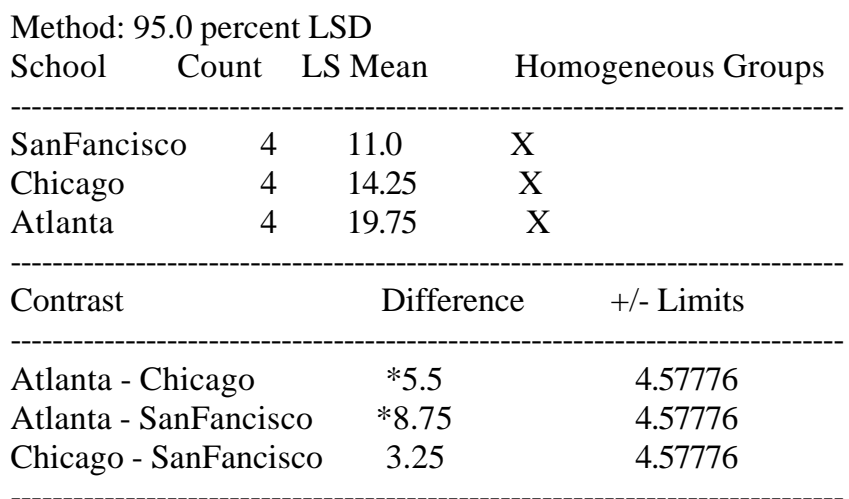

* denotes a statistically significant difference. 
Appendix E: Statgraphics Results

Exhibit E.7: Statgraphics Output for Table 13 Data using Variance Component Analysis

Dependent variable: $\mathrm{Y}$

Factors:

School

Instructor

Number of complete cases: 12

\section{Analysis of Variance for $\mathbf{Y}$}

\begin{tabular}{|c|c|c|c|c|c|}
\hline Source & Sum of Squares & Df & Mean Squa & & Var. Comp. Percent \\
\hline TOTAL (CORRECTED) & 766.0 & 11 & & & \\
\hline School & 156.5 & 2 & 78.25 & 0.0 & 0.00 \\
\hline Instructor & 567.5 & 3 & 189.167 & 91.0833 & 92.86 \\
\hline ERROR & 42.0 & 6 & 7.0 & 7.0 & 7.14 \\
\hline
\end{tabular}

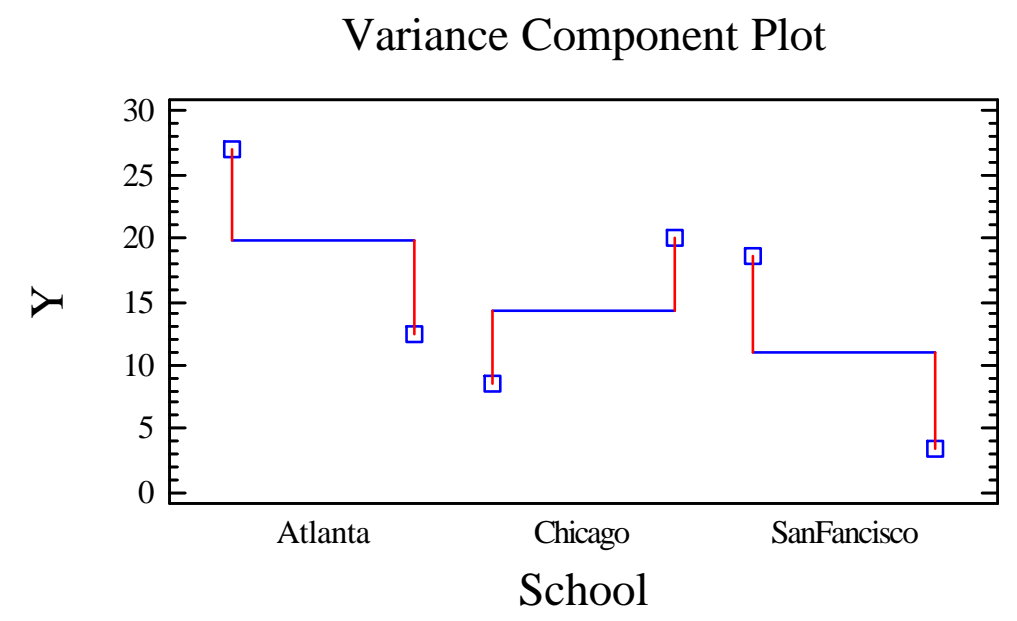

Y

\begin{tabular}{lccc} 
& & \multicolumn{2}{c}{ Standard } \\
Level & Count & Mean & Deviation \\
\hline GRAND MEAN & 12 & 15.0 & 8.34484
\end{tabular}

School

Atlanta

Chicago

SanFancisco

$\begin{array}{lll}4 & 19.75 & 8.61684 \\ 4 & 14.25 & 7.13559 \\ 4 & 11.0 & 8.83176\end{array}$


Appendix E: Statgraphics Results

Exhibit E.7: Statgraphics Output for Table 13 Data using Variance Component Analysis (continued)

$\begin{array}{lrrr}\text { Instructor } & & & \\ 1 & 2 & 27.0 & 2.82843 \\ 2 & 2 & 12.5 & 2.12132 \\ 1 & 2 & 8.5 & 3.53553 \\ 2 & 2 & 20.0 & 2.82843 \\ 1 & 2 & 18.5 & 2.12132 \\ 2 & 2 & 3.5 & 2.12132\end{array}$


Appendix E: Statgraphics Results

Exhibit E.8: Statgraphics Output for Fractional Factorial Design

Screening Design Attributes

\section{Design Summary}

Design class: Screening

Design name: Quarter fraction

Base Design

Number of experimental factors: 6

Number of responses: 1

Number of runs: 16

Number of blocks: 1

Randomized: No

Error degrees of freedom: 2

\begin{tabular}{lccc} 
Factors & Low & High & Continuous \\
\hline X1 & -1.0 & 1.0 & Yes \\
X4 & -1.0 & 1.0 & Yes \\
X3 & -1.0 & 1.0 & Yes \\
X2 & -1.0 & 1.0 & Yes \\
X6 & -1.0 & 1.0 & Yes \\
X5 & -1.0 & 1.0 & Yes
\end{tabular}

\begin{tabular}{|r|r|r|r|r|r|r|}
\hline Run & X1 & X2 & X3 & X4 & X5 & X6 \\
\hline 1 & -1 & -1 & -1 & -1 & -1 & -1 \\
\hline 2 & -1 & -1 & -1 & 1 & 1 & 1 \\
\hline 3 & -1 & -1 & 1 & -1 & 1 & 1 \\
\hline 4 & -1 & -1 & 1 & 1 & -1 & -1 \\
\hline 5 & -1 & 1 & -1 & -1 & 1 & -1 \\
\hline 6 & -1 & 1 & -1 & 1 & -1 & 1 \\
\hline 7 & -1 & 1 & 1 & -1 & -1 & 1 \\
\hline 8 & -1 & 1 & 1 & 1 & 1 & -1 \\
\hline 9 & 1 & -1 & -1 & -1 & -1 & 1 \\
\hline 10 & 1 & -1 & -1 & 1 & 1 & -1 \\
\hline 11 & 1 & -1 & 1 & -1 & 1 & -1 \\
\hline 12 & 1 & -1 & 1 & 1 & -1 & 1 \\
\hline 13 & 1 & 1 & -1 & -1 & 1 & 1 \\
\hline 14 & 1 & 1 & -1 & 1 & -1 & -1 \\
\hline 15 & 1 & 1 & 1 & -1 & -1 & -1 \\
\hline 16 & 1 & 1 & 1 & 1 & 1 & 1 \\
\hline
\end{tabular}

Exhibit E.8: Statgraphics Output for Fractional Factorial Design 
Appendix E: Statgraphics Results

(continued)

Alias Structure
Contrast Estimates
$\begin{array}{ll}\text { C----- } \\ 1 & \mathrm{~A} \\ 2 & \mathrm{~B} \\ 3 & \mathrm{C} \\ 4 & \mathrm{D} \\ 5 & \mathrm{E} \\ 6 & \mathrm{~F} \\ 7 & \mathrm{AB}+\mathrm{CE} \\ 8 & \mathrm{AC}+\mathrm{BE} \\ 9 & \mathrm{AD}+\mathrm{EF} \\ 10 & \mathrm{AE}+\mathrm{BC}+\mathrm{DF} \\ 11 & \mathrm{AF}+\mathrm{DE} \\ 12 & \mathrm{BD}+\mathrm{CF} \\ 13 & \mathrm{BF}+\mathrm{CD}\end{array}$


Appendix E: Statgraphics Results

Exhibit E.9: Statgraphics Output for Extreme Vertices

Design Summary

Design class: Mixture

Design name: Extreme vertices

Base Design

Number of components: 3

Number of responses: 1

Number of runs: 6

Model type: Linear

Randomized: Yes

\begin{tabular}{lccc} 
Components & Low & High & Units \\
\hline X1 & 0.2 & 0.6 & \\
X2 & 0.1 & 0.6 & \\
X3 & 0.1 & 0.5
\end{tabular}

Mixture total $=1.0$

\begin{tabular}{|r|r|r|r|}
\hline \multicolumn{1}{|c|}{ Run } & \multicolumn{1}{|c|}{ X1 } & \multicolumn{1}{|c|}{ X2 } & \multicolumn{1}{c|}{ X3 } \\
\hline 1 & 0.6 & 0.3 & 0.1 \\
\hline 2 & 0.6 & 0.1 & 0.3 \\
\hline 3 & 0.3 & 0.6 & 0.1 \\
\hline 4 & 0.2 & 0.6 & 0.2 \\
\hline 5 & 0.4 & 0.1 & 0.5 \\
\hline 6 & 0.2 & 0.3 & 0.5 \\
\hline
\end{tabular}


Appendix E: Statgraphics Results

Exhibit E.10: Statgraphics D-Optimality Results

\section{Optimize Experiment}

Selection criterion: D-optimality

Desired number of runs: 8

Selection method: Forward

Model order: 1

Number of runs already completed: 0

Additional candidate runs: 20

\section{D-optimal Design}

Design has been reduced to 8 runs.

D-efficiency $=100.0 \%$

A-efficiency $=100.0 \%$

G-efficiency $=100.0 \%$

\begin{tabular}{|c|c|c|c|c|}
\hline Select & Condition & X1 & $\mathbf{X} 2$ & $\mathbf{X 3}$ \\
\hline$*$ & 1 & -1 & -1 & 1 \\
\hline & 2 & $\mathbf{0}$ & $\mathbf{0}$ & $\mathbf{0}$ \\
\hline$*$ & 3 & 1 & -1 & 1 \\
\hline & 4 & $\mathbf{0}$ & 1 & 0 \\
\hline$*$ & 5 & 1 & 1 & 1 \\
\hline & 6 & $\mathbf{0}$ & $\mathbf{0}$ & 0 \\
\hline & 7 & $\mathbf{0}$ & $\mathbf{0}$ & 0 \\
\hline * & 8 & 1 & -1 & -1 \\
\hline$*$ & 9 & -1 & 1 & 1 \\
\hline & 10 & $\mathbf{0}$ & $\mathbf{0}$ & -1 \\
\hline$*$ & 11 & -1 & 1 & -1 \\
\hline & 12 & -1 & 0 & 0 \\
\hline & 13 & 0 & 0 & 1 \\
\hline & 14 & $\mathbf{0}$ & $\mathbf{0}$ & 0 \\
\hline & 15 & $\mathbf{0}$ & $\mathbf{0}$ & $\mathbf{0}$ \\
\hline & 16 & $\mathbf{0}$ & -1 & 0 \\
\hline$*$ & 17 & -1 & -1 & -1 \\
\hline & 18 & $\mathbf{0}$ & 0 & 0 \\
\hline & 19 & 1 & 0 & $\mathbf{0}$ \\
\hline$*$ & 20 & 1 & 1 & -1 \\
\hline
\end{tabular}

* indicates a run selected to achieve D-optimality 
Appendix E: Statgraphics Results

Exhibit E.11: Statgraphics X-bar and S Charts - X

Initial Study for $\mathrm{X}$

Number of subgroups $=20$

Average subgroup size $=4.0$

0 subgroups excluded

\section{X-bar Chart}

UCL: +3.0 sigma $=82.0667$

Centerline $=59.4375$

LCL: -3.0 sigma $=36.8083$

\section{S Chart}

UCL: +3.0 sigma $=31.496$

Centerline $=13.8991$

LCL: -3.0 sigma $=0.0$

\section{Estimates}

Process mean $=59.4375$

Process sigma $=15.0861$

Mean sigma $=13.8991$

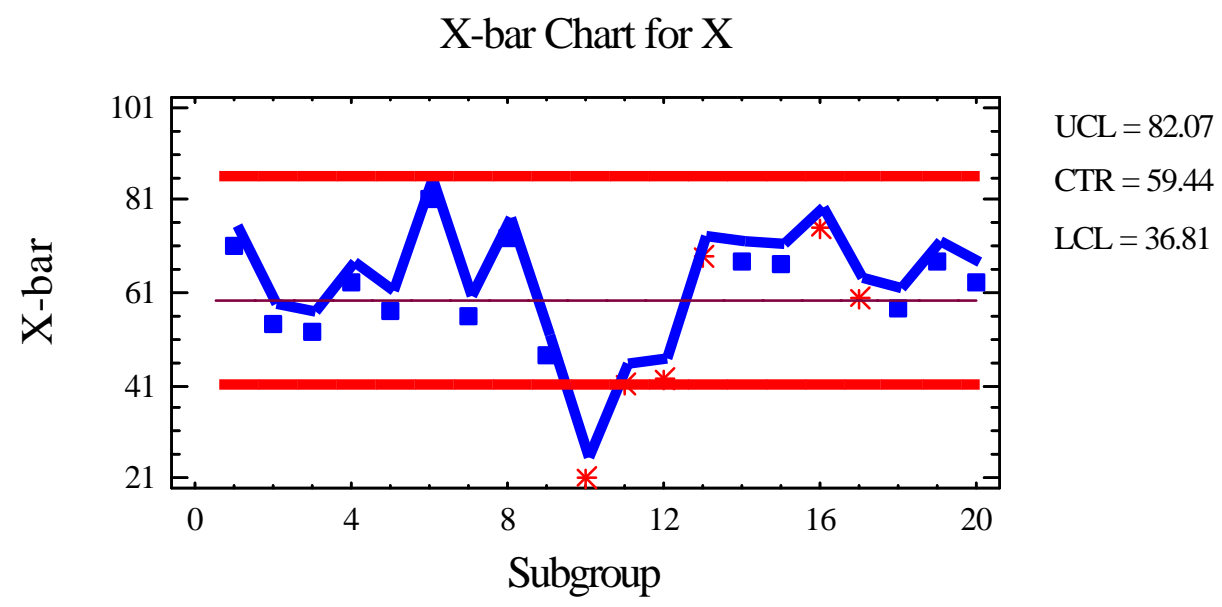


Appendix E: Statgraphics Results

Exhibit E.11: Statgraphics X-bar and S Charts - X

(continued)

\section{Subgroup Reports}

\begin{tabular}{|c|c|c|c|}
\hline \multicolumn{4}{|c|}{ All Subgroups } \\
\hline Subgroup & Size & X-bar & $\mathbf{S}$ \\
\hline 1 & 4 & 71.0 & 15.4704 \\
\hline 2 & 4 & 54.5 & 23.6432 \\
\hline 3 & 4 & 52.5 & 21.7025 \\
\hline 4 & 4 & 63.0 & 16.8523 \\
\hline 5 & 4 & 57.25 & 29.6802 \\
\hline 6 & 4 & 81.25 & 13.2759 \\
\hline 7 & 4 & 56.0 & 8.04156 \\
\hline 8 & 4 & 72.75 & 17.2313 \\
\hline 9 & 4 & 47.75 & 6.70199 \\
\hline 10 & 4 & $* 21.25$ & 11.3541 \\
\hline 11 & 4 & 41.25 & 11.5289 \\
\hline 12 & 4 & 42.5 & 15.7586 \\
\hline 13 & 4 & 69.0 & 16.8721 \\
\hline 14 & 4 & 67.75 & 11.5289 \\
\hline 15 & 4 & 67.0 & 6.0553 \\
\hline 16 & 4 & 75.0 & 12.7279 \\
\hline 17 & 4 & 59.75 & 9.97914 \\
\hline 18 & 4 & 57.75 & 12.4197 \\
\hline 19 & 4 & 68.0 & 9.83192 \\
\hline 20 & 4 & 63.5 & 7.32575 \\
\hline
\end{tabular}

S Chart for X

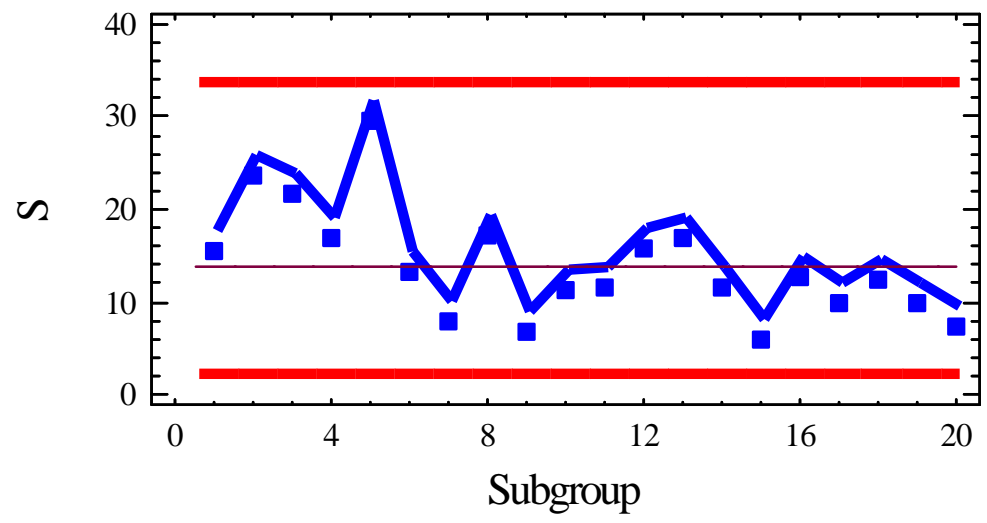

$\begin{aligned} \mathrm{UCL} & =31.50 \\ \mathrm{CTR} & =13.90 \\ \mathrm{LCL} & =0.00\end{aligned}$ 
Appendix F: JMP Version 4.0 Results

Table F.1: JMP Version 4.0 Sample Statistics for Data from Table 20

\begin{tabular}{|cccc|}
\hline Subgroup & N Rows & Mean(x) & Std Dev(x) \\
1 & 4 & 71 & 15.4704 \\
2 & 4 & 54.5 & 23.64318 \\
3 & 4 & 52.5 & 21.70253 \\
4 & 4 & 63 & 16.8523 \\
5 & 4 & 57.25 & 29.68024 \\
6 & 4 & 81.25 & 13.27592 \\
7 & 4 & 56 & 8.041559 \\
8 & 4 & 72.75 & 17.23127 \\
9 & 4 & 47.75 & 6.70199 \\
10 & 4 & 21.25 & 11.35415 \\
11 & 4 & 41.25 & 11.52895 \\
12 & 4 & 42.5 & 15.7586 \\
13 & 69 & 16.87207 \\
14 & 4 & 67.75 & 11.52895 \\
15 & 4 & 67 & 6.055301 \\
16 & 4 & 75 & 12.72792 \\
17 & 4 & 59.75 & 9.979145 \\
18 & 4 & 57.75 & 12.41974 \\
19 & 4 & 68 & 9.831921 \\
20 & 4 & 63.5 & 7.325754 \\
\hline
\end{tabular}




\section{Appendix F: JMP Version 4.0 Results}

Exhibit F.1: JMP Version 4.0 Output for Descriptive Statistics of Lot Size Information in Table 2

\section{Distributions \\ Lot Size (Xi)}

\begin{tabular}{|l|l|}
\hline & \\
\hline
\end{tabular}

\section{Moments}

$\begin{array}{lr}\text { Mean } & 50.00000 \\ \text { Std Dev } & 19.43651 \\ \text { Std Err Mean } & 6.14636 \\ \text { upper 95\% Mean } & 63.90416 \\ \text { lower 95\% Mean } & 36.09584 \\ \mathrm{~N} & 10.00000\end{array}$

\section{Stem and Leaf}

$\begin{array}{rrrr}\text { Stem Leaf } & \text { Count } \\ 8 & & \\ 8 & 0 & 1 \\ 7 & & \\ 7 & 0 & 1 \\ 6 & & \\ 6 & 000 & 3 \\ 5 & & \\ 5 & 0 & 1 \\ 4 & & \\ 4 & 0 & 1 \\ 3 & & \\ 3 & 00 & 2 \\ 2 & & \\ 2 & 0 & 1\end{array}$

Overlay Plot

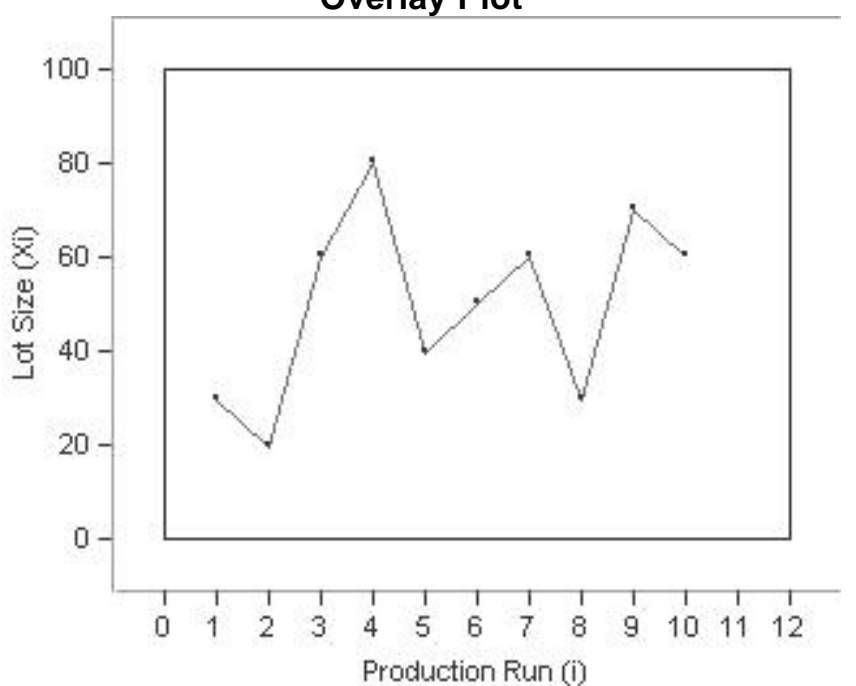

Note: There are several ways to determine estimates of quantiles. JMP computes them as follows [14]

"To compute the Pth quantile of $\mathrm{N}$ nonmissing values in a column, arrange the $\mathrm{N}$ values in ascending order and call these column values $y_{1}, y_{2}, \ldots y_{N}$. Compute the rank number for the Pth quantile as $\frac{P}{100}(N+1)$

If the result is an integer, the Pth quantile is that rank's corresponding value. If the result is not an integer, the Pth quantile is found by interpolation. Denote the integer portion of the computed rank number as I and the fractional portion as $\mathrm{f}$. The Pth quantile, denoted $q_{P}$, is computed $q_{P}=(1-f) y_{I}+(f) y_{I+1}$ 
Appendix F: JMP Version 4.0 Results

Revision 1

If $\mathrm{I}=\mathrm{N}$, then $\mathrm{y}_{\mathrm{N}}$ is taken as the quantile." 
Appendix F: JMP Version 4.0 Results

Exhibit F.2: JMP Version 4.0 Output for Regression Model for Information in Table 2 Using Fit Y by X

\section{Bivariate Fit of Man-Hours (Yi) By Lot Size (Xi)}

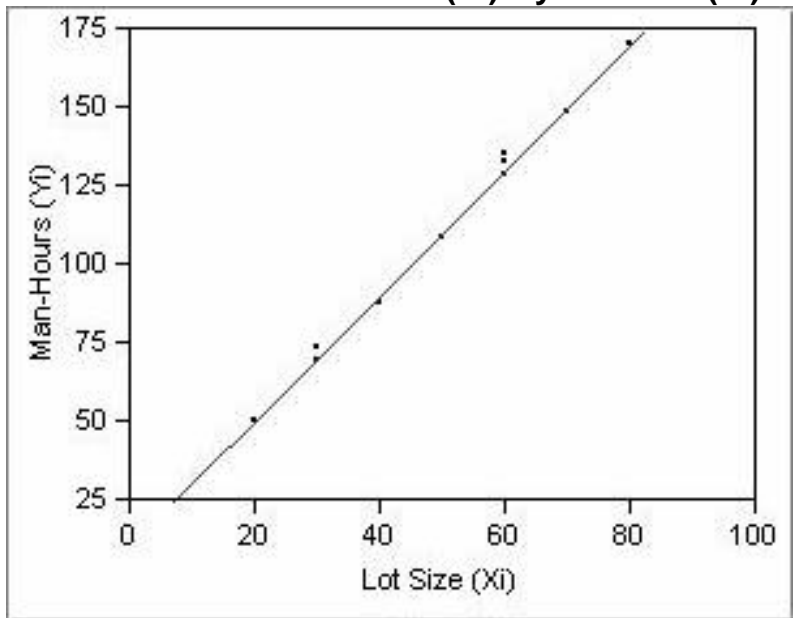

Linear Fit

\section{Linear Fit}

Man-Hours $(Y i)=10+2$ Lot Size $(X i)$

\section{Summary of Fit}

RSquare

RSquare Adj

Root Mean Square Error

Mean of Response

Observations (or Sum Wgts)
0.995608

0.995059

2.738613

110

Analysis of Variance

Source

Model

Error

C. Total

DF

1

8

9

\section{Parameter Estimates}

Term

Intercept

Lot Size (Xi)
Sum of Squares 13600.000

60.000

13660.000

$$
\begin{array}{rr}
\text { Mean Square } & \text { F Ratio } \\
13600.0 & 1813.333 \\
7.5 & \text { Prob }>\text { F } \\
& <.0001
\end{array}
$$

$\begin{array}{rr}t \text { Ratio } & \text { Prob }>|t| \\ 4.00 & 0.0040 \\ 42.58 & <.0001\end{array}$


Appendix F: JMP Version 4.0 Results

Exhibit F.3: JMP Version 4.0 Output for Regression Model for Information in Table 2 Using Fit Model

\section{Response Man-Hours (Yi) \\ Whole Model \\ Actual by Predicted Plot}

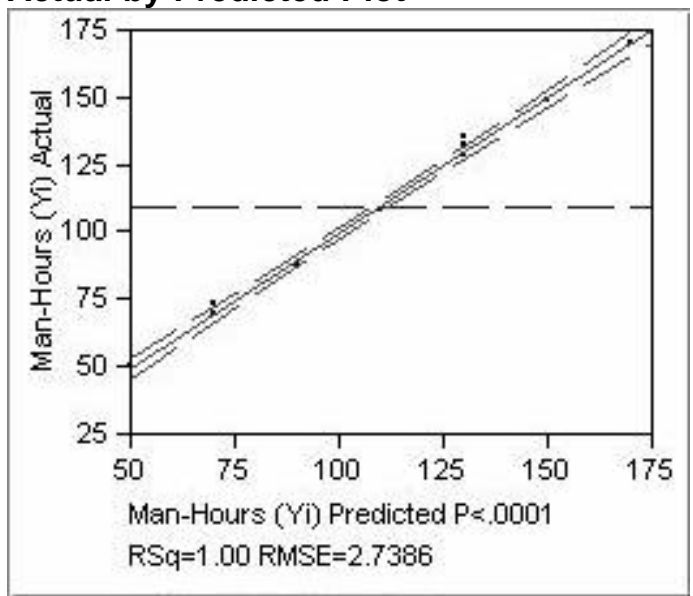

\section{Summary of Fit}

\section{RSquare}

RSquare Adj

Root Mean Square Error

Mean of Response

Observations (or Sum Wgts)

Analysis of Variance

Source

Model

Error

C. Total

Lack Of Fit

Source

Lack Of Fit

Pure Error

Total Error

DF
1
8
9

Sum of Squares 13600.000

60.000

13660.000

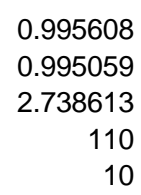

10

$\begin{array}{rr}\text { DF } & \text { Sum of Squares } \\ 5 & 27.333333 \\ 3 & 32.666667 \\ 8 & 60.000000\end{array}$

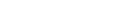

\section{Parameter Estimates}

Term

Intercept

Lot Size (Xi)

Effect Tests

Source

Lot Size (Xi)

.

Estimate

10
2

Nparm DF

11

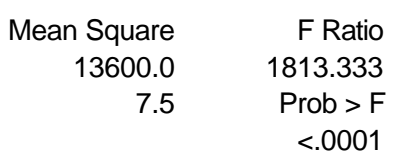

$$
\begin{array}{rr}
\text { Mean Square } & \text { F Ratio } \\
5.4667 & 0.5020 \\
10.8889 & \text { Prob }>\text { F } \\
& 0.7662 \\
& \text { Max RSq } \\
& 0.9976
\end{array}
$$

$$
\begin{array}{rrr}
\text { Std Error } & \text { t Ratio } & \text { Prob }>|t| \\
2.502939 & 4.00 & 0.0040 \\
0.046967 & 42.58 & <.0001
\end{array}
$$

$\begin{array}{rrr}\text { Sum of Squares } & \text { F Ratio } & \text { Prob }>\text { F } \\ 13600.000 & 1813.333 & <.0001\end{array}$


Appendix F: JMP Version 4.0 Results

Exhibit F.3: JMP Version 4.0 Output for Regression Model for Information in Table 2 Using Fit Model (continued)

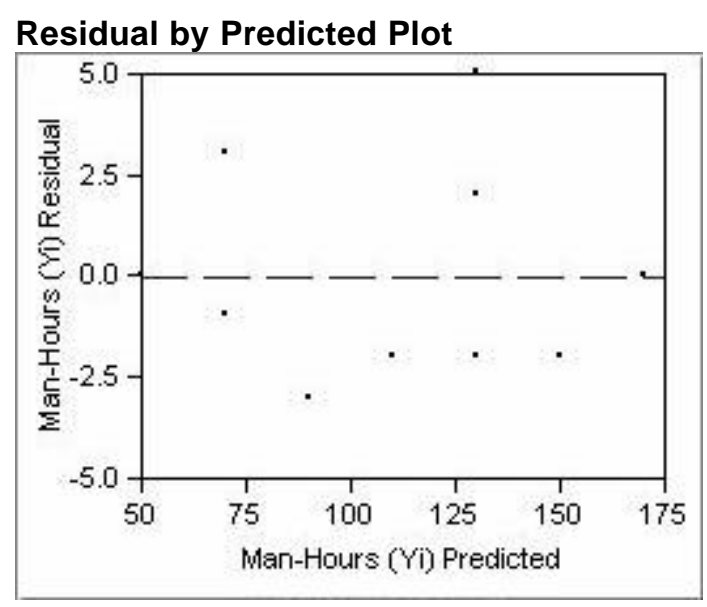

\section{Lot Size (Xi)}

Leverage Plot

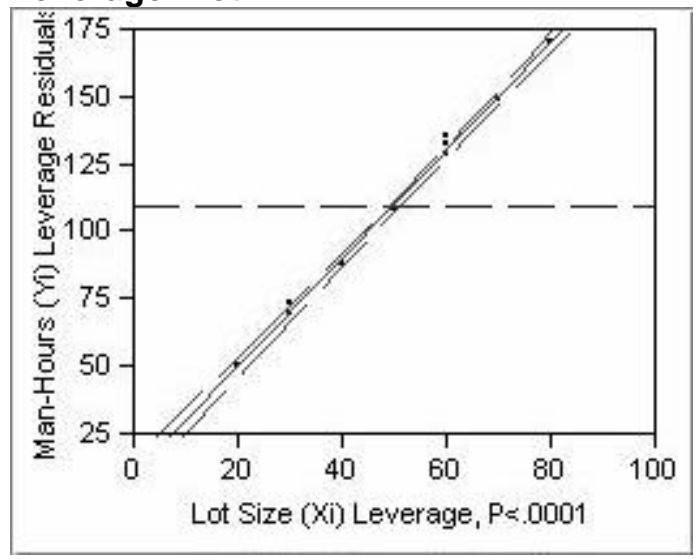


Appendix F: JMP Version 4.0 Results

Exhibit F.4: JMP Version 4.0 Output for ANOVA of Information in Table 5 Using Fit Model

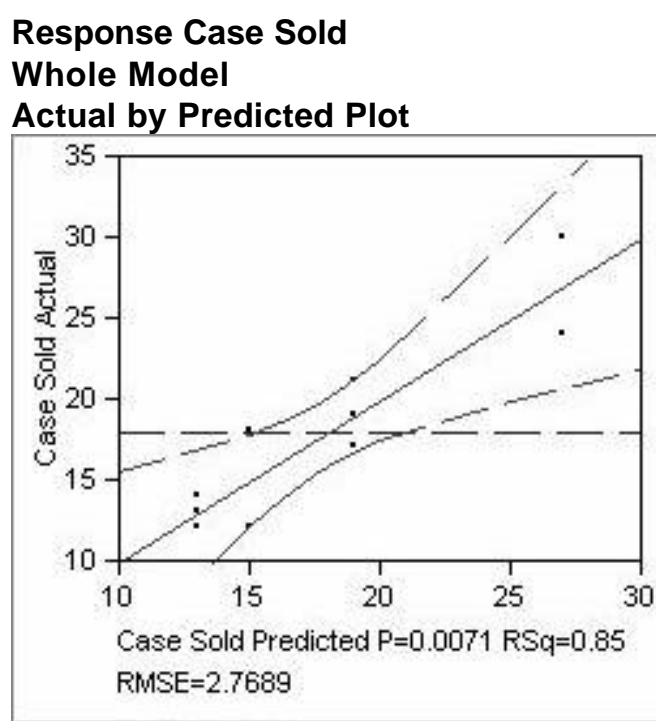

Summary of Fit

RSquare

RSquare Adj

0.848684

Root Mean Square Error

0.773026

Mean of Response

Observations (or Sum Wgts)

Analysis of Variance

$\begin{array}{lr}\text { Source } & \text { DF } \\ \text { Model } & 3 \\ \text { Error } & 6 \\ \text { C. Total } & 9\end{array}$

Parameter Estimates

Term

Intercept

Package Design[1]

Package Design[2]

Package Design[3]

Effect Tests

Source

Package Design

3

DF

3

Residual by Predicted Plot

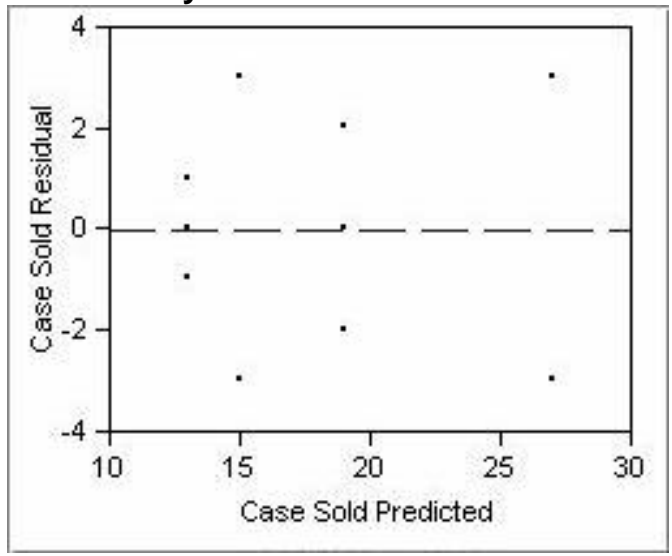

304.00000

Estimate
18.5
-3.5
-5.5
0.5

Mean Square 86.0000 7.6667

F Ratio

11.2174

Prob $>\mathrm{F}$

0.0071

$$
\begin{array}{r}
\text { Std Error } \\
0.89365 \\
1.64781 \\
1.440968 \\
1.440968
\end{array}
$$

Sum of Squares 258.00000

$\begin{array}{rr}\text { t Ratio } & \text { Prob }>|t| \\ 20.70 & <.0001 \\ -2.12 & 0.0778 \\ -3.82 & 0.0088 \\ 0.35 & 0.7404\end{array}$

\section{F Ratio} 11.2174
Prob $>\mathrm{F}$ 0.0071 
Appendix F: JMP Version 4.0 Results

Exhibit F.4: JMP Version 4.0 Output for ANOVA of Information in Table 5 Using Fit Model (continued)

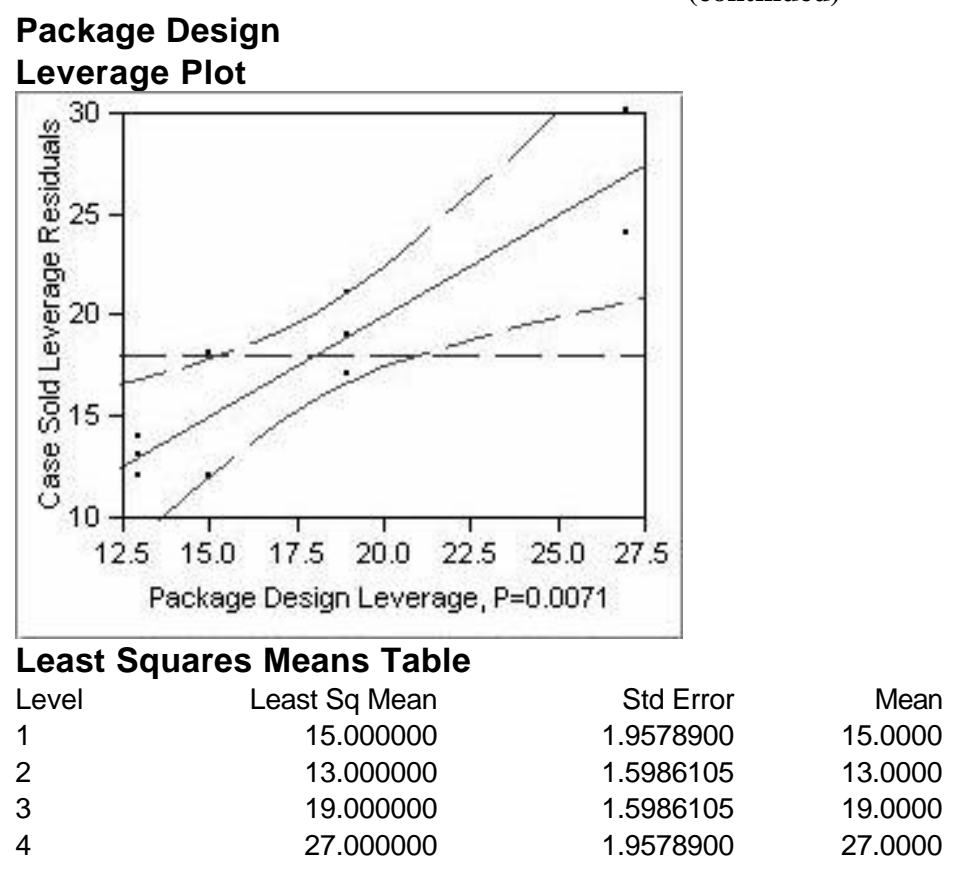




\section{Appendix F: JMP Version 4.0 Results}

\section{Exhibit F.5: JMP Version 4.0 Output for ANOVA of Information in Table 8 Using Fit Model with Random Factor}

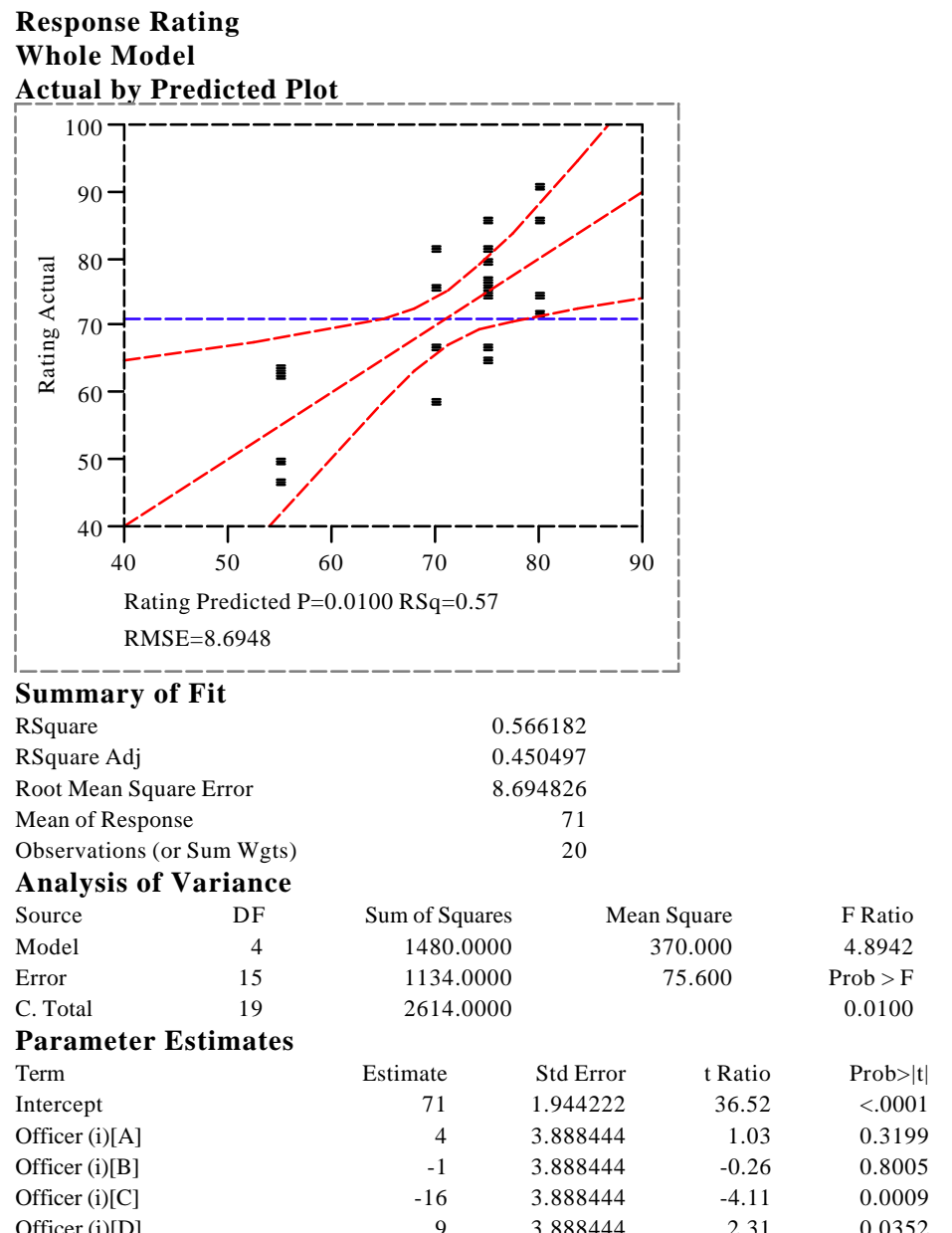

$\begin{array}{lllll}\text { Officer (i)[D] } & 9 & 3.888444 & 2.31 & 0.0352\end{array}$

Expected Mean Squares

The Mean Square per row by the Variance Component per column

$\begin{array}{lrr}\text { EMS } & \text { Intercept } & \text { Officer (i)\&Random } \\ \text { Intercept } & 0 & 0\end{array}$

Officer (i)\&Random

plus 1.0 times Residual Error Variance

Variance Component Estimates

Component Var Comp Est Percent of Total

$\begin{array}{lrr}\text { Officer (i)\&Random } & 73.6 & 49.330\end{array}$

$\begin{array}{lrr}\text { Residual } & 75.6 & 50.670\end{array}$

$\begin{array}{lll}\text { Total } & 149.2 & 100.000\end{array}$

These estimates based on equating Mean Squares to Expected Value.

Test Denominator Synthesis

Source MS Den

DF Den Denom MS Synthesis

Officer (i)\&Random $\quad 75.6 \quad 15$ Residual

Tests wrt Random Effects

Source

Officer (i)\&Random

$\begin{array}{rrrrr}\text { SS } & \text { MS Num } & \text { DF Num } & \text { F Ratio } & \text { Prob > F } \\ 1480 & 370 & 4 & 4.8942 & 0.0100\end{array}$


Appendix F: JMP Version 4.0 Results

Exhibit F.5: JMP Version 4.0 Output for ANOVA of Information in Table 8 Using Fit Model with Random Factor (continued)

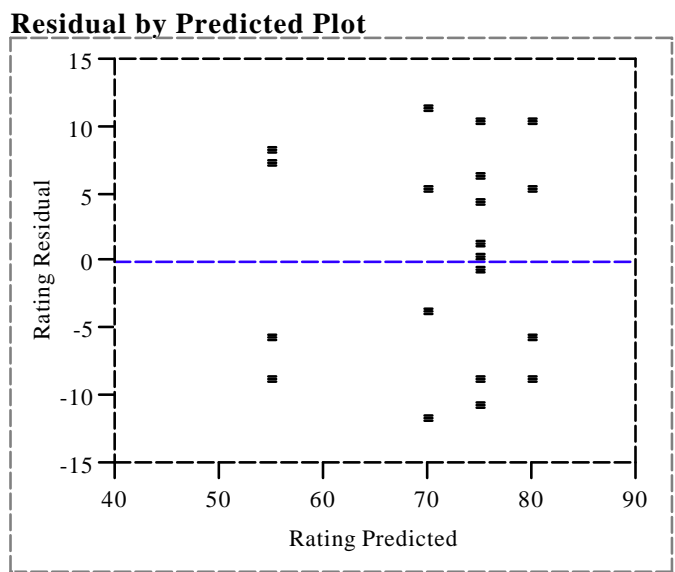

Officer (i)\& Random

Leverage Plot

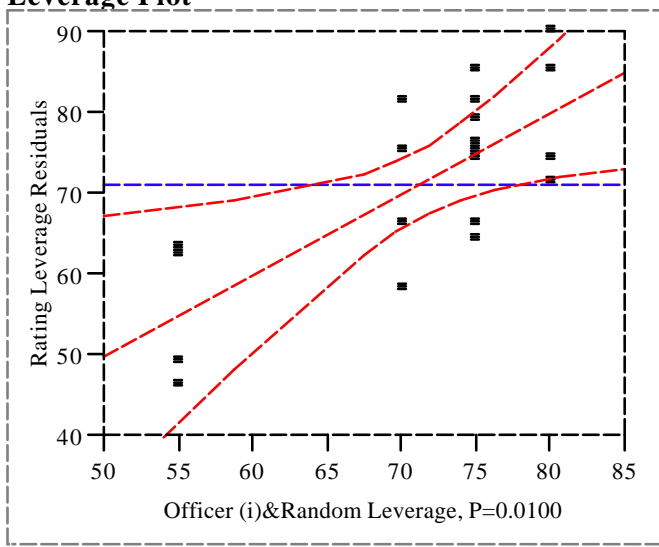

\section{Effect Test}

$$
\begin{array}{rrrr}
\text { Sum of Squares } & \text { F Ratio } & \text { DF } & \text { Prob > F } \\
1480.0000 & 4.8942 & 4 & 0.0100
\end{array}
$$

Denominator MS Synthesis:

Residual

Least Squares Means Table

$\begin{array}{lrrr}\text { Level } & \text { Least Sq Mean } & \text { Std Error } & \text { Mean } \\ \text { A } & 75.000000 & 4.3474130 & 75.0000 \\ \text { B } & 70.000000 & 4.3474130 & 70.0000 \\ \text { C } & 55.000000 & 4.3474130 & 55.0000 \\ \text { D } & 80.000000 & 4.3474130 & 80.0000 \\ \text { E } & 75.000000 & 4.3474130 & 75.0000\end{array}$


Appendix F: JMP Version 4.0 Results

Exhibit F.6: JMP Version 4.0 Output for ANOVA of Information in Table 10 Using Fit Model with Two Factors

Response Premium (\$)

Whole Model

Actual by Predicted Plot

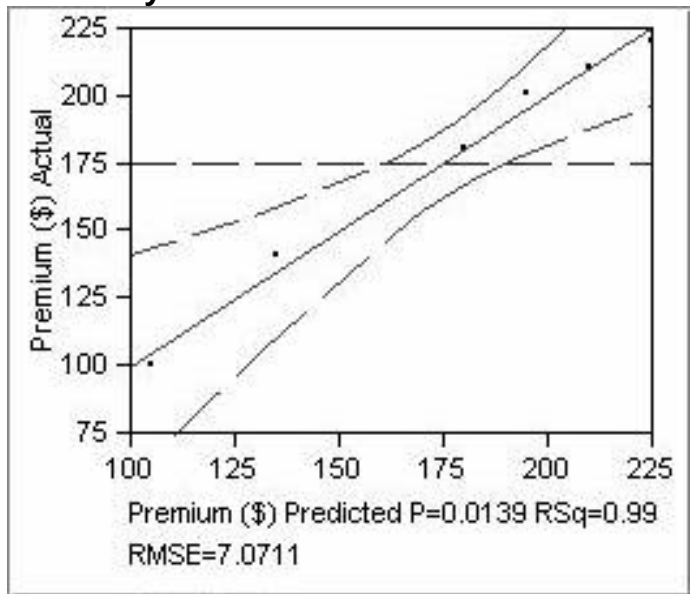

\section{Summary of Fit}

RSquare

RSquare Adj

Root Mean Square Error

Mean of Response

Observations (or Sum Wgts)

Analysis of Variance

$\begin{array}{lr}\text { Source } & \text { DF } \\ \text { Model } & 3 \\ \text { Error } & 2 \\ \text { C. Total } & 5\end{array}$

Parameter Estimates

Term

Intercept

Size of City[Large]

Size of City[Medium]

Region[East]

\section{Effect Tests}

Source

Size of City

Region

DF

3

5

tes

\section{Residual by Predicted Plot}

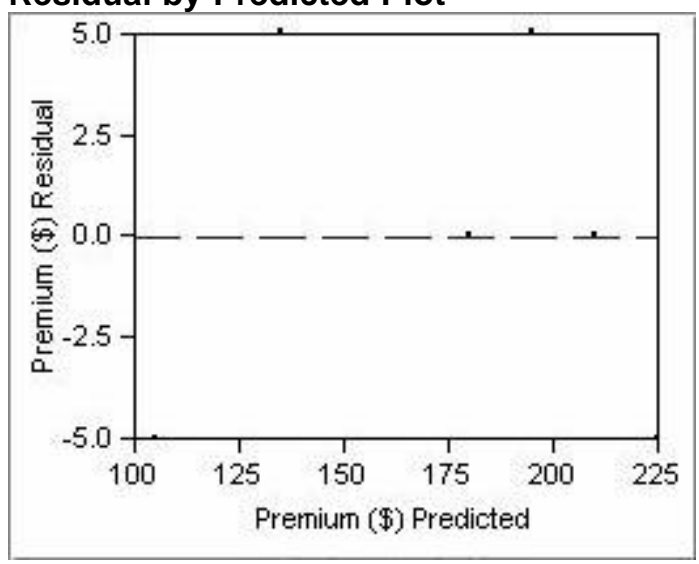

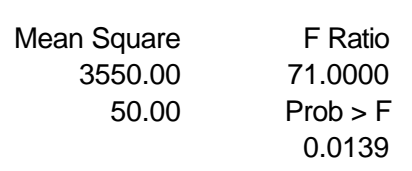

$\begin{array}{lrr}\text { Std Error } & \text { t Ratio } & \text { Prob }>|t| \\ 2.886751 & 60.62 & 0.0003 \\ 4.082483 & 8.57 & 0.0133 \\ 4.082483 & 4.90 & 0.0392 \\ 2.886751 & 5.20 & 0.0351\end{array}$

F Ratio Prob $>$ F

$93.0000 \quad 0.0106$

$27.0000 \quad 0.0351$ 
Appendix F: JMP Version 4.0 Results

Exhibit F.6: JMP Version 4.0 Output for ANOVA of Information in Table 10 Using Fit Model with Two Factors (continued)

Size of City

Leverage Plot

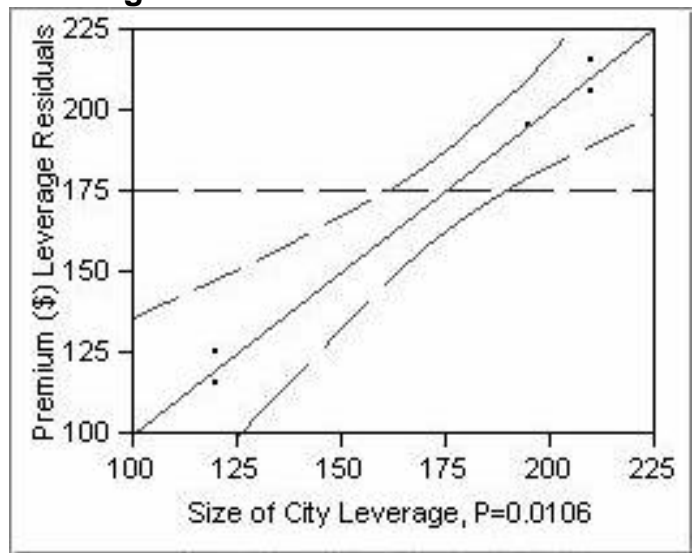

Least Squares Means Table

Level Least Sq Mean

Large $\quad 210.00000$

Medium $\quad 195.00000$

Small $\quad 120.00000$

Region

Leverage Plot

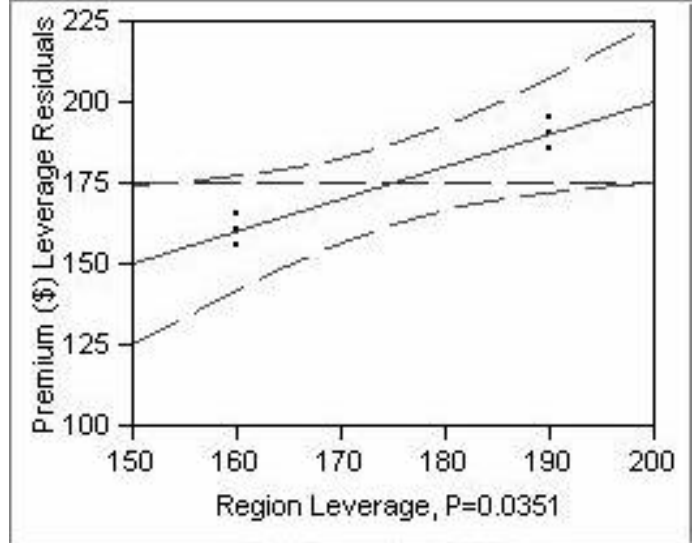

Least Squares Means Table

Level

East

West

Least Sq Mean

190.00000

160.00000

$\begin{array}{rr}\text { Std Error } & \text { Mean } \\ 5.0000000 & 210.000 \\ 5.0000000 & 195.000 \\ 5.0000000 & 120.000\end{array}$

120.000 
Appendix F: JMP Version 4.0 Results

Revision 1

Exhibit F.7: JMP Version 4.0 Output for Nested ANOVA of Information in Table 13 Using Fit Model with A Nested Factor

Response Class Learning Scores (coded)

Whole Model

Actual by Predicted Plot

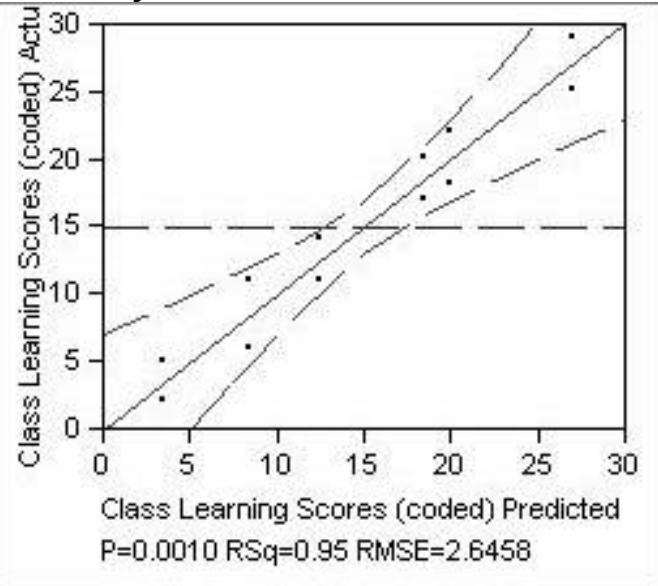

\section{Summary of Fit}

RSquare

RSquare Adj

0.94517

Root Mean Square Error

0.899478

Mean of Response

Observations (or Sum Wgts)

Analysis of Variance

$\begin{array}{lrr}\text { Source } & \text { DF } & \text { Sum of Squares } \\ \text { Model } & 5 & 724.00000 \\ \text { Error } & 6 & 42.00000 \\ \text { C. Total } & 11 & 766.00000\end{array}$

\section{Parameter Estimates}

Term

Intercept

School[Atlanta]

School[Chicago]

School[Atlanta]:Instructor[1]

School[Chicago]:Instructor[1]

School[San Francisco]:Instructor[1]

Effect Tests

Source

School

Instructor[School]

$\begin{array}{rr}\text { Nparm } & \text { DF } \\ 2 & 2 \\ 3 & 3\end{array}$

$$
\begin{array}{rr}
\text { Mean Square } & \text { F Ratio } \\
144.800 & 20.6857 \\
7.000 & \text { Prob > F } \\
& 0.0010
\end{array}
$$

$\begin{array}{rrrr}\text { Estimate } & \text { Std Error } & \mathrm{t} \text { Ratio } & \text { Prob }>|\mathrm{t}| \\ 15 & 0.763763 & 19.64 & <.0001 \\ 4.75 & 1.080123 & 4.40 & 0.0046 \\ -0.75 & 1.080123 & -0.69 & 0.5134 \\ 7.25 & 1.322876 & 5.48 & 0.0015 \\ -5.75 & 1.322876 & -4.35 & 0.0048 \\ 7.5 & 1.322876 & 5.67 & 0.0013\end{array}$

Sum of Squares

156.50000

567.50000
F Ratio
11.1786
27.0238

Prob $>\mathrm{F}$

0.0095

0.0007 
Appendix F: JMP Version 4.0 Results

\section{Residual by Predicted Plot}

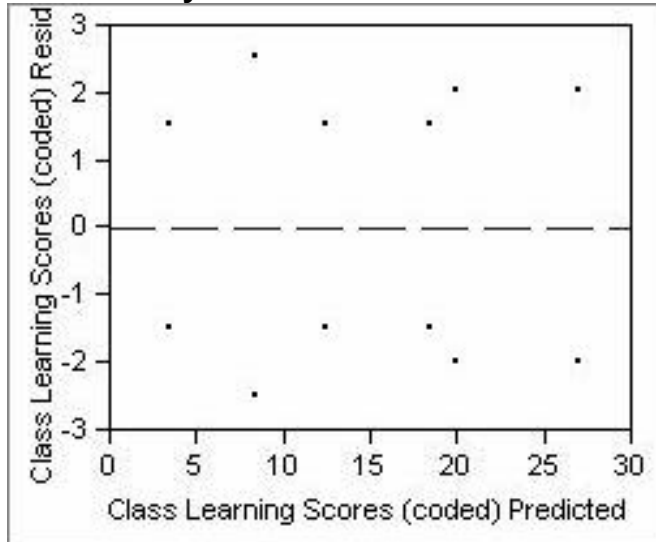


Appendix F: JMP Version 4.0 Results

Exhibit F.7: JMP Version 4.0 Output for Nested ANOVA of Information in Table 13 Using Fit Model with A Nested Factor (continued)

\section{School}

Leverage Plot

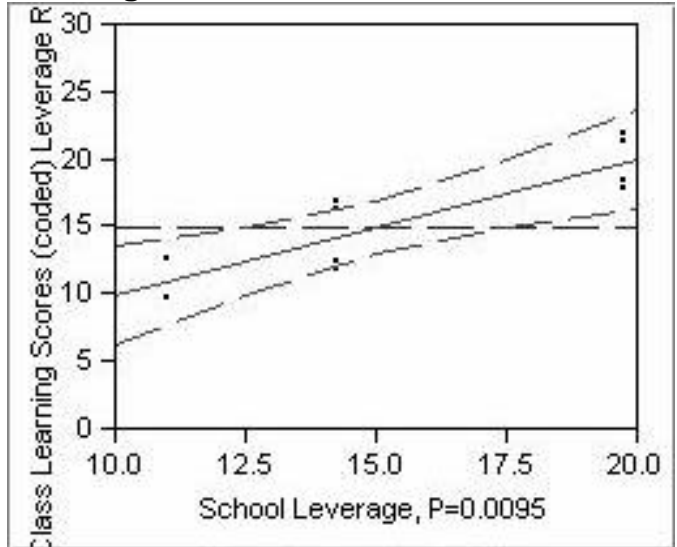

Least Squares Means Table

Level

Atlanta

Chicago

San Francisco

\section{Instructor[School]}

Leverage Plot

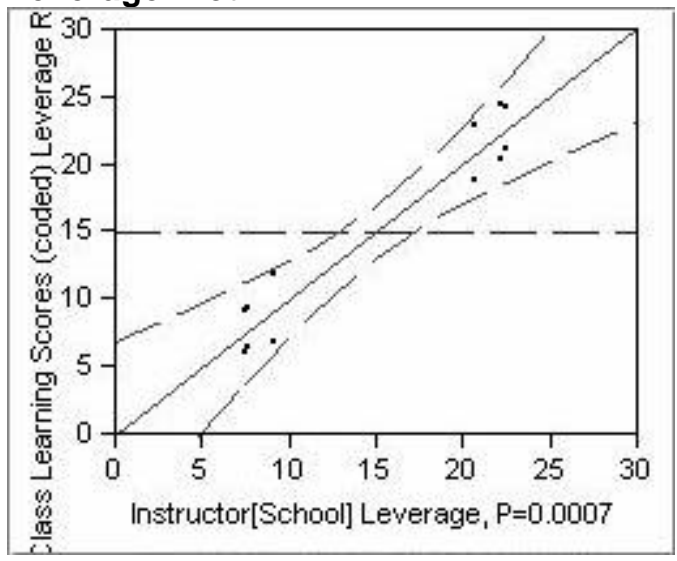

Least Squares Means Table

Level

[Atlanta]1

[Atlanta]2

[Chicago]1

[Chicago]2

[San Francisco]1

[San Francisco]2
Least Sq Mean

19.750000

14.250000

11.000000

Least Sq Mean

27.000000

12.500000

8.500000

20.000000

18.500000

3.500000
Std Error

1.8708287

1.8708287

1.8708287

1.8708287

1.8708287

1.8708287 
WSRC-RP-99-00422

Revision 1

Appendix F: JMP Version 4.0 Results

Exhibit F.8: JMP Version 4.0 Output for Nested ANOVA of Information in Table 13 Using Fit Model with Random Factors

\section{Response Class Learning Scores (coded) \\ Whole Model \\ Actual by Predicted Plot}

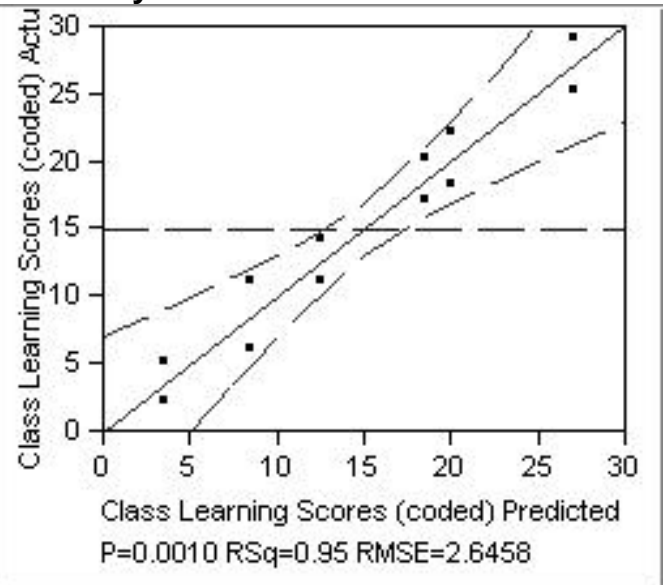

\section{Analysis of Variance}

Source

Model

DF

Error

C. Total

5

Sum of Squares

724.00000

42.00000

766.00000

\section{Parameter Estimates}

Term

Intercept

School[Atlanta]

School[Chicago]

School[Atlanta]:Instructor[1]

School[Chicago]:Instructor[1]

School[San Francisco]:Instructor[1]

\section{Expected Mean Squares}

The Mean Square per row by the Variance Component per column

$\begin{array}{lrrr}\text { EMS } & \text { Intercept } & \text { School\&Random Instructor[School]\& } \\ \text { Intercept } & 0 & 0 & 0 \\ \text { School\&Random } & 0 & 4 & 2 \\ \text { Instructor[School]\& } & 0 & 0 & 2 \\ \text { Random } & & & \end{array}$

plus 1.0 times Residual Error Variance

\section{Variance Component Estimates}

Component

School\&Random

Instructor[School]\&Random

Residual

Total

$\begin{array}{rr}\text { Var Comp Est } & \text { Percent of Total } \\ -27.7292 & -39.414 \\ 91.08333 & 129.464 \\ 7 & 9.950 \\ 70.35417 & 100.000\end{array}$

These estimates based on equating Mean Squares to Expected Value.

Test Denominator Synthesis

Source

School\&Random

Instructor[School]\&Random

Tests wrt Random Effects

Source

School\&Random

\section{Summary of Fit}

RSquare

RSquare Adj

Root Mean Square Error

Mean of Response

Observations (or Sum Wgts)

0.94517

0.899478

2.645751

15

12

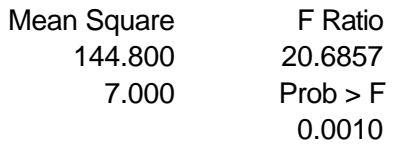

$\begin{array}{rrrr}\text { Estimate } & \text { Std Error } & \mathrm{t} \text { Ratio } & \text { Prob }>|\mathrm{t}| \\ 15 & 0.763763 & 19.64 & <.0001 \\ 4.75 & 1.080123 & 4.40 & 0.0046 \\ -0.75 & 1.080123 & -0.69 & 0.5134 \\ 7.25 & 1.322876 & 5.48 & 0.0015 \\ -5.75 & 1.322876 & -4.35 & 0.0048 \\ 7.5 & 1.322876 & 5.67 & 0.0013\end{array}$

MS Den DF Den Denom MS Synthesis

189.167

7

3 Instructor[School]\&Random

6 Residual

$\begin{array}{rrrrr}\text { SS } & \text { MS Num } & \text { DF Num } & \text { F Ratio } & \text { Prob > F } \\ 156.5 & 78.25 & 2 & 0.4137 & 0.6940\end{array}$


WSRC-RP-99-00422

Revision 1

Appendix F: JMP Version 4.0 Results

$\begin{array}{lrrrrr}\text { Source } & \text { SS } & \text { MS Num } & \text { DF Num } & \text { F Ratio } & \text { Prob > F } \\ \text { Instructor[School]\&Random } & 567.5 & 189.167 & 3 & 27.0238 & 0.0007\end{array}$

Instructor[School]\&Random

189.167

3

27.0238

0.0007 
Appendix F: JMP Version 4.0 Results

Exhibit F.8: JMP Version 4.0 Output for Nested ANOVA of Information in Table 13 Using Fit Model with Random Factors

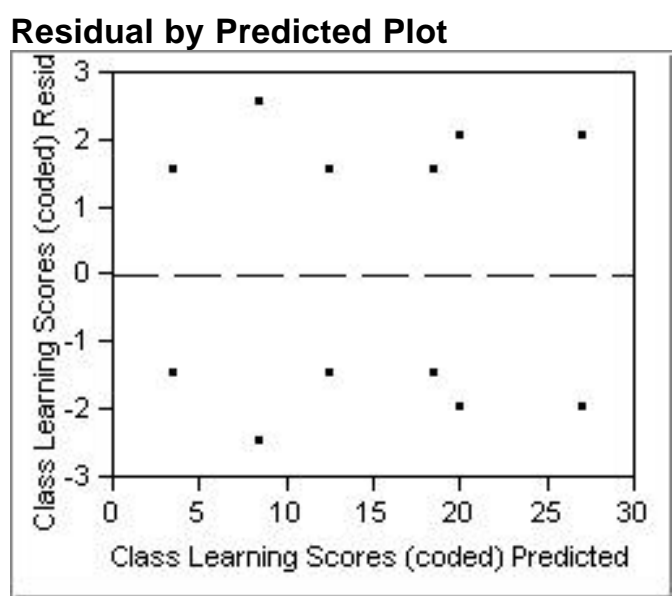

\section{School\&Random}

Leverage Plot

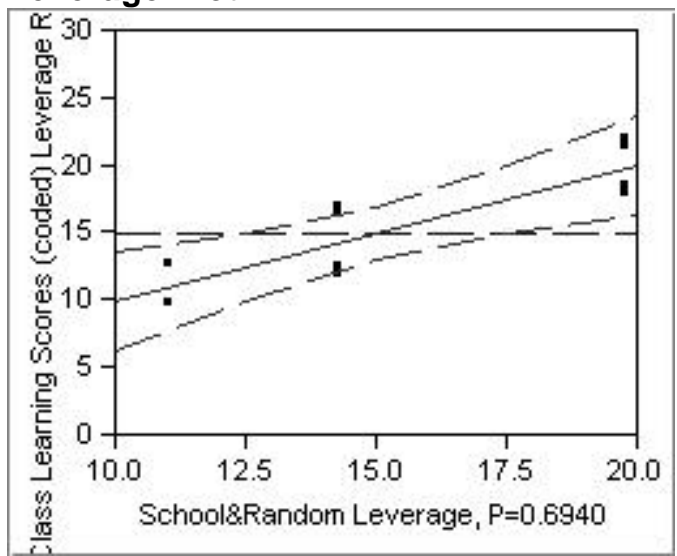

Effect Test

Sum of Squares
156.50000

Denominator MS Synthesis:

Instructor[School]\&Random

\section{Least Squares Means Table}

Level

Atlanta

Chicago

San Francisco

$$
\begin{array}{rrr}
\text { F Ratio } & \text { DF } & \text { Prob > F } \\
0.4137 & 2 & 0.6940
\end{array}
$$

Least Sq Mean

19.750000

14.250000

11.000000
Std Error

6.8768937

6.8768937

6.8768937
Mean

19.7500

14.2500

11.0000 
Appendix F: JMP Version 4.0 Results

Exhibit F.8: JMP Version 4.0 Output for Nested ANOVA of Information in Table 13 Using Fit Model with Random Factors (continued)

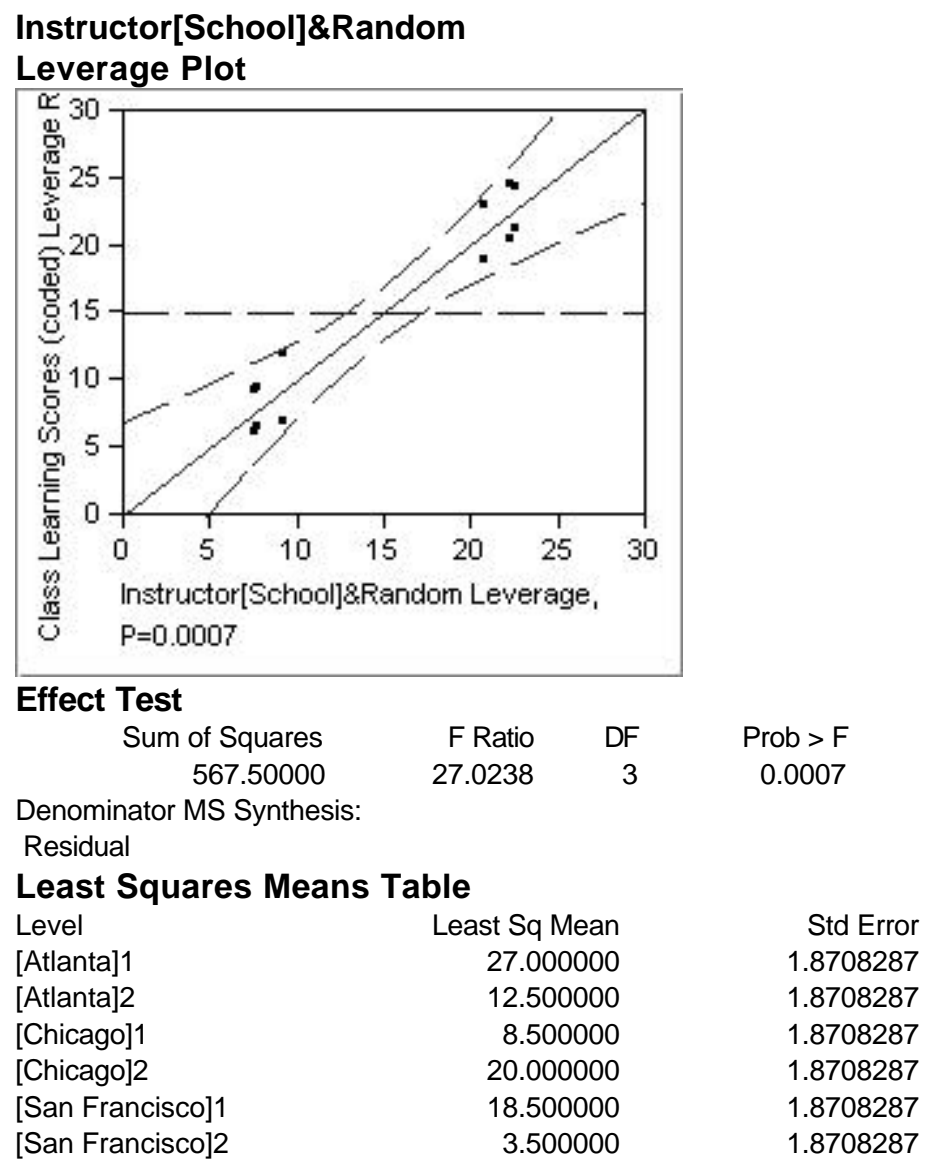


Appendix F: JMP Version 4.0 Results

Exhibit F.9: JMP Version 4.0 Output for a Fractional Factorial Experiment using the Design Experiment Feature

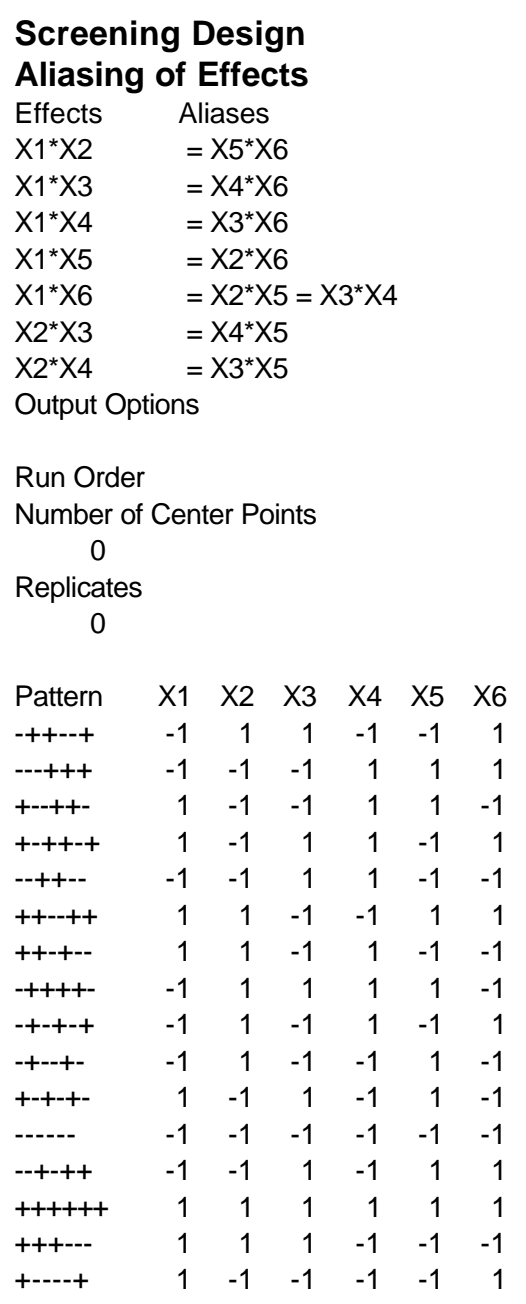


Appendix F: JMP Version 4.0 Results

Exhibit F.10: JMP Version 4.0 Output for Mixture Problem Defined by Equation (2)

\begin{tabular}{|c|c|c|c|}
\hline \multicolumn{2}{|c|}{ Mixture Design } & & \\
\hline \multicolumn{4}{|c|}{ Factor Settings } \\
\hline Run & $\mathrm{X} 1$ & $\mathrm{x} 2$ & $X_{3}$ \\
\hline 1 & 0.40000 & 0.10000 & 0.50000 \\
\hline 2 & 0.60000 & 0.10000 & 0.30000 \\
\hline 3 & 0.60000 & 0.30000 & 0.10000 \\
\hline 4 & 0.20000 & 0.30000 & 0.50000 \\
\hline 5 & 0.30000 & 0.60000 & 0.10000 \\
\hline 6 & 0.20000 & 0.60000 & 0.20000 \\
\hline \multicolumn{4}{|c|}{ Output Options } \\
\hline \multicolumn{4}{|c|}{ Run Order } \\
\hline \multicolumn{4}{|l|}{ Replicates } \\
\hline \multicolumn{4}{|l|}{0} \\
\hline \multicolumn{2}{|c|}{$\mathrm{X} 1$} & $\mathrm{x} 2$ & $\mathrm{X} 3$ \\
\hline \multicolumn{2}{|c|}{0.2} & 0.6 & 0.2 \\
\hline \multicolumn{2}{|c|}{0.6} & 0.3 & 0.1 \\
\hline \multicolumn{2}{|c|}{0.4} & 0.1 & 0.5 \\
\hline \multicolumn{2}{|c|}{0.6} & 0.1 & 0.3 \\
\hline \multicolumn{2}{|c|}{0.2} & 0.3 & 0.5 \\
\hline \multicolumn{2}{|c|}{0.3} & 0.6 & 0.1 \\
\hline
\end{tabular}

JMP Version 4.0 is capable of evaluating more than just the extreme vertices of this region. The table below provides the extreme vertices, center points along an edge of the region, and finally, the centroid of the entire region. This centroid is computed as part of the discussion in [see SAS Institute, Inc.'s "JMP® Design of Experiments," Version $4,2000]$, and the value reported there (on page 358$)$ is $(0.384,0.333,0.283)$ the same value as shown in the table below.

Mixture Design

3 Factors

Factor Settings

$\begin{array}{rrrr}\text { Run } & \text { X1 } & \text { X2 } & \text { X3 } \\ 1 & 0.40000 & 0.10000 & 0.50000 \\ 2 & 0.60000 & 0.10000 & 0.30000 \\ 3 & 0.60000 & 0.30000 & 0.10000 \\ 4 & 0.20000 & 0.30000 & 0.50000 \\ 5 & 0.30000 & 0.60000 & 0.10000 \\ 6 & 0.20000 & 0.60000 & 0.20000 \\ 7 & 0.20000 & 0.45000 & 0.35000 \\ 8 & 0.60000 & 0.20000 & 0.20000 \\ 9 & 0.50000 & 0.10000 & 0.40000 \\ 10 & 0.25000 & 0.60000 & 0.15000 \\ 11 & 0.45000 & 0.45000 & 0.10000 \\ 12 & 0.30000 & 0.20000 & 0.50000 \\ 13 & 0.38333 & 0.33333 & 0.28333\end{array}$

Output Options

Run Order

Replicates

0

$\begin{array}{rrr}\text { X1 } & \text { X2 } & \text { X3 } \\ 0.3 & 0.2 & 0.5 \\ 0.6 & 0.2 & 0.2 \\ 0.38333333 & 0.33333333 & 0.28333333 \\ 0.2 & 0.3 & 0.5 \\ 0.6 & 0.1 & 0.3 \\ 0.25 & 0.6 & 0.15\end{array}$


Appendix F: JMP Version 4.0 Results

$\begin{array}{rrr}X 1 & X 2 & X 3 \\ 0.4 & 0.1 & 0.5 \\ 0.45 & 0.45 & 0.1 \\ 0.3 & 0.6 & 0.1 \\ 0.6 & 0.3 & 0.1 \\ 0.2 & 0.6 & 0.2 \\ 0.2 & 0.45 & 0.35 \\ 0.5 & 0.1 & 0.4\end{array}$


Appendix F: JMP Version 4.0 Results

Exhibit F.11: JMP Version 4.0 Results for x-Bar and s Charts for Data in Table 20

Variable Control Chart

XBar of $\mathbf{x}$

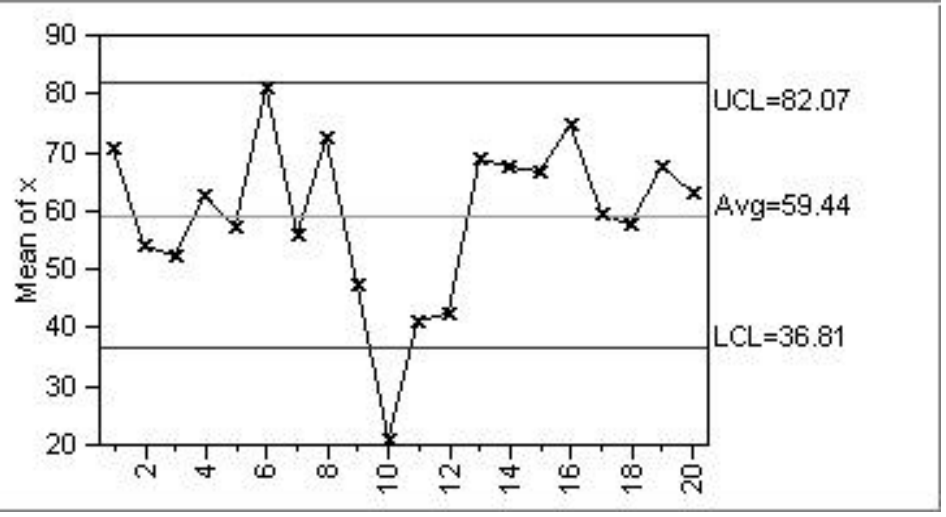

Note: Sigma used for limits based on standard deviation.

S of $x$

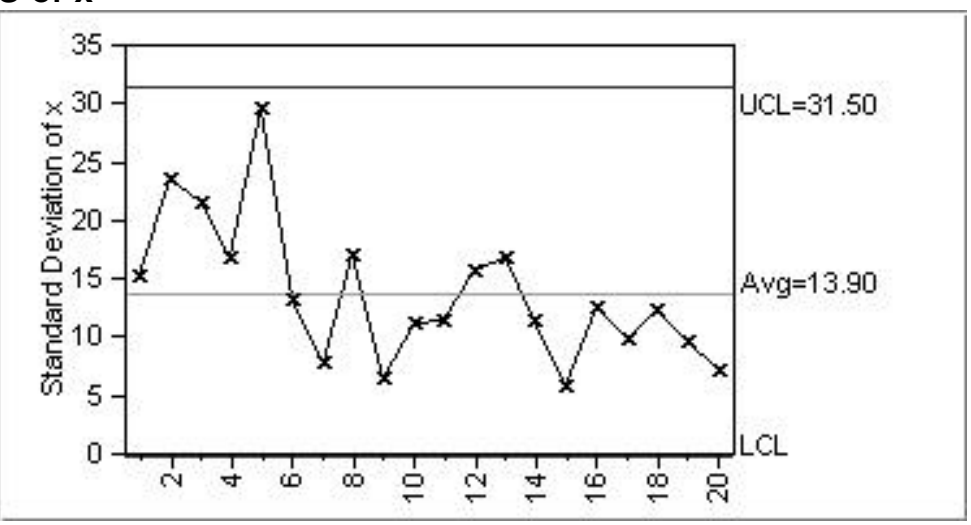

